Cassius Riul

\title{
DESENVOLVIMENTO DE COMPÓSITOS ESTRUTURAIS DE POLITETRAFLUORETILENO (PTFE) COM FIBRAS CONTÍNUAS
}

Tese de doutorado apresentada à Escola de Engenharia de São Carlos da Universidade de São Paulo, como parte dos requisitos para obtenção do título de Doutor em Engenharia Mecânica

Versão corrigida - a versão original de defesa se encontra arquivada na Secretaria de Pós-Graduação do Departamento de Engenharia Mecânica da EESC.

Orientador: Prof. Dr. Jonas de Carvalho Coorientador: Prof. Dr. Rodrigo Bresciani Canto

São Carlos 
AUTORIZO A REPRODUC̃̃O E DIVULGAÇÃO TOTAL OU PARCIAL DESTE TRABALHO, POR QUALQUER MEIO CONVENCIONAL OU ELETRÔNICO, PARA FINS DE ESTUDO E PESQUISA, DESDE QUE CITADA A FONTE.

Ficha catalográfica preparada pela Seção de Tratamento da Informação do Serviço de Biblioteca - EESC/USP

\begin{tabular}{|c|c|}
\hline \multirow[t]{3}{*}{ C615d } & $\begin{array}{l}\text { Riul, Cassius } \\
\text { Desenvolvimento de compósitos estruturais de } \\
\text { politetrafluoretileno (PTFE) com fibras contínuas / } \\
\text { Cassius Riul; orientador Jonas Carvalho e co-orientador } \\
\text { Rodrigo Bresciani Canto. -- São Carlos, } 2009 \text {. }\end{array}$ \\
\hline & $\begin{array}{l}\text { Tese (Doutorado-Programa de Pós-Graduação e Área de } \\
\text { Concentração em Engenharia Mecânica) - - Escola de } \\
\text { Engenharia de São Carlos da Universidade de São Paulo, } \\
2009 \text {. }\end{array}$ \\
\hline & $\begin{array}{l}\text { 1. Compósitos. 2. PTFE. 3. Fibras Contínuas. } \\
\text { 3. Parâmetros de fabricação. } 4 \text {. Propriedades mecânicas. } \\
\text { I. Título. }\end{array}$ \\
\hline
\end{tabular}


Candidato: Licenciado CASSIUS RIUL

Tese defendida e julgada em 05/11/2009 perante a Comissão Julgadora:


Prof. Associado JONAS DE CARVALHO (Orientador)

(Escola de Engenharił de São Carlos/USP)

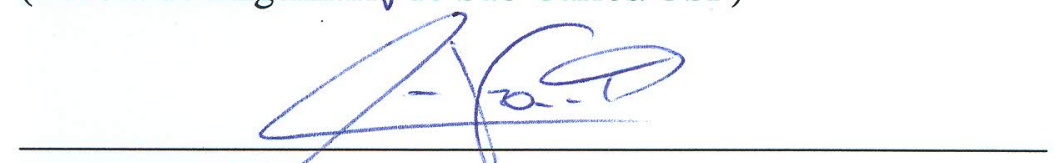

Prof. Doutor CARLOS ALBERTO FORTULAN

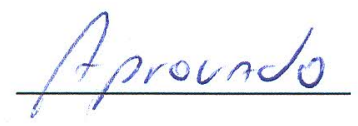

(Escola de Engenharia d’São Carlos/USP)

Prof. Associado JOSE RICARDO TARPANI

(Escola de Engenharia de São Carlos/USP)
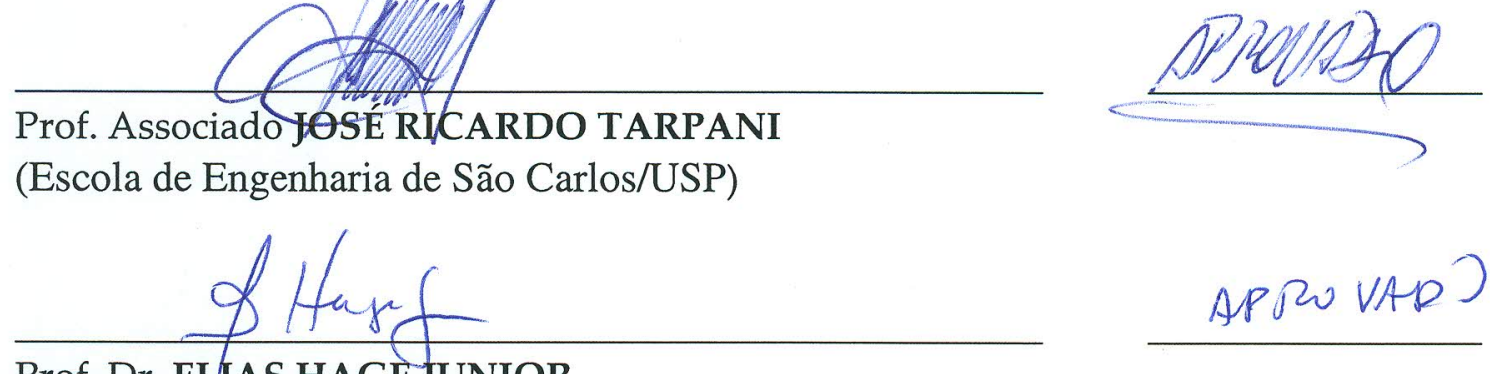

Prof. Dr. ELIAS HAGE JUNIOR

(Universidade Federal de São Carlos/UFSCar)



Prof ${ }^{\mathrm{a}}$. Dr ${ }^{\mathrm{a}}$. CECÍlIA AMÉLIA DE CARVALHO ZAVAGLIA

(Universidade Estadual de Campinas/UNICAMP)<smiles>CC(C)OC12CC3CC(CC(C3)C1)C2</smiles>

Prof. Associado JONAS DE CARVALHO

Coordenador do Programa de Pós-Graduação em

Engenharia Mecânica



Prof. Titular GERALDO ROBERTO MARTINS DA COSTA

Presidente da Comiissão da Pós-Graduação da EESC 

Aos meus pais, Shirley e Ary. 


\section{Agradecimentos}

Agradeço a todos que de alguma forma colaboraram para a realização deste trabalho.

Em especial agradeço:

Ao Prof. Jonas de Carvalho, orientador, pela oportunidade dada, pela confiança depositada e liberdade no desenvolvimento do trabalho junto ao Rodrigo. Agradeço por todas as discussões e contribuições no trabalho, e pelas excelentes condições de trabalho.

Ao Prof. Rodrigo Bresciani Canto, orientador, pela proposta e por todo comprometimento com o trabalho. Pela participação integral na pesquisa e todo imenso tempo dispensado com ela. Agradeço por todas as discussões e todo conhecimento passado, principalmente em relação ao PTFE e aos ensaios mecânicos. Pela grande amizade construída e por ter me transmitido um pouco de sua visão apaixonada sobre a pesquisa.

Ao Prof. Volnei Tita, colaborador, por toda a contribuição dada no trabalho, pelas discussões e sugestões valiosas. Agradeço também pela participação e contribuições em meu exame de qualificação.

A Ricardo Afonso Angélico pelas excelentes contribuições no texto final.

Ao Prof. Leonardo Bresciani Canto, por todas as análises de TGA e DSC e pelas informações sobre materiais.

A José Carlos Risardi e Mauro Olivatto pelo apoio técnico na fabricação do molde e dispositivos mecânicos.

Ao Prof. Luiz Carlos Casteletti pela disponibilização da máquina de ensaios e confiança no uso do equipamento.

Ao Prof. Waldek Wladimir Bose Filho pela disponibilização da máquina de ensaios, microscópio e infraestrutura de laboratório.

Ao professor José Ricardo Tarpani por ter disponibilizado o equipamento de captura de imagens e pela participação e contribuições em meu exame de qualificação.

A Eliezer Dias Francisco (Tico) pelo apoio técnico nos ensaios.

Aos amigos de laboratório: Alejandra, Altibano, Carlos Castro, Cláudia, Geraldo, Karen, Lucas, Renan, Ricardo, Rodrigo, Rogério, Romeu, Thaís, Zilda.

Ao Prof. Carlos Alberto Fortulan, pelas conversas e bons conselhos.

Ao Prof. Benedito de Morais Purquerio, pelo acesso a toda infraestrutura disponível no LTC.

À minha querida namorada Lilian, por todo apoio, incentivo, pela ajuda com a pesquisa e com o texto. Por toda a compreensão e carinho e por estar sempre ao meu lado em todos os momentos.

Aos meus pais, Shirley e Ary, meus irmãos, Débora, Douglas e Marcelo e aos meus sobrinhos, Lucas, Thiago, Pedro, Beatriz, Marcos e Eduardo, por todo 
carinho e apoio e pela compreensão pela eterna falta de tempo.

Pelo apoio e bons momentos juntos, aos tios: Pedro (em memória), Zeca, Leonor (em memória), Tereza, Neide, Marlene, Lurdes e João Alberto. Aos primos: Vitor, Sandra, Natali, Juliana, Rafael, Angelita e João (Sandra). Aos meus cunhados: João, Alessandra e Juliana. A todo restante de minha família!

À Lúcia Bonjorne por todo apoio e amizade.

Aos amigos (por serem amigos): Flávio (OvO), Líria, Cacheffo, Samuel, Neto, Eliézer (por comer minha pimenta), Lula (por beber minha cachaça), Netanias (por comer o meu pão), Prancha, Rulli, Helena, Silvio, Elvis, Carlos Portezani, Cesar, Guilherme, Gunter, Norba e Parê.

A todos os companheiros de república que convivi durante os 14 anos de vida em São Carlos.

Aos funcionários da Engenharia Mecânica: Ana Paulo, Maragno, Cristina, Juliana, João Pedro, por todo apoio.

A Paulo Henrique da Silva por toda contribuição dada à pesquisa.

À Saint-Gobain Cerâmicas e Plásticos de Vinhedo - SP, pelo fornecimento do material necessário para a pesquisa.

Ao LMT-Cachan, pelo acesso ao programa CORRELI.

À Universidade de São Paulo por todo o suporte oferecido.

À Coordenação de Aperfeiçoamento de Pessoal de Nível Superior (CAPES) e ao Conselho Nacional de Desenvolvimento Científico e Tecnológico (CNPq) por todo o apoio financeiro desde a iniciação científica. 


\section{Resumo}

RIUL, C (2009). DESENVOLVIMENTO DE COMPÓSITOS ESTRUTURAIS DE POLITETRAFLUORETILENO (PTFE) COM FIBRAS CONTÍNUAS. Tese (Doutorado) - Escola de Engenharia de São Carlos, Universidade de São Paulo, São Carlos - SP, 2009.

Este trabalho apresenta o desenvolvimento de compósitos estruturais de politetrafluoretileno (PTFE) com fibras de vidro contínuas e tem como objetivo a obtenção de um compósito com propriedades mecânicas que possibilite o uso em aplicações estruturais e que mantenham as características inerentes do PTFE sem reforços, tais como: baixo coeficiente de atrito, baixa interação química e elevada temperatura de trabalho. O PTFE é um polímero termoplástico, mas sua elevada viscosidade no estado fundido impede a utilização de moldagem por injeção. Componentes fabricados com PTFE são geralmente obtidos por compactação a frio do material granulado seguido de tratamento térmico. Neste estudo foi desenvolvida uma metodologia de fabricação de um laminado de PTFE e fibras contínuas, a partir do empilhamento, prensagem e tratamento térmico, de tecidos de fibra de vidro impregnados com PTFE. Foram estudadas as influências dos parâmetros de fabricação (prensagem e tratamento térmico) e de mecanismos que levam à degradação do laminado durante a fabricação, nas propriedades mecânicas finais dos compósitos. Foi também estudada a adição de uma quantidade complementar de PTFE ao laminado, com o intuito de se averiguar a possibilidade de se obter compósitos com revestimentos mais espessos de PTFE. O laminado foi avaliado por meio de ensaios de flexão 3-pontos e tração, para verificação dos ganhos na rigidez e resistência mecânica frente ao PTFE puro e por um ensaio de adesão fibra-matriz, baseado na norma ASTM D3167-03a. Como resultados, foram encontrados valores expressivos de resistência máxima - aproximadamente $165 \mathrm{MPa}$ - e rigidez - módulo de elasticidade de aproximadamente $14 \mathrm{GPa}$ - para valores adequados de processo de fabricação que minimizam efeitos de degradação dos laminados durante a fabricação. O trabalho mostrou a viabilidade de fabricação dos compósitos propostos e indicou uma rota a ser seguida para esta fabricação.

Palavras-chave: PTFE, compósitos, fibras contínuas, parâmetros de fabricação, propriedades mecânicas 


\section{Abstract}

RIUL, C (2009). DEVELOPMENT AND CHARACTERIZATION OF STRUCTURAL COMPOSITES OF POLYTETRAFLUOROETHYLENE WITH CONTINUOUS FIBRES. Thesis (cotutorship doctorate) - Escola de Engenharia de São Carlos, Universidade de São Paulo, São Carlos - SP, 2009.

This work presents a study of the manufacturing of Polytetrafluoretylene (PTFE) composite with continuous fibres, which has the purpose of obtaining a composite with mechanical properties equivalent or better than that of engineering polymers, but that preserve the characteristics of PTFE products with no reinforcement (as low friction coefficient, low chemical interaction and high work temperature amplitude). The PTFE is a thermoplastic material, however its high molten viscosity prevents the use of melt injection techniques, and its components are obtained through cold compaction process followed by sintering. In this study it is proposed a methodology of PTFE laminate with continuous fibre manufacturing. The laminate was obtained by the pilling of PTFE-coated glass-fibre fabric in a metallic mold for the pressing and that were sinterised afterwards. The mechanisms that lead to degradation of the laminate and process parameters which influence the final mechanical properties of the product were speciafied. It was also studied the possibility of addition of a larger quantity of PTFE to the laminate in order to verify the possibility of making continuous laminate coating. The material was analysed through three-point bending test and tensile test - applied to the manufactured test specimen to verify the gains of mechanical stiffness and strength in comparison to the pure PTFE - and an adhesion test based on ASTM D3167-03a. The experimental results showed significant values of mechanical stiffness and strength for appropriate values of process parameters that minimize the effects of degradation of the laminate.

Keywords: PTFE, composites, continuous fibres, process parameters, mechanical properties 


\section{Lista de Figuras}

$1 \quad$ Acoplamento de uma fibra curta envolta por uma matriz. . . . . . . 29

2 Representação esquemática do tamanho crítico das fibras. . . . . . 30

3 Representação da orientação das fibras em um compósito. . . . . . 30

$4 \quad$ Processo de impregnação de resina em tecidos por imersão. . . . . 33

5 PTFE: Representação molecular. . . . . . . . . . . . . . . . . . . . . . 34

$6 \quad$ Diagrama de transformações da fase cristalina do PTFE. . . . . . . . . 36

7 Foto de microscopia eletrônica de varredura de partículas de PTFE em dispersão aquosa. . . . . . . . . . . . . . . . 38

$8 \quad$ Tecido de fibra de vidro impregnado com PTFE. . . . . . . . . . . . 44

9 Análise de termogravimetria (TGA) para os materiais Chemfab ${ }^{(R)}$ 008 e Chemfab ${ }^{\mathbb{R}}$ 013. . . . . . . . . . . . . . . 45

10 Fotomicrografias de microscopia óptica dos tecidos: Chemfab $^{(\mathbb{}}$ 013 e Chemfab ${ }^{\mathbb{R}}$ 008. . . . . . . . . . . . . . 46

11 Tecido de fibra de vidro impregnado com PTFE em laboratório. . . . 47

12 Fotografias obtidas em microscópio estereoscópico: Teflon ${ }^{(R)}$ 6407. . 48

13 Processo de fabricação dos corpos-de-prova do compósito fabricado a partir de tecidos de fibra de vidro impregnados com PTFE. . 49

14 Ensaio de flexão 3-pontos em um CDP do compósito obtido pelos tecidos de fibra de vidro impregnados com PTFE. $\ldots . . . . .52$

15 Ensaio de adesão . . . . . . . . . . . . . . . . . . . . . 53

16 Medidas do CDP de tração e CDP recoberto com tinta para análise por correlação de imagens. . . . . . . . . . . . . . . . 54

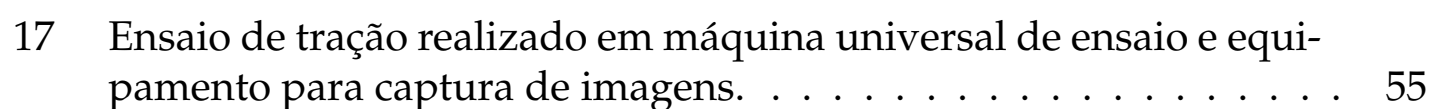

18 CDPs de PTFE puro e compósito de PTFE e fibras. . . . . . . . . . . 58

19 Comparação do ensaio de flexão 3-pontos dos CDPs de PTFE puro e compósito de PTFE e fibras. . . . . . . . . . . . . . . . 59

20 Plano de ensaios com variações dos parâmetros de prensagem e sinterização. . . . . . . . . . . . . . 60

21 Análise da influência da pressão de compactação para laminados de tecido Chemfab ${ }^{\mathbb{R}} 013 \ldots \ldots \ldots$. . . . . . . . . . . 61 
22 Análise da influência da temperatura de sinterização para laminados de tecido Chemfab ${ }^{\circledR} 013 \ldots \ldots \ldots \ldots \ldots$

23 Análise da influência do tempo de sinterização para laminados de tecido Chemfab ${ }^{\mathbb{R}} 013 \ldots \ldots \ldots \ldots \ldots$. . . . . . . . . . . 64

24 Análise da influência da taxa de resfriamento para laminados de tecido Chemfab $^{\circledR} 013 \ldots \ldots \ldots \ldots \ldots \ldots$

25 Ilustração: eliminação de aditivos da fibra de vidro durante trata-

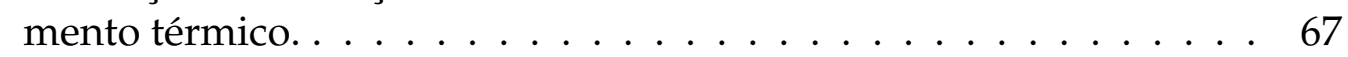

26 Análise de TGA feita em fibra de vidro usada na fabricação do tecido Chemfab $^{\mathbb{R}} 013$ STD. . . . . . . . . . . . . . . . . . . 68

$27 \quad$ Diferença de tonalidade entre o tecido Chemfab $\left.^{(}\right)$013 STD tratado termicamente em laboratório e o mesmo tecido como vem de fábrica. 68

28 Plano de ensaios efetuado, destacando-se os parâmetros de processo que resultaram no melhor desempenho estrutural dentre os



29 Falha por descolamento das lâminas durante ensaio de flexão 3pontos dos laminados. $\ldots \ldots \ldots \ldots \ldots \ldots \ldots \ldots \ldots \ldots \ldots$

30 Resultados do ensaio de adesão para laminados de tecido Chemfab $^{\mathbb{B}} 013 . \ldots \ldots \ldots \ldots \ldots \ldots \ldots \ldots$

31 Estratégia para o estudo da influência do tempo e temperatura nas propriedades mecânicas dos laminados. $\ldots \ldots \ldots \ldots 72$

32 Resultados obtidos por ensaios de flexão 3-pontos para o estudo da influência do tempo e temperatura. . . . . . . . . . . . . . 74

33 Verificação do tempo de permanência de cada CDP acima da temperatura crítica. $\ldots \ldots \ldots \ldots \ldots \ldots \ldots \ldots 74$

34 Curva de tendência da resistência máxima pelo tempo de permanência acima da temperatura crítica. $\ldots \ldots \ldots \ldots \ldots 75$

35 Revestimento contínuo de PTFE em laminados de PTFE e fibras. . . 75

36 Processo de fabricação dos CDPs fabricados a partir do tecido co-

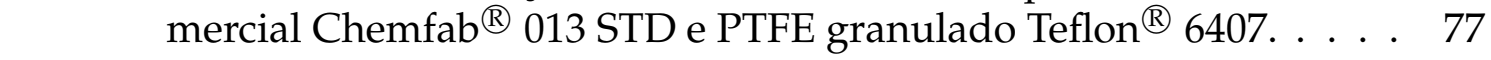

37 DSCs: a) PTFE - Teflon $\left.{ }^{(}\right)$6407; b) tecido de fibra de vidro impreg-

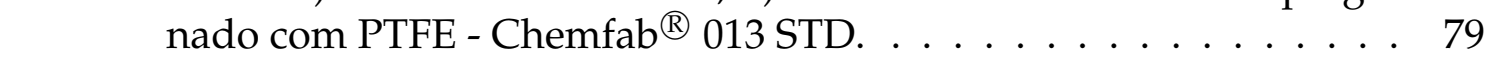

38 CDPs de PTFE granular e tecidos impregnados Chemfab ${ }^{\circledR} 013$ tra-

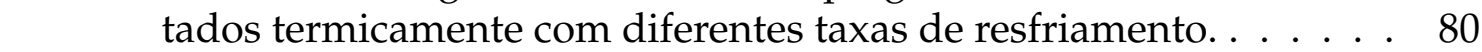

39 Dimensões finais dos CDPs após sinterização comparados com a \begin{tabular}{|l|l|}
\hline dimensão no estado a verde para as diferentes frações volumétri- \\
\hline cas de fibras.
\end{tabular}

40 Curvas de tendência do módulo de Young à flexão e tensão máxima à flexão, em função da fração volumétrica de fibras. . . . . . . . 82 
41 Análise da influência da pressão de conformação para laminados de tecido Chemfab ${ }^{\mathbb{R}} 008 \ldots \ldots \ldots \ldots$. . . . . . . . . . 84

42 Análise da influência da taxa de aquecimento para laminados de tecido Chemfab ${ }^{R} 008 \ldots \ldots \ldots \ldots 6$

43 Análise da influência da temperatura de sinterização para laminados de tecido Chemfab ${ }^{\circledR} 008 \ldots \ldots$. . . . . . . . . 87

44 Análise da influência do tempo de sinterização para laminados de tecido Chemfab $^{\mathbb{R}} 008 \ldots \ldots \ldots$. . . . . . . . . . . 88

45 Análise da influência da taxa de resfriamento para laminados de tecido Chemfab ${ }^{R} 008 \ldots \ldots \ldots$. . . . . . . . . . . . . 89

46 Resultados do ensaio de adesão para laminados de tecido Chemfab ${ }^{(R)} 008 . \ldots \ldots \ldots$. . . . . . . . . . . . . 91

47 Fotomicrografia de microscopia eletrônica de varredura da superfície do CDP de adesão após ensaio. . . . . . . . . . . . . . 92

48 Fotomicrografia de microscopia eletrônica de varredura do tecido Chemfab ${ }^{(R)} 008$ arrancado durante ensaio de adesão. . . . . . . . . . 93

49 Comparação entre os módulos de Young à flexão para os tecidos

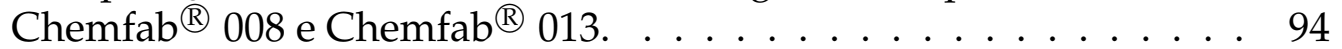

50 Campos de deslocamentos e deformações analisados pelo programa CORRELI em CDP de tração. . . . . . . . . . . . . . . 994

51 Curvas de deformações longitudinal (esquerda) e transversal em função do tempo para o ensaio cíclico de tração.. . . . . . . . . . . 95

52 Tensão nominal $\left(\sigma_{1}\right)$ pelas deformações longitudinal $\left(\varepsilon_{1}\right)$ e transversal $\left(\varepsilon_{2}\right)$ num ensaio de tração cíclico . . . . . . . . . . . . . . 96

53 Curva de tensão pela deformação em ensaios de flexão 3-pontos com e sem aplicação de pressão durante a sinterização. . . . . . . . . 97

54 Fotomicrografia de MEV de CDP de adesão fabricados com o tecido Chemfab ${ }^{\mathbb{R}}$ 008: descolamento do PTFE impregnado do tecido e fibra de vidro. . . . . . . . . . . . . . . . 98

55 PTFE aderido à fibra de vidro (tecido Chemfab $^{(\mathrm{R})} 008$ ) após o ensaio de adesão evidenciando a adesão química do PTFE à fibra. . . . . . . 99

56 Curva de tensão pela deformação em ensaios de flexão 3-pontos em CDPs feitos com tecido impregnado em laboratório. . . . . . . . 100

57 Vistas do projeto do molde de prensagem. . . . . . . . . . . . . . . . 112

58 Foto do molde de prensagem utilizado na fabricação dos Laminados.112

59 Pino para apoio dos roletes com encaixe para rolamentos. . . . . . . 114

60 Roletes de apoio para o CDP de adesão. . . . . . . . . . . . . . . . . 115

61 Pino para apoio superior com encaixe para rolamentos. . . . . . . . 115 
62 Apoio superior de encaixe na máquina de ensaios. . . . . . . . . 116

63 Lateral do dispositivo de adesão. . . . . . . . . . . . . . . . . 116

64 Lateral do dispositivo de adesão para visualização do ensaio. ‥ ․ 117

65 Montagem do dispositivo para o ensaio de adesão. . . . . . . . . . . 117

66 Montagem do dispositivo com lateral para visualização. … . . 118

67 Fabricação da garra para fixação da última camada para execução

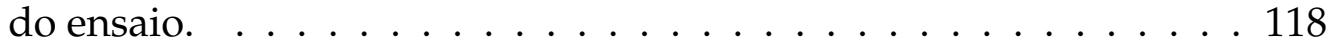




\section{Lista de Tabelas}

$1 \quad$ Propriedades das fibras de vidro do tipo E. . . . . . . . . . . . 31

2 Dados dos tecidos comerciais Chemfab ${ }^{\circledR} 008$ e 013 . . . . . . . . . . 46

3 Valores padrão dos parâmetros de sinterização para o desenvolvi-



4 Parâmetros de fabricação - variação da pressão de conformação . . 61

5 Parâmetros de fabricação - variação da temperatura de sinterização 62

6 Parâmetros de fabricação - variação do tempo de sinterização . . . 64

7 Parâmetros de fabricação - variação da taxa de resfriamento . . . . 65

8 Parâmetros de fabricação e valores de ensaios de flexão 3-pontos e ${ }_{71}$

9 Parâmetros de fabricação e valores de ensaios de flexão 3-pontos para o estudo da influência do tempo e temperatura . . . . . . . . 73

10 Valores de parâmetros de fabricação considerados mais adequados para o tecido Chemfab ${ }^{\circledR} 013 \ldots \ldots \ldots \ldots$

11 Parâmetros de fabricação - variação da pressão de conformação . . 84

12 Parâmetros de fabricação - variação da taxa de aquecimento . . . . 85

13 Parâmetros de fabricação - variação da temperatura de sinterização 86

14 Parâmetros de fabricação - variação do tempo de sinterização . . . 87

15 Parâmetros de fabricação - variação da taxa de resfriamento . . . . 88

16 Valores de parâmetros de fabricação e propriedades mecânicas obtidas em ensaios de flexão 3-pontos para 4 CDPs $\ldots \ldots$. . . . . . 90

17 Parâmetros de fabricação e valores de ensaios de flexão 3-pontos e

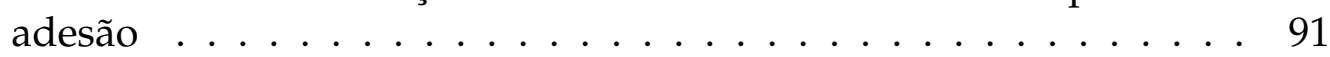

18 Propriedades mecânicas obtidas em ensaios de tração para 4 CDPs 96

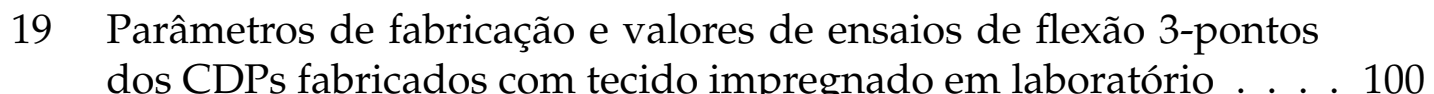




\section{Lista de Abreviaturas e Siglas}

CDPs - Corpos-de-prova

DSC - Calorimetria exploratória diferencial

IMA - Instituto de Macromoléculas

LMT - Laboratoire de Mécanique et Technologie

MEV - Microscopia especular de varredura

PBT - Polibutileno tereftalato

PTFE - Politetrafluoretileno

TGA - Análise termogravimétrica

UFRJ - Universidade Federal do Rio de Janeiro

UHMWPE - Polietileno de ultra alto peso molecular 


\section{Lista de Símbolos}

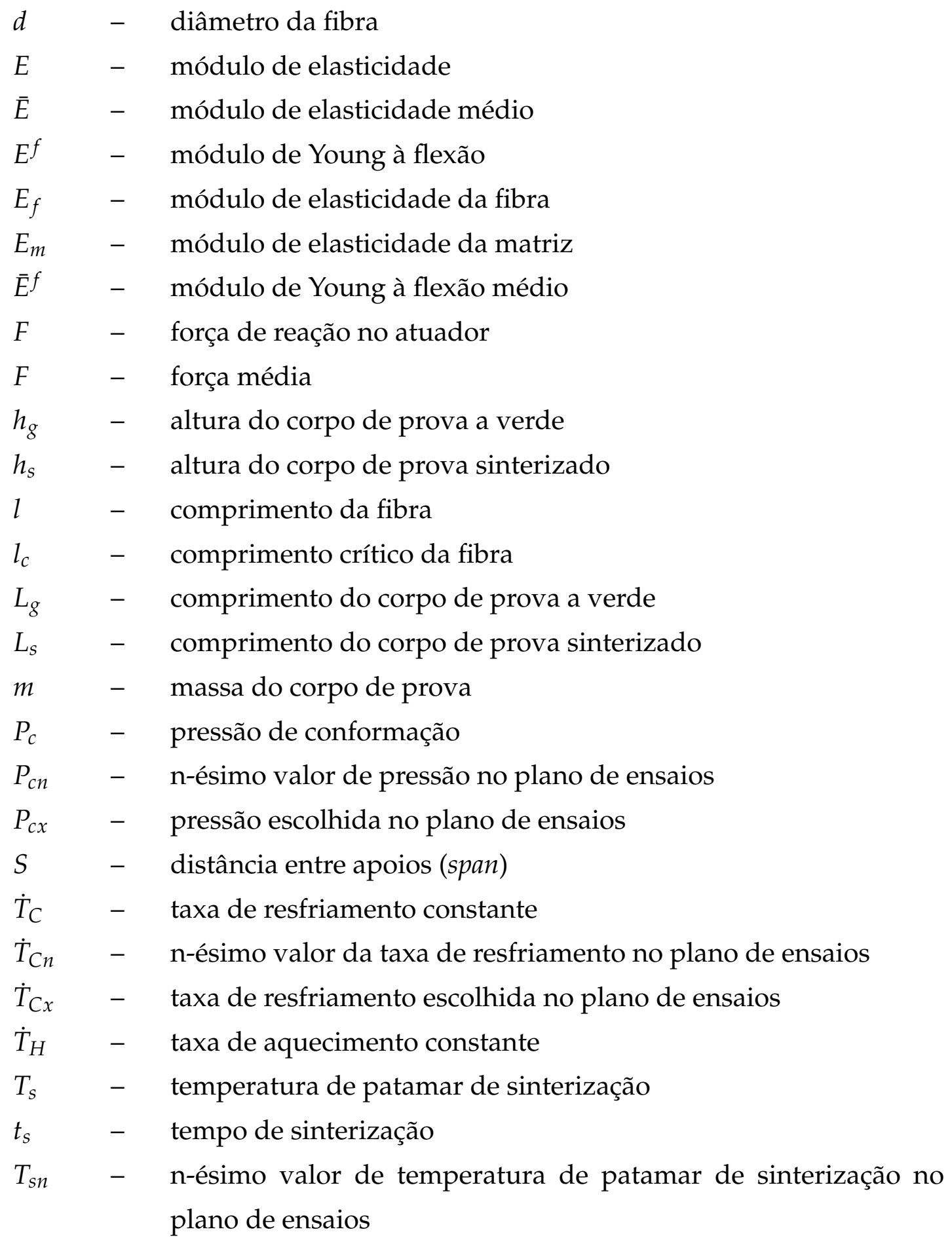









\section{Sumário}

$\begin{array}{lll}1 & \text { Introdução } & 19\end{array}$



1.2 Justificativas . . . . . . . . . . . . . . . 22

1.3 Apresentação dos Capítulos . . . . . . . . . . . . . . . . . 23

2 Revisão Bibliográfica 25

2.1 Compósitos Poliméricos . . . . . . . . . . . . . . . . 25

2.1 .1 Matrizes poliméricas . . . . . . . . . . . 26

2.1.1.1 Matrizes termorrígidas . . . . . . . . . 26

2.1.1.2 Matrizes termoplásticas . . . . . . . . . . . 27

2.1 .2 Fibras . . . . . . . . . . . . . . . . 27

2.1.2.1 Influência do comprimento e orientação das fibras 28

2.1.2.2 Fibras de vidro . . . . . . . . . . . . . . . 31

2.1.2.3 Tecidos impregnados . . . . . . . . . . 32



2.2.1 Polimerização do tetrafluoroetileno . . . . . . . . . . 36

2.2.1.1 Suspensão . . . . . . . . . . . . . 37

2.2 .1 .2 Dispersão . . . . . . . . . . . . . . 37

2.3 Compósitos de PTFE reforçados com fibras . . . . . . . . . . . . . . 38

2.3.1 Tecidos comerciais de PTFE e fibras de vidro . . . . . . . . . 41

3 Processo de Fabricação e Metodologia de Avaliação dos Laminados 43

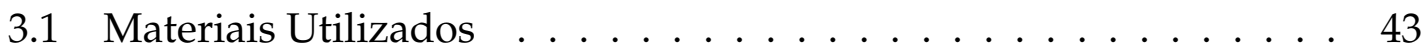

3.1.1 Tecidos comerciais: Chemfab $\left.{ }^{\circledR}\right]$. . . . . . . . . . . . . . 44

3.1.2 Tecidos impregnados em laboratório . . . . . . . . . . . . 46

3.1 .3 PTFE granulado Teflon ${ }^{\mathrm{R}} 6407$. . . . . . . . . . . . . 48

3.2 Metodologia de Fabricação dos Laminados . . . . . . . . . . . . . . 48 
3.3 Metodologia de Avaliação das Propriedades Mecânicas dos Lami-

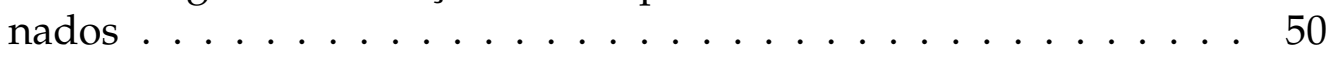

3.3 .1 Ensaio de flexão 3-pontos . . . . . . . . . . . . . . . . . . 51

3.3 .2 Ensaio de adesão fibra-matriz . . . . . . . . . . . . . . . 52

3.3 .3 Ensaio de Tração . . . . . . . . . . . . . . . . . . . 53

3.3.3.1 Avaliação por correlação de imagens . . . . . . . . 54

4 Parâmetros de Fabricação e Propriedades Finais 57

4.1 Laminados de Tecido Comercial Chemfab ${ }^{\circledR} 013$. . . . . . . . . . 57

4.1 .1 Avaliação por ensaio de flexão 3-pontos . . . . . . . . . . . . 57

4.1 .2 Avaliação por ensaio de adesão fibra-matriz . . . . . . . . . 69

4.1.3 Investigação do tempo e temperatura do tratamento térmico 72

4.1 .4 Estudo sobre revestimento adicional de PTFE $\ldots . . . . . .74$

4.2 Laminados de Tecido Comercial Chemfab ${ }^{(R)} 008$. . . . . . . . . 82

4.2 .1 Avaliação por ensaio de flexão 3-pontos . . . . . . . . . . . 82

4.2 .2 Avaliação por ensaio de adesão fibra-matriz . . . . . . . . 90

4.2 .3 Avaliação por ensaio de tração . . . . . . . . . . . . . . . 93

$4.2 .4 \quad$ Laminado sinterizado sob pressão … . . . . . . . . . 96

4.3 Análise por fotomicrografias de MEV . . . . . . . . . . . . . . 98

4.4 Laminados de Tecido Impregnado em Laboratório . . . . . . . . . . 99

$\begin{array}{lll}5 \text { Conclusões } & 103\end{array}$

Referências

\begin{tabular}{|l|}
\hline Apêndice A - Molde de Prensagem \\
\hline 12
\end{tabular}

Apêndice B - Dispositivo para o Ensaio de Adesão: Projeto e Montagem 114

\begin{tabular}{ll}
\hline Anexo A - Publicações & 120
\end{tabular}

A.1 Artigos completos publicados em anais de congressos nacionais . . 120

A.2 Artigos completos publicados em anais de congressos internacionais 120

A.3 Artigos completos em periódicos internacionais - submetido . . . . 120

A.4 Artigos completos em periódicos internacionais - em preparação . 121 



\section{Introdução}

A combinação multifásica de dois diferentes materiais para a obtenção de um terceiro com propriedades diferentes é uma ideia relativamente simples e seu uso é historicamente documentado. É conhecido, por exemplo, que a civilização egípcia do segundo milênio antes de Cristo usava palha picada para reforçar tijolos em construções simples (MENDONÇA, 2005; VINSON; SIERAKOWSKI, 2002). Materiais como este são denominados compostos ou compósitos e são definidos como um conjunto de dois ou mais materiais combinados de maneira multifásica, na elaboração de um novo material que combina uma significativa parcela das propriedades de cada material resultando em propriedades que nenhum dos componentes apresenta individualmente (CALLISTER, 2005; MENDONÇA, 2005). Um exemplo atual e bastante conhecido de material compósito é o concreto de cimento portland, que é o concreto amplamente usado na construção civil, obtido por um agregamento de brita e areia ligadas quimicamente pelo cimento e que constituem, desta maneira, um corpo sólido. Adicionando ainda estruturas de aço como reforço adicional, tem-se o chamado concreto armado, cujos valores de resistências à tração, à compressão e ao cisalhamento são ainda maiores, devido justamente ao reforço do aço. Neste caso, a ligação entre o aço e o restante do concreto é predominantemente mecânica, ou seja, a parcela de adesão química entre as duas partes é pequena; mesmo assim, há um grande aumento em algumas de suas propriedades mecânicas.

Apesar de se tratar de uma ideia antiga, a primeira patente de um compósito 
estrutural data de 1916, e apenas em 1949, com o advento das fibras de vidro, teve início o desenvolvimento dos materiais compósitos modernos - principalmente polímeros reforçados por fibras. O desenvolvimento de alta tecnologia em compósitos iniciou-se de forma considerável apenas na década de 1970, marcado pelo início da aplicação na área aeronáutica, área esta em que é mais difundido o uso dos compósitos (PIGGOT, 2002; HARPER, 2000; TSAI, 1992). No desenvolvimento deste tipo de material, busca-se melhorar as combinações de características mecânicas, tais como: rigidez, tenacidade e resistência, principalmente em função da composição e do processamento. Além disso, geralmente estes materiais são mais leves e menos susceptíveis à corrosão quando comparados aos materiais convencionais, tais como os metais.

Outras propriedades importantes dos compósitos - por exemplo, a resistência à abrasão -, podem ser obtidas a partir de algumas da imensa gama de combinações multifásicas entre diferentes materiais, sendo que cada diferente combinação nos remete a um novo material em termos das propriedades únicas apresentadas (CALLISTER, 2005). Estas características tornam os compósitos uma alternativa muito importante para a indústria em geral e, principalmente, para as indústrias aeronáutica - que já conta em alguns casos com 50\% de compósitos na estrutura de alguns aviões -, automobilística, naval, petroquímica, de eletro-eletrônicos e de equipamentos esportivos (GAY, 2003).

Pela recente exploração comercial e pela grande variedade de combinações possíveis, o desenvolvimento e aplicações de novos compósitos poliméricos possuem ainda um grande potencial, exigindo estudos constantes para a elaboração e caracterização de novos materiais. O avanço nas técnicas de manufatura torna possível associações aparentemente improváveis de materiais e traz a possibilidade de resultados promissores em diversas áreas de aplicação, não apenas na substituição dos materiais tradicionais, como também no desenvolvimento de componentes que dependam invariavelmente do uso de compósitos. 
O presente trabalho trata com originalidade do projeto e manufatura de compósitos estruturais feitos de politetrafluoretileno (PTFE) e tecidos de fibra de vidro (fibras contínuas), com caracterização das rotas de fabricação, fornecendo informações importantes para o projeto e desenvolvimento de produtos. Geralmente, os reforços usados em componentes de PTFE são fibras curtas - fibras de vidro ou carbono picadas e adicionadas ao PTFE em pó, anteriormente a seu processamento. São poucos os trabalhos científicos que tratam de compósitos estruturais de PTFE e fibras contínuas, e não há relatos de trabalhos acadêmicos que fazem uma caracterização detalhada a respeito deste tipo de compósito.

\subsection{Objetivos}

Este trabalho tem como objetivo principal a obtenção de compósitos laminados estruturais de PTFE com fibras contínuas a partir de tecidos comerciais de fibra de vidro impregnados com PTFE que tenham propriedades mecânicas módulo de elasticidade e resistência mecânica - superiores às do PTFE puro, mas que mantenham as principais características deste polímero: baixo coeficiente de atrito, ampla temperatura de trabalho, baixa interação química, alta resistência à chama, baixa constante dielétrica ${ }^{1}$ e baixa perda dielétrica ${ }^{2}$.

São também objetivos do trabalho:

- Estudar os parâmetros relacionados ao processo de fabricação do compósito - compreendido basicamente pela prensagem a frio seguida de tratamento térmico à pressão atmosférica -, visando valores adequados de processamento que proporcionem um aumento efetivo das propriedades mecânicas (módulo de elasticidade e resistência), em comparação ao PTFE puro;

\footnotetext{
${ }^{1}$ Para um meio dielétrico isotrópico o cociente entre permitividade do meio e a permitividade do vácuo*. Um material é bom isolante quando possui uma alta constante dielétrica.

${ }^{2}$ Taxa na qual a energia elétrica é transformada em energia térmica em um dielétrico quando este é submetido a uma mudança de campo elétrico.

*RODITI, I. Dicionário Houaiss de física. Editora Objetiva, 2005.
} 
- Analisar a influência de dois diferentes tipos de trama de tecidos de fibra nas propriedades mecânicas finais do compósito, verificando, de maneira qualitativa, a adesão da fibra ao PTFE por intermédio de ensaio específico de análise da adesão e análise de fotomicrografias de microscopia óptica e microscopia eletrônica de varredura (MEV);

- Estudar a viabilidade da fabricação de compósitos com camadas superficiais de PTFE mais espessas, através da análise da adesão dessas camadas adicionais de PTFE ao PTFE impregnado nos tecidos, e das deformações residuais pós-tratamento térmico. Esta etapa considera a possível necessidade de um compósito com revestimento externo contínuo de PTFE para que características como a resistência a corrosão sejam melhor aproveitadas.

\subsection{Justificativas}

Embora não faça parte dos objetivos o desenvolvimento de um componente ou produto, este trabalho se justifica pela potencialidade de aplicação de compósitos estruturais de PTFE. Características do PTFE puro, como a baixa interação química, baixas constante e perda dielétrica (EBNESAJJAD, 2000) e baixo coeficiente de atrito, podem continuar a serem aproveitadas mesmo no material compósito. Considerando estas propriedades, é possível entender a potencialidade de uso do material desenvolvido pelos exemplos detalhados seguir.

A baixa interação química é uma característica de grande interesse para a indústria relacionada à produção ou uso de produtos químicos. Por possuir esta propriedade, o PTFE é muito usado como proteção contra fluidos corrosivos. Porém, as limitadas características estruturais deste polímero tornam seu uso restrito a revestimentos ou sob forma de 'liners 3 , em válvulas, tubulações e vasos (KERBOW, 1996: EBNESAJJAD, 2000). Assim, os componentes estruturais

\footnotetext{
${ }^{3}$ Liners são tubos finos que revestem o interior de tubos de paredes mais espessas.
} 
nestas aplicações são as partes metálicas isoladas dos meios corrosivos pelo revestimento de PTFE. Estas estruturas ou parte delas podem ser substituídas por outras fabricadas inteiramente por compósitos de PTFE que, eventualmente, poderiam apresentar uma camada de PTFE com espessura variável dependendo do grau de segurança em se evitar o contato das substâncias corrosivas às fibras do reforço. Além disso, soma-se o fato de que, num eventual contato destas substâncias com o reforço, as fibras de vidro, assim como o PTFE, tem baixa interação química, reagindo apenas com ácido fluorídrico e bases fortes (EBNESAJJAD, 2000).

O PTFE possui baixa constante dielétrica $(2,1)$ e baixa perda dielétrica $(0,0001)$ (EBNESAJJAD, 2000). Em associação com fibra de vidro, a constante dielétrica e o fator de perda dielétrica são respectivamente 3,06 e 0,0036 (PENGGANG et al. 2008). Estes valores, ainda considerados baixos, indicam uma boa permeabilidade a ondas para o uso em cúpulas de radares ('radomes') - como proposto por Birch et al. (1983) - e são requisitos essenciais na fabricação de placas de circuito impresso para circuitos de alta velocidade 4 (JAWITZ, 1997, THIERAUF, 2004, COOMBS, 2007). A resistência à corrosão e a excelente estabilidade térmica inerentes do PTFE (EBNESAJJAD, 2000) são também características importantes na fabricação de placas de circuito impresso (JAWITZ, 1997; JAWITZ; JAWITZ, 2006).

Por fim, com relação ao coeficiente de atrito, como a camada mais externa do laminado é constituída unicamente de PTFE e pode ter espessura variada, as propriedades tribológicas do PTFE puro são mantidas nas superfícies das estruturas.

\subsection{Apresentação dos Capítulos}

No que se segue, o restante do texto é dividido em outros quatro capítulos com os seguintes conteúdos:

\footnotetext{
${ }^{4}$ Um circuito projetado para transportar dados a uma velocidade maior que a necessária para comunicação por voz. SAIGH, R. The international dictionary of data communications. Global Professional Publishing, 1998.
} 
No capítulo 2 é feita uma revisão bibliográfica sobre materiais compósitos, PTFE e compósitos de PTFE e fibras, com o intuito de mostrar em que linha de pesquisa está inserido este trabalho.

No capítulo 3 são descritos os materiais utilizados, os métodos de fabricação, a metodologia utilizada para o estudo da influência de algumas variáveis do processo de fabricação nas propriedades mecânicas finais e os métodos de caracterização mecânica aplicados no desenvolvimento dos compósitos propostos.

No capítulo 4 é apresentada a caracterização mecânica dos compósitos em função da metodologia utilizada para esta análise. São expostos os resultados dos ensaios mecânicos e avaliadas as variáveis que influenciam em sua qualidade estrutural. Visando facilitar a leitura do texto, algumas informações - consideradas de caráter local no trabalho - sobre materiais utilizados e metodologias de fabricação e avaliação são abordadas oportunamente neste capítulo.

Por fim, o capítulo 5 traz as conclusões sobre o estudo e trata de pontos que podem ser usados em uma possível continuação do trabalho. 


\title{
2 Revisão Bibliográfica
}

\begin{abstract}
Neste capítulo é apresentada uma revisão sobre os compósitos poliméricos reforçados com fibras, dando principal enfoque à fibra de vidro como reforço e ao uso do PTFE como matriz polimérica. É mostrado o contexto em que se inserem estes materiais na fabricação de compósitos visando dar o embasamento necessário para a compreensão do restante do trabalho.
\end{abstract}

\subsection{Compósitos Poliméricos}

Os compósitos são formados, em grande parte, por duas fases distintas, denominadas matriz e fase dispersa. A matriz é contínua e envolve a fase dispersa, sendo esta última responsável pelo reforço do material (CALLISTER, 2005). Como primeiro exemplo, pode-se citar os tijolos egípcios comentados no capítulo anterior, em que o barro (matriz) que envolvia a palha, que é um material fibroso e que melhora a resistência do tijolo, fazendo o papel da fase dispersa.

Os compósitos em que fibras fazem o papel de fase dispersa têm extrema importância tecnológica. As fibras são responsáveis pelas elevadas resistência e rigidez nesses materiais. Nos compósitos poliméricos com fibras, polímeros fazem o papel de matriz e transmitem a maior parcela do carregamento às fibras 
(MAZUMDAR, 2002).

\subsubsection{Matrizes poliméricas}

As matrizes de compósitos poliméricos envolvem e protegem as fibras de possíveis ataques químicos ou exposições a condições ambientais adversas. A matriz é a responsável pela ligação entre as fibras e por transmitir a tensão aplicada externamente a elas, sendo as fibras as principais responsáveis por suportar os carregamentos. Este carregamento é melhor transmitido quanto menor for o módulo de elasticidade e quanto maior a ductilidade da matriz (WILLIAM; CALLISTER, 2000; MAZUMDAR, 2002). As matrizes são selecionadas dependendo da aplicação dos compósitos, pois determinam a temperatura de trabalho e o uso do material quanto à performance, em que incluem, além das possíveis exposições químicas e ambientais do material, parâmetros como propriedades elétricas e requisitos para sua manufatura. Pode-se dividir as matrizes poliméricas em dois grupos: matrizes termorrígidas e termoplásticas.

\subsubsection{Matrizes termorrígidas}

Os polímeros termorrígidos ou termofixos são materiais que passam por uma reação química irreversível durante a polimerização. Neste processo, são formadas ligações cruzadas entre as cadeias poliméricas principais, o que causa perda de mobilidade das cadeias moleculares que vem a provocar solidificação. Este processo é chamado de cura. Após processados, estes materiais não adquirem mais o estado líquido e se tornam insolúveis, o que impossibilita sua reciclagem (CANEVAROLO, 2002). Temperaturas altas causarão a quebra das ligações cruzadas e a degradação do polímero. Este tipo de material é o mais usado na fabricação de compósitos, é de fácil manipulação e promove uma boa impregnação à fibra devido ao fato de ser aplicado no estado líquido, envolvendo toda superfície da fibra. Este tipo de material geralmente oferece uma grande estabilidade 
térmica e dimensional, além de altas resistências elétrica, química e à dissolução. Entre as resinas mais importantes desta família podem ser citadas a resina epóxi e o poliéster (MAZUMDAR, 2002).

\subsubsection{Matrizes termoplásticas}

Os termoplásticos são polímeros que quando expostos a um aumento de temperatura ou de temperatura e pressão amolecem gradativamente, podendo alcançar um grau de mobilidade de suas moléculas que permite sua moldagem. Quando resfriados se tornam sólidos novamente.

Diferentemente dos termorrígidos, este tipo de polímero não forma ligação cruzada, podendo chegar novamente a um estado de maior fluidez pelo reprocessamento com temperatura e pressão, tornando-os recicláveis e solúveis (CANEVAROLO, 2002). Alguns polímeros desta classe, como por exemplo o PTFE e o polietileno de ultra alto peso molecular UHMWPE, têm altas viscosidades quando no estado fundido, o que impossibilita serem moldados por processo de injeção. Os termoplásticos podem ser amorfos ou semicristalinos, pois a complexa natureza de suas moléculas não permitem que sejam totalmente cristalinos. Esses materiais possuem menores rigidez, resistência mecânica e resistência à fluência em relação aos termorrígidos e, por esse motivo, são amplamente usados na forma de compósitos reforçados com fibras. Além de poderem ser reciclados, os termoplásticos oferecem uma capacidade de reparo mais simples que os termorrígidos, qualidade de grande valia para a indústria (MAZUMDAR, 2002).

\subsubsection{Fibras}

Geralmente, o material em forma de fibras apresenta uma maior resistência nessa configuração quando comparado ao material bruto em forma de blocos com maiores dimensões. Segundo Hyer e White (1998) uma fibra se forma seguindo uma orientação preferencial das ligações atômicas e moleculares mais fortes em 
sua direção longitudinal, o que promove às fibras melhores propriedades mecânicas nesta direção. Além disso, devido ao diâmetro reduzido, as fibras apresentam menor probabilidade de falha que materiais mais volumosos (ROESLER et al., 2007). Como exemplo da eficácia das fibras pode-se citar o vidro comum, que apresenta uma resistência a ruptura de 0,7 GPa no estado bruto, enquanto que, em forma de fibra, este valor pode subir pra 4,6 GPa (CALLISTER, 2005; MENDONÇA, 2005).

As principais fibras usadas nos dias atuais são: fibras de vidro, fibra de carbono, aramida (Kevlar ${ }^{\circledR}$ - marca pertencente a DuPont), fibra de boro e carbeto de silício (GAY, 2003).

\subsubsection{Influência do comprimento e orientação das fibras}

O comprimento das fibras exerce uma influência muito importante nas propriedades mecânicas dos materiais compósitos. Quando um compósito reforçado com fibras sofre um carregamento, a matriz transmite, em determinado grau, esta carga para as fibras. Desta forma, a região de contato da matriz com a fibra se torna importante para a transmissão da carga. Fixando-se o diâmetro das fibras, a magnitude da região de contato passa a ser determinada pelo seu comprimento.

Na Figura (1) é esquematizado o acoplamento fibra-matriz para o caso de uma fibra curta, representada pelo retângulo central, sendo que as linhas verticais representam um padrão de deformação da matriz. Considerando ser um compósito sujeito a um tracionamento em uma direção coincidente com a direção longitudinal de uma fibra, pode-se notar que o carregamento transmitido da matriz para a fibra, é interrompido em suas extremidades, reduzindo a eficácia em relação a uma fibra de maior comprimento (CALLISTER, 2005; ROESLER et al. 2007).

Supondo agora a fibra da Figura (1) submetida à sua resistência final, ou seja, ao seu limite de resistência à tração $\left(\sigma_{f}\right)$. Pode-se verificar que há um compri- 


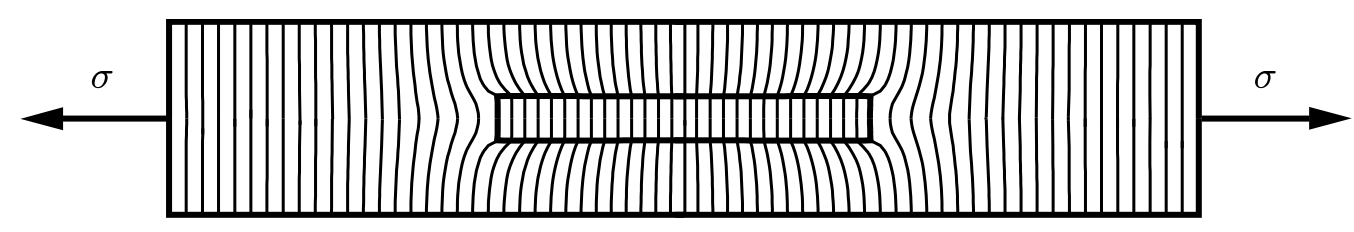

Figura 1: Acoplamento de uma fibra curta envolta por uma matriz sob tração na direção longitudinal da fibra (ROESLER et al., 2007).

mento crítico $\left(l_{c}\right)$ para que os aumentos de resistência e rigidez no compósito sejam consideráveis. Este comprimento é dado pela Eq. 2.1 e depende ainda do diâmetro da fibra $d$ e da tensão tangencial admissível na interface fibra-matriz $\tau_{c}$ ou da tensão limite de escoamento em cisalhamento da matriz, se esta for menor (CALLISTER, 2005).

$$
l_{c}=\frac{\sigma_{f} d}{2 \tau_{c}}
$$

O tamanho crítico das fibras pode ser melhor entendido pela Figura (2), considerando o caso de carregamentos de tração na direção longitudinal à fibra. Em (a) tem-se um comprimento de fibra no limite mínimo de aproveitamento, mas com a tensão máxima atingida somente no ponto central da fibra. Em (b) a carga imposta à matriz é transmitida de forma mais significativa para a fibra pelo fato desta ter um maior comprimento, permitindo que a tensão máxima seja alcançada em uma extensão maior, de modo a servir como reforço mais efetivo. Em (c) tem-se uma situação de baixa efetividade, em que o comprimento da fibra é menor que o valor de comprimento crítico. A tensão máxima que o material pode suportar é menor que $\sigma_{f}$.

Quando o valor do comprimento da fibra $l$ for muito maior que $l_{c}$, ou seja, $l>15 l_{c}$, ela passa a ser denominada fibra longa; fibras menores que esse valor são denominadas fibras curtas. Segundo Roesler et al. (2007), quando as fibras de um componente são comparáveis com as dimensões do próprio componente pode-se denominá-las de fibras contínuas.

Na Figura (3) é exposta uma sequência de diferentes configurações dos refor- 


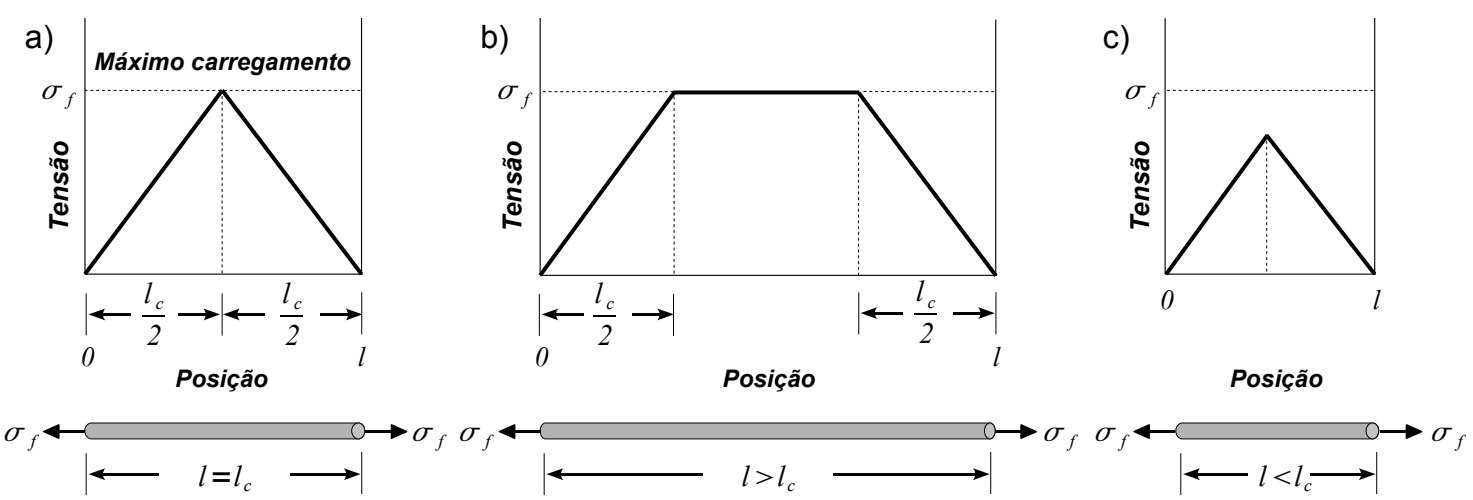

Figura 2: Representação esquemática do tamanho crítico das fibras: a) valor crítico de comprimento; b) fibra longa, melhor transmissão de tensões; c) fibra muito curta, menor aproveitamento (adaptado de Callister (2005)).

ços em ordem da menor para a maior eficácia, considerando constantes as massas da matriz e das fibras, para um tracionamento vertical. Em (a) têm-se fibras curtas aleatoriamente dispostas; em (b) as mesmas fibras alinhadas na direção do carregamento; e, em (c) e (d) estão representados compósitos de fibras contínuas em forma de tecidos bidirecional e unidirecional. $\mathrm{O}$ tecido unidirecional se torna mais eficaz que o bidirecional por possuir todas as fibras dispostas na direção do carregamento (CALLISTER, 2005; ROESLER et al., 2007). O processo de laminação com tecidos pré-impregnado traz uma grande gama de possibilidades de alinhamento das fibras, podendo haver uma orientação diferente a cada camada do tecido depositado.
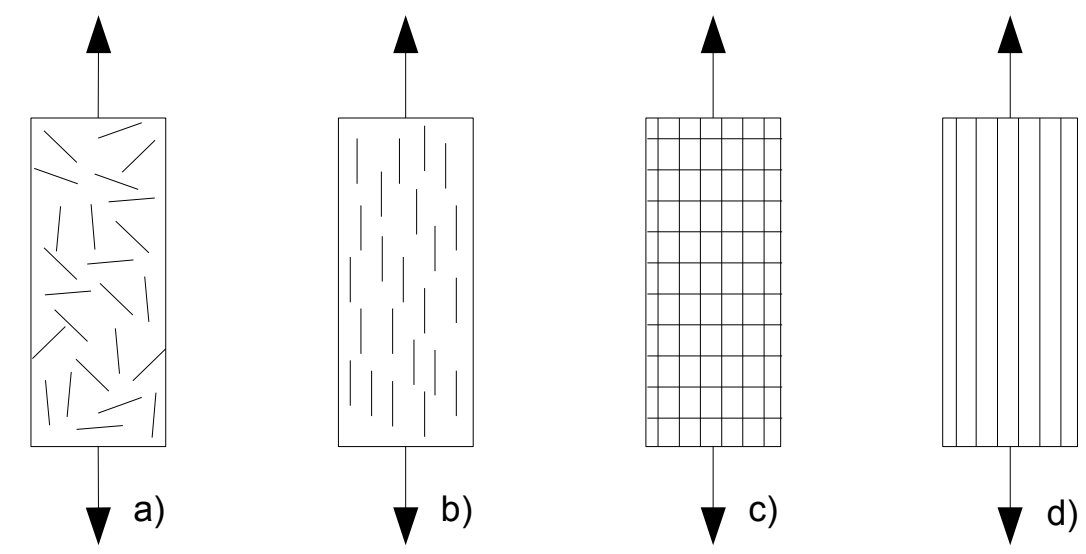

Eficácia do reforço

Figura 3: Representação da orientação das fibras em um compósito: a) fibras curtas com distribuição aleatória; b) fibras curtas alinhadas; c) tecido bidirecional - fibras contínuas; d) tecido unidirecional - fibras contínuas. 


\subsubsection{Fibras de vidro}

A fibra de vidro é o tipo de fibra mais usado entre os compósitos poliméricos. Isso se dá devido à sua baixa interatividade química - qualidade de uso - e ao seu baixo custo associado a uma alta resistência à tração em relação aos materiais poliméricos. Existem alguns pontos negativos com relação à fibra de vidro, como seu baixo módulo de elasticidade e baixa resistência à fadiga em compósitos, quando comparada, por exemplo, às fibras de carbono (LEVY; PARDINI, 2006).

O processo de fabricação das fibras de vidro é feito pela fundição do vidro ou dos componentes que o compõe a uma temperatura de aproximadamente $1250{ }^{\circ} \mathrm{C}$. O material fundido escoa por uma placa de platina perfurada e é então estirado, causando uma redução em seu diâmetro até valores predefinidos. Os fios são então resfriados e agrupados, formando os denominados strands (filamentos bobinados), geralmente compostos por centenas de filamentos.

No processo conhecido como ensimagem, geralmente as fibras de vidro são recobertas por agentes ligantes - que vêm a promover uma melhora na adesão química entre a fibra e a matriz - ou por camadas protetoras que permitem melhorar algumas características do material, como resistência à abrasão. As fibras destinadas à fabricação de tecidos (trançagem), por exemplo, são recobertas com material lubrificante para facilitar o processo de trançagem e este material pode ser posteriormente removido por processo de queima (LEVY; PARDINI, 2006).

O tipo de fibra mais usado para reforços estruturais é a feita com o vidro tipo E, algumas características deste tipo de fibra de vidro são mostradas na Tabela (1).

Tabela 1: Propriedades das fibras de vidro do tipo E (BRIAN, 2004)

\begin{tabular}{cccc}
\hline \multicolumn{4}{c}{ Fibras de Vidro Tipo E } \\
\hline \hline Densidade & Temperatura de fusão & Módulo de elasticidade & Resistência \\
\hline $2,54 \mathrm{~g} / \mathrm{cm}^{3}$ & $1316^{\circ} \mathrm{C}$ & $72 \mathrm{GPa}$ & $3455 \mathrm{MPa}$ \\
\hline
\end{tabular}




\subsubsection{Tecidos impregnados}

Com a aplicação dos compósitos em áreas que exigem um maior controle de qualidade e de desempenho, como na indústria aeronáutica, foi necessário desenvolver processos de fabricação mais confiáveis que os processos de manufatura tradicionais, tais como o de moldagem manual (hand Lay-up) - no qual são depositadas manualmente em um molde, camadas de resina e de tecidos de fibras (LEVY; PARDINI, 2006). O controle da fração volumétrica de fibras em um compósito é um parâmetro difícil de se controlar e como a concentração de fibra é um fator determinante na resistência mecânica desses materiais, criou-se a necessidade do desenvolvimento de uma nova tecnologia de manufatura em que se possa controlar melhor este e outros parâmetros.

No processo de impregnação são utilizadas as matérias-primas, fibra e matriz. Na Figura (4) é esquematizado o processo de impregnação de um tecido de fibras por uma matriz polimérica. O processo mostrado é utilizado na maioria das vezes para matrizes termorrígidas, e mostra um tecido passando por um banho de resina e, em seguida, sofrendo um tratamento térmico para a cura parcial da resina. Este processo garante uma grande homogeneidade na impregnação das fibras pela matriz polimérica (LEVY; PARDINI, 2006).

Um dos processos de fabricação de materiais compósitos usando os materiais pré-impregnados é a moldagem por compressão, a qual é geralmente realizada com resina termorrígida. Neste processo é feito um empilhamento das lâminas do material pré-impregnado com a orientação desejada em cada camada e, na sequência, é aplicada uma pressão juntamente com tratamento térmico para a finalização do processo de cura, resultando num produto denominado laminado. Na confecção dos laminados, cada lâmina pode ser disposta de forma a ter uma orientação diferente das fibras. Esta orientação, como visto, influencia no comportamento mecânico do material e pode ser controlada de acordo com a aplica- 


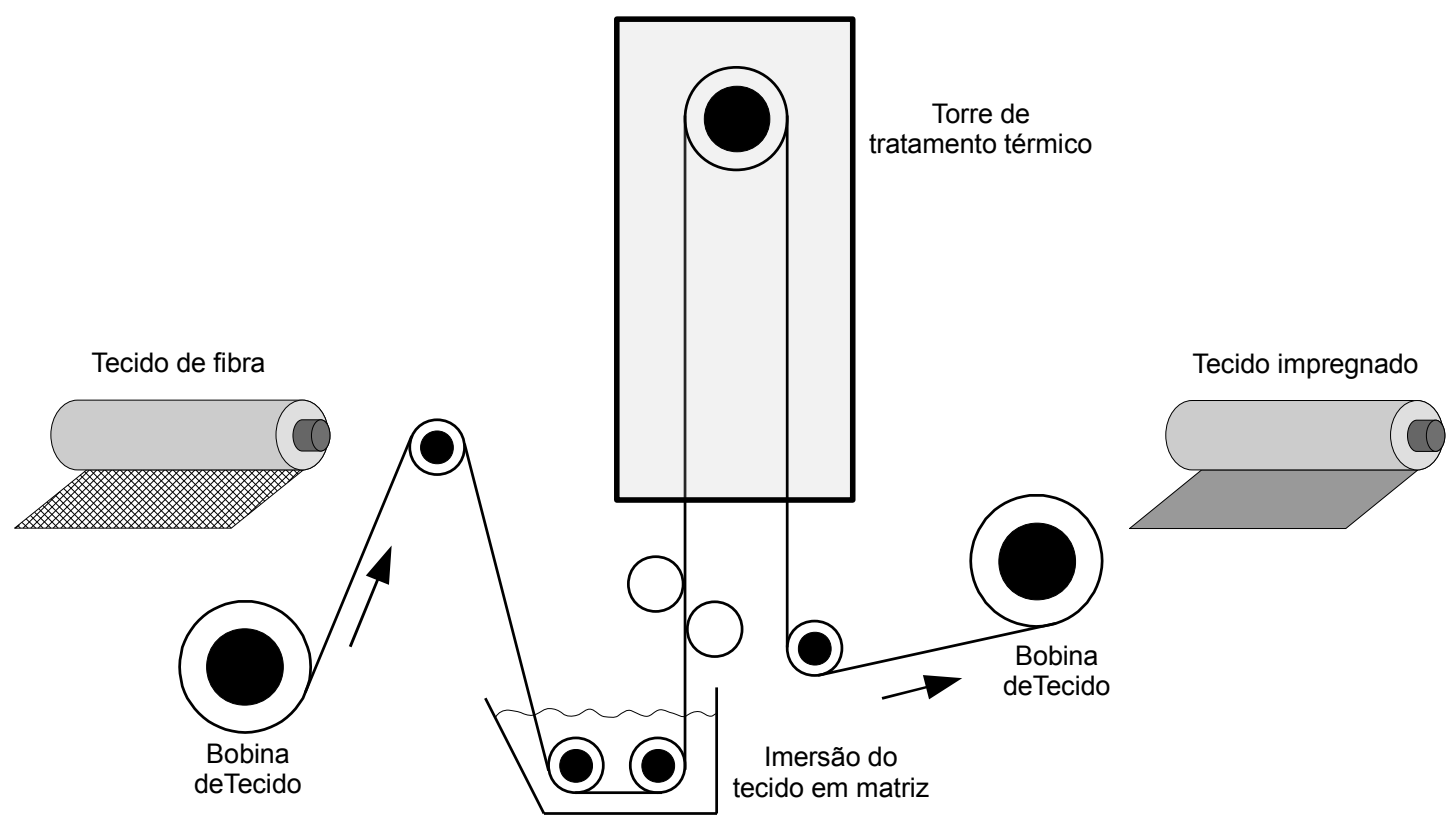

Figura 4: Processo de impregnação de resina em tecidos por imersão.

ção e o tipo de carregamento no qual o compósito será submetido.

Um processo de impregnação do PTFE em tecidos de fibra de vidro análogo ao esquematizado na Figura (4) será melhor discutido na seção 2.3.1 (página 41).

\subsection{O PTFE}

A descoberta do PTFE se deu em 1938, por Roy Plunkett, quando trabalhava no desenvolvimento de gases refrigerantes fluorados na empresa DuPont Company. No entanto, o uso comercial do PTFE se iniciou apenas em 1950 pela própria DuPont, que adotou o nome comercial de Teflon ${ }^{\circledR}$ para o PTFE por ela comercializado. Com esta descoberta nasceu também a classe dos fluoropolímeros, que são polímeros formados por ligações entre carbono e flúor. A Figura (5a) mostra a representação de uma molécula de PTFE e a Figura (5b) representa os átomos de flúor envolvendo a cadeia de carbono em uma molécula de PTFE. O tamanho do átomo de flúor e o comprimento da cadeia C-F (carbono flúor) são tais que a cadeia de carbono fica coberta pelos átomos de flúor (EBNESAJJAD, 2000). Algumas propriedades particulares dos fluoropolímeros, como baixa interação 
química, podem ser explicadas por esta blindagem dos átomos de carbono pelos átomos de flúor. A descoberta dos fluoropolímeros e suas propriedades características revolucionaram a indústria dos polímeros, devido à sua ampla gama de aplicações (EBNESAJJAD, 2000; ROESLER et al., 2007).



a)

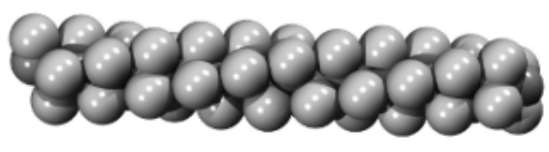

b)

Figura 5: PTFE: a) Representação química bidimensional de uma molécula; b) Blindagem dos átomos de carbono pelos átomos de flúor (ROESLER et al. 2007).

O PTFE é um polímero termoplástico que possui características de muito interesse para a indústria, as quais permitem um alto potencial de utilização deste material, tais como: em juntas ou anéis de vedação - devido ao baixo coeficiente de atrito -, em componentes sujeitos à ação de produtos corrosivos - devido à baixa interação química (HOUGHAM et al., 2002). Outras potenciais qualidades e usos deste material e seus compósitos foram abordadas anteriormente na seção 1.2 (página 22).

O PTFE apresenta uma alta temperatura de fusão cristalina de aproximadamente $344{ }^{\circ} \mathrm{C}$, para o material polimerizado, no estado a verde $\mathrm{I}^{1}$ (antes de passar pela primeira fusão) e de aproximadamente $327^{\circ} \mathrm{C}$ quando o material foi submetido a ao menos uma fusão. Possui uma alta estabilidade térmica resultante da forte ligação carbono-flúor, que caracteriza este polímero como tendo uma alta temperatura de uso. O PTFE possui um alto peso molecular, em uma faixa de $10^{6}-10^{7} \mathrm{~g} / \mathrm{mol}$ e, consequentemente, alta viscosidade dinâmica no estado fundido, $10^{10}-10^{12}$ Pa.s a $380{ }^{\circ} \mathrm{C}$ (GANGAL, 2001; EBNESAJJAD, 2000; TERVOORT et al. 2002), fato que torna praticamente inviável sua moldagem por injeção. Assim, o

\footnotetext{
${ }^{1} \mathrm{O}$ termo "a verde" é usado neste trabalho para designar o PTFE que ainda não passou por processo de fusão, ou seja, para o material que ainda não foi sinterizado.
} 
processo de fabricação de produtos à base de PTFE é realizado por compactação a frio do seu pó, seguida de sinterização. Nesse processo, o PTFE granulado ou em forma de pó é geralmente compactado em matrizes metálicas submetidas à ação de uma prensa uniaxial, ou em matrizes flexíveis (elastoméricas) no caso da prensagem isostática. O termo sinterização se refere à aplicação de um tratamento térmico sob temperatura superior à temperatura de fusão. O processo de sinterização ${ }^{2}$ no PTFE é responsável pelo aumento da coesão do material à medida que promove a coalescência dos grãos compactados - eliminando a maior parte da eventual porosidade resultante do processo de compactação - e a interdifusão das cadeias poliméricas entre grãos adjacentes (WU et al., 2002).

A Figura (6) mostra o diagrama de fases do PTFE, sendo que a única fase que não pode ser alcançada à pressão atmosférica é a fase III, o que requer uma alta pressão para que as moléculas assumam a configuração de cristal ortorrômbico. A polimerização do PTFE produz uma molécula linear sem ramificações. Abaixo de $19^{\circ} \mathrm{C}$ e a pressão atmosférica uma formação helicoidal com um ângulo de $13,8^{\circ}$ na ligação carbono-carbono. Entre 19 e $30^{\circ} \mathrm{C}$ há uma expansão de $1,8 \%$ (MCCRUM, 1959) do volume do material. Acima de $19{ }^{\circ} \mathrm{C}$ a quantidade de $C F_{2}$ para completar um ângulo de $180^{\circ}$ passa de 13 para 15 , e o material deixa de se apresentar na forma de cristal triclílico e passa para cristal hexagonal. Na transição de fase a $30{ }^{\circ} \mathrm{C}$, a forma de cristal hexagonal passa para a configuração de cristal pseudo-hexagonal. Essas transições são de grande importância devido ao fato de estas temperaturas serem muito próximas da temperatura ambiente, (GANGAL, 2001; EBNESAJJAD, 2000), na qual geralmente o material é processado (compactado) e utilizado, e estas transições causam diferenças nas propriedades

\footnotetext{
${ }^{2}$ Em processamento de metais e de cerâmicas, o termo sinterização indica que o tratamento é realizado abaixo da temperatura de fusão, no entanto, a sinterização é um termo frequentemente usado para descrever um tratamento térmico a temperaturas acima da temperatura de transição vítrea de polímeros amorfos ou acima da temperatura de fusão de polímeros semicristalinos. VICK, L.; KANDER, R. Ambient temperature compaction of polycarbonate powder. Polymer Engineering $\mathcal{E}$ Science, Wiley Subscription Services, Inc., A Wiley Company Hoboken, v. 37, n. 1, 1997.
} 
mecânicas do material (BROWN; DATTELBAUM, 2005).



Figura 6: Diagrama de transformações da fase cristalina do PTFE. Figura adaptada de Eby et al. (1990)).

O PTFE apresenta em seu estado a verde (antes de ser sinterizado) um alto grau de cristalinidade, aproximadamente 90\% (GANGAL, 2001). O grau de cristalinidade final após a fusão e recristalização parcial é dependente da taxa de resfriamento aplicada durante o tratamento térmico, e varia em torno de 30 à $50 \%$ para condições usuais de processamento (CANTO, 2007).

\subsubsection{Polimerização do tetrafluoroetileno}

O PTFE é produzido pela polimerização do tetrafluoroetileno $\left(C_{2} F_{4}\right)$, que é feita, principalmente, por dois processos distintos: suspensão e dispersão. Além dos caminhos diferentes que seguem os dois processos, a quantidade de surfactante ${ }^{3}$ adicionada para a reação de polimerização e a taxa de cisalhamento aplicada durante a reação (agitação) são as principais diferenças entre os dois procedimentos.

\footnotetext{
${ }^{3}$ Agente químico capaz de reduzir a tensão superficial de um líquido no qual é dissolvido. Ajuda a disseminação do PTFE em todo volume de água.
} 


\subsubsection{Suspensão}

Neste tipo de processo, o tetrafluoroetileno é polimerizado em suspensão aquosa para a produção de PTFE granular. Suas principais características são dadas pelo baixo (ou nenhum) uso de agente de dispersão no processo de polimerização e pela alta agitação a elevadas temperatura e pressão. Pela alta agitação empregada, o processo de suspensão gera partículas fibrosas e longas. A produção do PTFE em pó, já voltado para uso comercial, é dada pela quebra e secagem destas partículas.

Os pós finos de PTFE gerados pelo processo de suspensão têm pouca fluidez e baixa densidade aparente - que são características ruins para o uso em técnicas de moldagem. Com a intensão de facilitar o emprego deste tipo de técnica, estes pós finos são aglomerados (peletizados) para aumentar a fluidez e a densidade aparente do pó. Cada aglomeração é composta por numerosas e finas partículas e tem um diâmetro médio da ordem de algumas centenas de mícrons.

\subsubsection{Dispersão}

O método de dispersão (ou emulsão) consome muito mais surfactante que o de suspensão e produz partículas submicrométricas ${ }^{4}$ (Figura 7) que são base para aquisição de pós finos e produtos de dispersão. No processo é usada agitação média a elevadas temperatura e pressão.

A dispersão aquosa de PTFE consiste em um líquido de aspecto leitoso constituído por partículas muito pequenas $(<0,25 \mu \mathrm{m})$ deste polímero que ficam em suspensão na água. Esta forma de PTFE é altamente cristalino (96 - 98\%) e é produzido em uma ampla gama de pesos moleculares. O monômero é polimerizado pelo método de dispersão, em que um surfactante é adicionado ao meio aquoso, antes do início da polimerização.

\footnotetext{
${ }^{4}$ Medida do diâmetro de partícula, que se situa entre $5 \times 10^{-6}$ e $2 \times 10^{-4} \mathrm{~mm}$
} 




Figura 7: Foto de microscopia eletrônica de varredura de partículas de PTFE em dispersão aquosa (EBNESAJJAD, 2000).

A dispersão de PTFE pode ser usada na impregnação de materiais porosos ou fibrosos, como fibra de vidro, mas são usadas também em filmes fundidos, embalagens, juntas, rolamentos e aditivos poliméricos. O produto composto combina as propriedades do PTFE e substrato (EBNESAJJAD, 2000).

\subsection{Compósitos de PTFE reforçados com fibras}

O PTFE possui algumas propriedades mecânicas insuficientes para que seja usado na fabricação de componentes com fins estruturais. Sua resistência à flexão é de aproximadamente $18 \mathrm{MPa}$ e seu módulo de Young à flexão, de aproximadamente 0,7 GPa (JAHIER, 1992), valores bem inferiores a de polímeros de engenharia, como por exemplo, o poli(tereftalato de butileno) (프), que possui resistência à flexão de $88 \mathrm{MPa}$ e módulo de Young à flexão de 2, $4 \mathrm{GPa}$ (KUTZ, 2002). Compósitos de PTFE são geralmente utilizados com o objetivo de melhorar algumas de suas propriedades mecânicas e os tipos de reforços usados dependem da aplicação destinada. No entanto, este é um dos mais problemáticos polímeros para se fazer compósitos devido a neutralidade funcional das cadeias poliméricas que dificulta sua interação com os reforços. Sua alta viscosidade no estado fundido impede que o PTFE flua envolvendo os reforços e o baixo coeficiente de 
atrito reduz a interação mecânica com os reforços (EBNESAJJAD, 2000).

Devido às dificuldades no processo de fabricação e ao complexo mecanismo de deformação desenvolvido durante a sinterização do PTFE (CANTO et al., 2009), é comum a aplicação de reforços com dimensões de mesma ordem de grandeza dos grãos do polímero, como pós metálicos, pós cerâmicos e fibras curtas (BONNET, 2004; EBNESAJJAD, 2000). Estes reforços são misturados ao PTFE em forma de pó - por processo de tombamento seguido de moagem para garantir a homogeneidade do material -, ou por processo de aglomeração do PTFE (seção 2.2.1.2 página 37) juntamente com os reforços, que garante uma melhor fluidez ao material e uma chance menor de separação do PTFE e reforço. Reforços hidrofílicos podem ser tratados com organosilanos ou silicone para prevenir sua separação do polímero na solução aquosa. Este tipo de produto torna relativamente simples a fabricação de componentes de PTFE e reforços de mesma ordem de grandeza de seu pó.

Existem muitos trabalhos na literatura científica que tratam de compósitos com reforços com dimensões próximas às dos grãos de PTFE. Entretanto, o principal objetivo destes trabalhos é o de melhorar a resistência a abrasão do material sem causar muita interferência em suas características tribológicas. Tais reforços são pouco efetivos ou até nocivos a propriedades como módulo de elasticidade e resistência mecânica. Dados da DuPont 5 (1992 apud Ebnesajjad (2000) apresentam resultados para o PTFE com adição, em massa, de $25 \%$ de fibras de vidro trituradas, em que a resistência máxima à flexão e módulo de Young à flexão são de, respectivamente, 5,5 MPa e $1 \mathrm{GPa}$. Shi et al. (2007) apresentaram um trabalho com valores próximos a $22 \mathrm{MPa}$ para o PTFE reforçado com nanofibras de carbono, sendo que este desempenho foi obtido para uma fração mássica de 1\% de fibras. O trabalho ainda mostra que este desempenho diminui com o aumento desta concentração de fibras. Alguns destes trabalhos utilizam aditivos como si-

\footnotetext{
5“Filled Compounds of Teflon ${ }^{\circledR)}$ DuPont Co. Publication, Oct., 1992.
} 
lanos e terras raras (XUE; CHENG, 2002; QIAN-QIAN; XIAN-HUA, 2006; CHENG et al., 2002) pra promover uma melhor adesão do PTFE às fibras.

Estudos em compósitos de PTFE que utilizam fibras longas como reforço como o proposto neste trabalho - são pouco relatados pela literatura. Oshima et al. (2001b) apresenta a fabricação de um compósito de camada única de PTFE com fibras longas, a partir da impregnação de PTFE em dispersão aquosa, de um tecido unidirecional de fibra de carbono. Neste trabalho é feita a aplicação de radiação por acelerador de elétrons para promover ligações cruzadas no PTFE, tendo, entre outros propósitos, o de melhorar as propriedades mecânicas do compósito. Em outros dois trabalhos similares (OSHIMA et al. 2001a: OSHIMA et al., 2001c) são fabricados laminados a partir do empilhamento do mesmo tipo de lâmina de PTFE e fibra de carbono, que são também irradiados e avaliados mecanicamente. Os melhores valores apresentados para este tipo de compósito é de resistência máxima à flexão de 42,6 MPa e módulo de Young à flexão de 10,9 GPa para o compósito fabricado com uma fração mássica de fibras de 54,3\%, com apenas uma camada e sem a aplicação de radiação. Estes trabalhos citam a baixa interação entre fibra e matriz e a decomposição de agentes orgânicos que recobrem as fibras de carbono como principal dificuldade na obtenção de compósitos de alto desempenho.

Gu e Liang (2007), Penggang et al. (2008) e Gu et al. (2009) realizaram estudos em laminados de PTFE e fibras de vidro contínuas, e os trabalhos tratam basicamente da aplicação de um terceiro material, por processos de infusão, para o preenchimento de vazios nestes compósitos. Nestes trabalhos as fibras de vidro são impregnadas também com PTFE em dispersão aquosa e secas em seguida sob temperaturas que variam de 100 a $200{ }^{\circ} \mathrm{C}$ - inferiores a temperatura de fusão. Em seguida, os tecidos impregnados são empilhados e prensados a frio, passando então, por um processo de sinterização $-330{ }^{\circ} \mathrm{C}$ por 1 hora e $380{ }^{\circ} \mathrm{C}$ por de 2 a 3 horas. Após estes processos, os compósitos sofrem um processo de infusão se- 
guido de cura de tipos diferentes de resinas de alta performance, em cada um dos trabalhos, tendo como objetivo o preenchimento de vazios decorrentes da baixa pressão de compactação aplicada ou gerados pela queima de compostos orgânicos das fibras durante sinterização do laminado. Estas resinas aderem bem a fibra de vidro e promovem aumentos significativos de resistência e rigidez nestes compósitos. Alguns valores referentes às propriedades mecânicas dos compósitos são mencionadas: resistência máxima à tração de $81,8 \mathrm{MPa}$ (PENGGANG et al. 2008) e resistência máxima à flexão de 64,6 MPa Penggang et al. (2008) e de aproximadamente $100 \mathrm{MPa}$ (GU; LIANG, 2007; GU et al., 2009). Além do aparecimento de porosidade pela queima de aditivos orgânicos que recobrem as fibras, os autores também citam a baixa interatividade entre PTFE e fibras como fator limitante para a melhoria das propriedades mecânicas.

\subsubsection{Tecidos comerciais de PTFE e fibras de vidro}

Existem tecidos comerciais de fibra de vidro impregnados com PTFE que são fabricados segundo o processo mostrado na Figura (4). Este processo é amplamente aplicado na fabricação de prepregs de matrizes termorrígidas e é similar aos descritos nos trabalhos sobre compósitos de PTFE com fibras longas citados nesta seção. No processo industrial, a impregnação é feita pela imersão do tecido em dispersão aquosa de PTFE (ver seção 2.2.1.2 - página 37), seguido de sinterização a temperaturas próximas a $390^{\circ} \mathrm{C}$, executado em torre de tratamento térmico em que o tecido impregnado é submetido a um resfriamento rápido após sair da torre e ter contato com atmosfera à temperatura ambiente. Geralmente o processo é repetido algumas vezes para o mesmo tecido, visando obter uma cobertura mais espessa de PTFE.

Os tecidos compósitos de PTFE e fibras de vidro são usados, entre outras aplicações, como: tecidos estruturais tensionados (Tensioned Fabric Structures TFS) em coberturas permanentes (coberturas de estádio de futebol, por exem- 
plo), devido a baixa interação química e a boa resistência a variações climáticas (SHAEFFER, 1996: EBNESAJJAD, 2000) e proteção de antenas de telefonia, pelas mesmas propriedades, além das boas características dielétricas citadas na seção 1.2 (página 22). No presente trabalho serão utilizados estes tipos de tecidos comerciais impregnados - sinterizados - para a fabricação de laminados estruturais de PTFE. 


\title{
3 Processo de Fabricação e Metodologia de Avaliação das Propriedades Mecânicas de Laminados de PTFE com Fibras de Vidro
}

\begin{abstract}
Neste capítulo são apresentados, de forma detalhada, as matérias-primas usadas no desenvolvimento dos compósitos propostos, o processo de fabricação destes compósitos e os equipamentos e técnicas usadas na caracterização dos materiais.
\end{abstract}

\subsection{Materiais Utilizados}

A fabricação dos laminados é feita a partir de tecidos de fibra de vidro bidirecionais impregnados com PTFE (Figura 8), estes tecidos são flexíveis e de fácil manipulação. O processo de impregnação é executado como explicado na seção 2.3.1 (página 41). Para este trabalho, foram utilizadas duas classes de tecidos de fibra de vidro impregnados com PTFE: tecidos comerciais e tecidos produzidos em laboratório. 


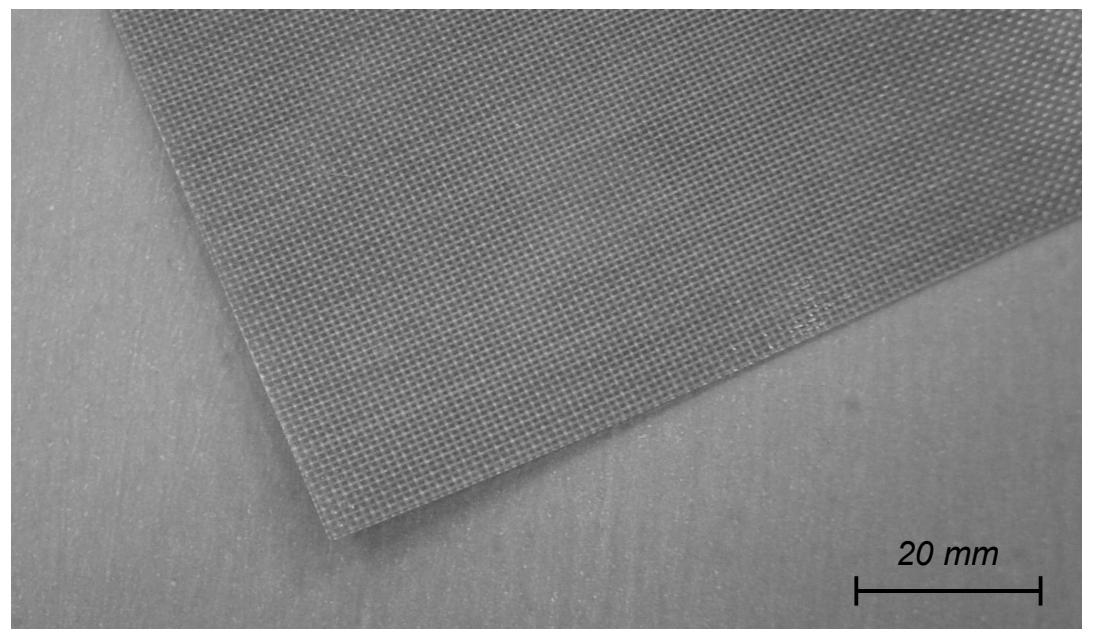

Figura 8: Tecido de fibra de vidro impregnado com PTFE.

\subsubsection{Tecidos comerciais: Chemfab ${ }^{\circledR}$}

Foram disponibilizadas, pela Saint-Gobain Cerâmicas \& Plásticos Ltda de Vinhedo-SP, amostras de diferentes tipos do tecido comercial Chemfab ${ }^{\circledR}: 008$ STD, 013 STD, 060 SI e TCK 042. Após realizados ensaios mecânicos preliminares com laminados obtidos a partir destes tecidos, foram escolhidos os tipos Chemfab ${ }^{\circledR} 008$ STD e Chemfab ${ }^{\circledR} 013$ STD para a continuação do trabalho. A escolha foi feita devido às propriedades mecânicas superiores apresentadas com relação aos demais - que por este motivo, não foram usados no restante da pesquisa.

Segundo Silva (informação pessoal) ${ }_{1}^{1}$ a temperatura durante o tratamento térmico a que é exposto o Chemfab ${ }^{\circledR}$ em cada etapa da impregnação fica próxima de $400{ }^{\circ} \mathrm{C}$, ou seja, bem superior à temperatura de fusão do PTFE $\left(344^{\circ} \mathrm{C}\right.$ para o material no estado a verde). Portanto, ao final do processo, tem-se um tecido impregnado com PTFE sinterizado. A Figura (9) apresenta análises termogravimétricas (TGA) para os dois tecidos usados como matéria-prima.

As TGAs mostram curvas similares da degradação dos PTFEs que recobrem os tecido de fibra de vidro. Nota-se que com a elevação da temperatura o PTFE é

\footnotetext{
${ }^{1}$ SILVA, P. H. Saint-Gobain do Brasil. Informação recebida em visita a Saint-Gobain unidade de Cerâmicas e Plásticos de Vinhedo - SP em 2007.
} 


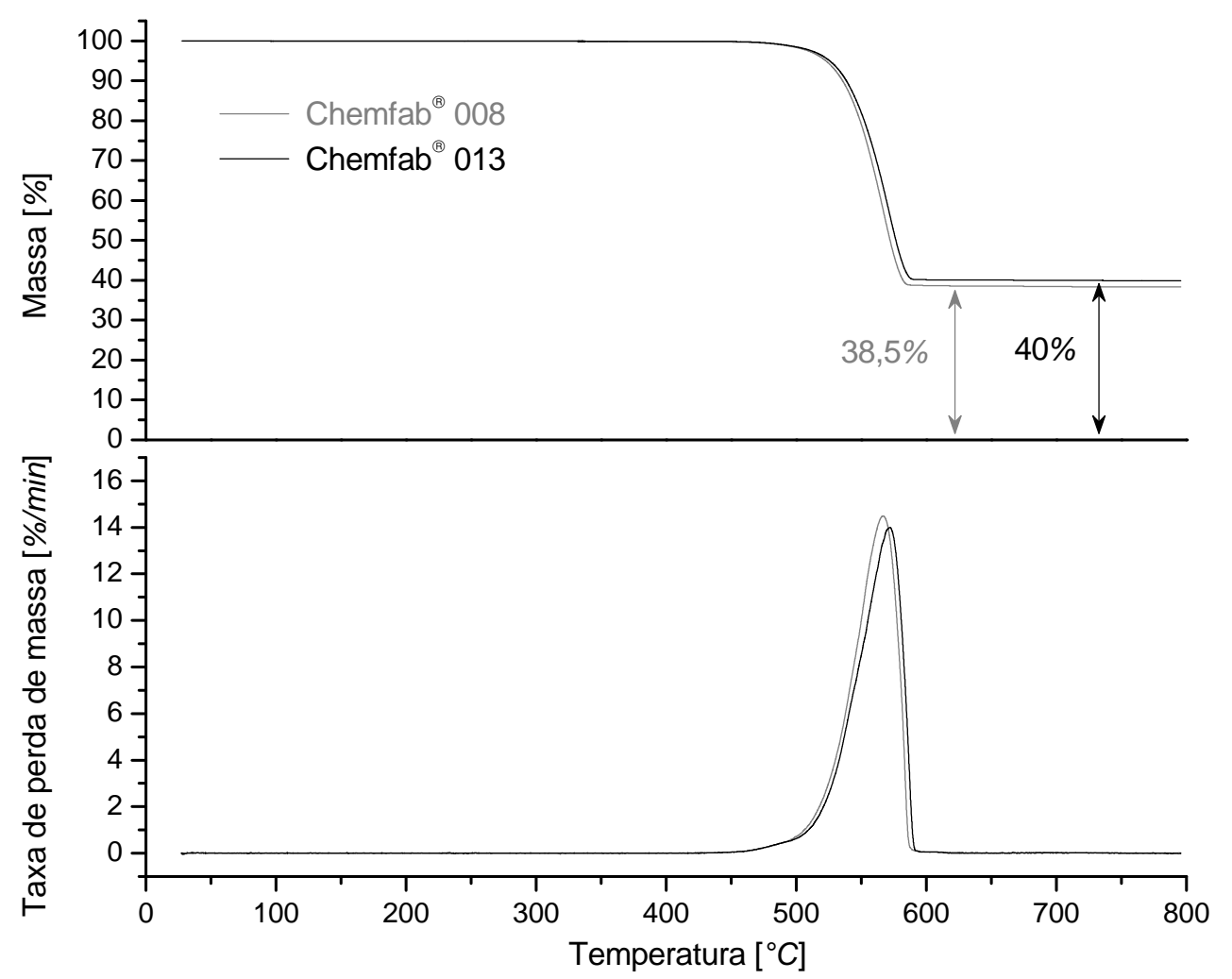

Figura 9: Análise de termogravimetria (TGA) para os materiais Chemfab ${ }^{\circledR} 008 \mathrm{e}$ Chemfab $^{\circledR} 013$.

totalmente pirolizado, sendo que a porcentagem de massa restante é atribuída à fração mássica de fibra de vidro que compõe o material, aproximadamente 38, 5 e $40 \%$ para o Chemfab ${ }^{\circledR} 008$ STD e Chemfab ${ }^{\circledR} 013$ STD respectivamente (Figura 9). As TGAs foram realizadas em um equipamento TGA Q500 da TA instruments, gentilmente cedido pelo Instituto de Macromoléculas (IMA) da Universidade Federal do Rio de Janeiro (UFRJ). As análises foram realizadas em atmosfera inerte de $N_{2}$ a uma taxa de aquecimento de $10^{\circ} \mathrm{C} / \mathrm{min}$.

Na tabela (2) são mostrados alguns valores referentes aos tecidos impregnados usados como matéria prima. Na Figura 10 são apresentadas fotomicrografias obtidas por meio de um microscópio estereoscópico, modelo Carl Zeiss Jena Citoval 2. A diferença entre as tramas de cada tecido de fibra de vidro evidencia um espaçamento entre os feixes de fibras muito maior no Chemfab ${ }^{\circledR} 008$. A gramatura maior do Chemfab ${ }^{\circledR} 013$ é compensada por uma quantidade maior de PTFE no recobrimento quando comparado com o Chemfab ${ }^{\circledR} 008$, fazendo com 
que os dois tecidos impregnados tenham frações mássicas de fibras muito próximas, como indicada na TGA dos materiais.

Tabela 2: Dados dos tecidos comerciais Chemfab ${ }^{\circledR} 008$ e $013^{1}$

\begin{tabular}{lccl}
\hline & Espessura $[\mathrm{mm}]$ & Gramatura $\left[g \cdot \mathrm{m}^{-2}\right]$ & $\begin{array}{l}\text { Temperatura de } \\
\text { Trabalho }\left[{ }^{\circ} \mathrm{C}\right]\end{array}$ \\
\hline $\mathrm{Chemfab}^{\circledR} 008$ & 0,08 & $153 \pm 15$ & $-73,3$ a 260 \\
\hline $\mathrm{Chemfab}^{\circledR} 013$ & 0,13 & $270 \pm 15$ & $-73,3$ a 260 \\
\hline
\end{tabular}

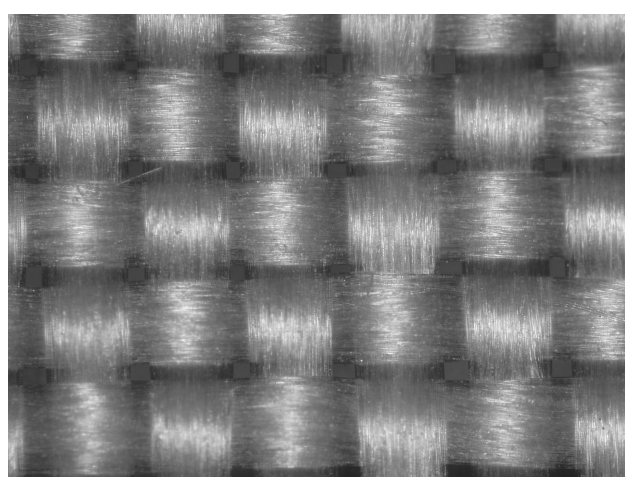

a)

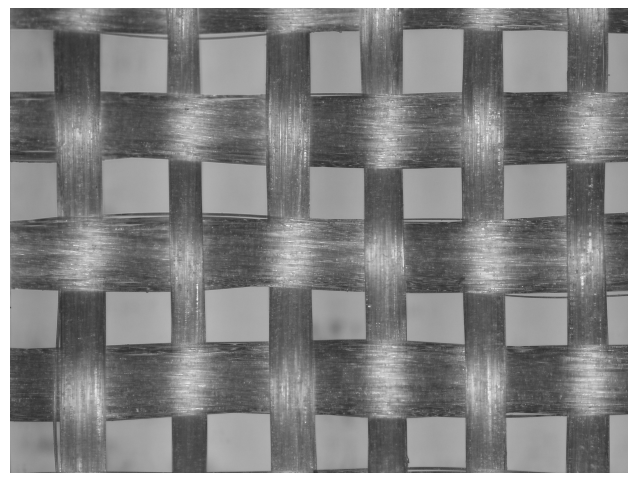

b)
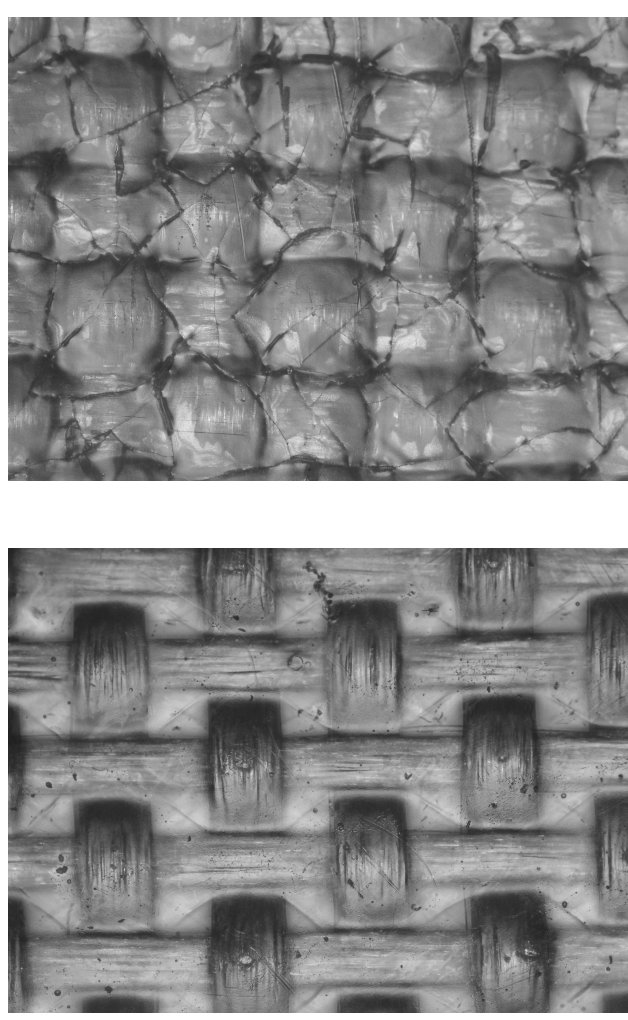

$0,5 \mathrm{~mm}$

Figura 10: Fotomicrografias de microscopia óptica de: a) tecido Chemfab ${ }^{\circledR} 013$, tecido puro (esquerda) e tecido impregnado com PTFE (direita); b) tecido Chemfab ${ }^{\circledR} 008$, tecido puro (esquerda) e tecido impregnado com PTFE (direita).

\subsubsection{Tecidos impregnados em laboratório}

Assim como para o tecido comercial, a fabricação do tecido impregnado em laboratório foi realizada pela imersão do tecido de fibra de vidro em uma dis-

\footnotetext{
${ }^{1}$ Dados fornecidos pelo fabricante
} 
persão aquosa de PTFE - solução coloidal similar a da fabricação dos tecidos comerciais - e tratado termicamente a cada passo para obter o recobrimento desejado. Os materiais utilizados para a obtenção destes tecidos foram: tecido de fibra de vidro - o mesmo usado pela Saint-Gobain na fabricação do Chemfab 013 STD $^{\circledR}$ (Tabela 2) - e dispersão aquosa de PTFE, Teflon ${ }^{\circledR}$ PTFE TE-3893 Aqueous Dispersion (com 60\% em massa de PTFE) de fabricação da DuPont.

O tecido foi imerso na solução e, antes de ser tratado termicamente, foi passado em um bastão de vidro para a retirada do excesso de PTFE. Diferentemente do tecido comercial, o tratamento térmico realizado neste tecido visou apenas a secagem do PTFE sobre a fibra a cada etapa da impregnação. Para essa secagem, o tecido molhado foi colocado em uma estufa a uma temperatura em torno de $100{ }^{\circ} \mathrm{C}$ - bem abaixo da temperatura de fusão do PTFE - por cerca de $10 \mathrm{~min}$. Foi obtido, como produto final (Figura 11), um tecido impregnado com PTFE a verde.

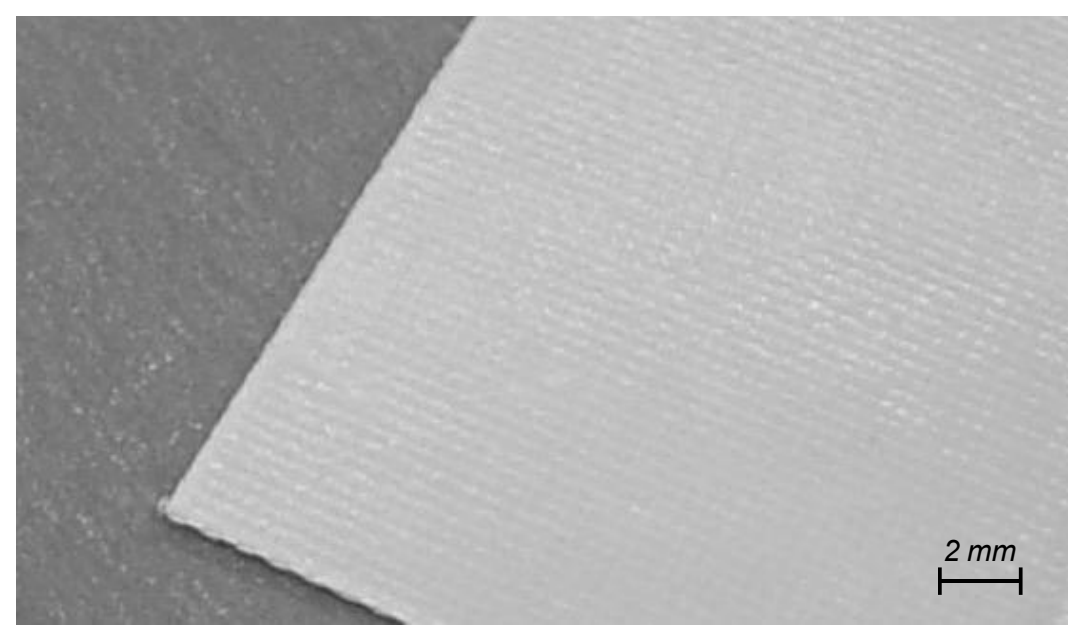

Figura 11: Tecido de fibra de vidro impregnado com PTFE em laboratório.

Foram produzidos dois tecidos impregnados: o primeiro, feito em 7 etapas que proporcionou uma fração mássica de fibras de aproximadamente 0,6 -, e, o segundo, em 12 etapas, que foi dividido em parte superior - com fração mássica de fibras de aproximadamente 0,43 - e parte inferior - em que houve um acúmulo maior de PTFE - com fração mássica de fibras de aproximadamente 0,36. 


\subsubsection{PTFE granulado Teflon ${ }^{\circledR} 6407$}

Em alguns estudos deste trabalho foi usado o PTFE granulado Teflon ${ }^{\circledR} 6407$ (Figura 12 com densidade aparente do pó de aproximadamente $0,86 \mathrm{~g} / \mathrm{cm}^{3}$, de fabricação da DuPont e fornecido pela Tecnofluor Indústria e Comércio Ltda, de Cotia-SP.

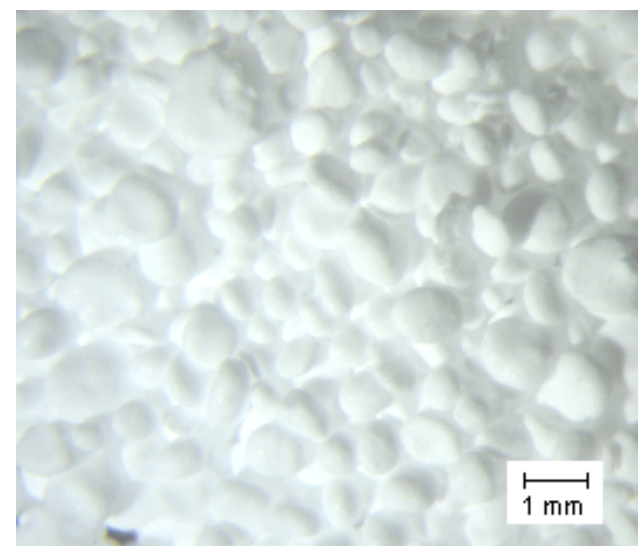

a)

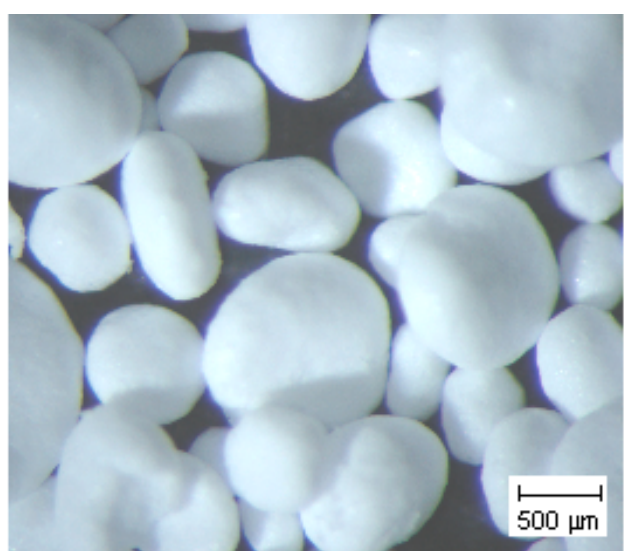

b)

Figura 12: Fotografias obtidas em microscópio estereoscópico: (a) Material Teflon ${ }^{\circledR} 6407$ (PTFE puro) na forma em que é recebido para o processamento e (b) aproximação mostrando detalhes dos grãos (pellets) (CANTO, 2007).

\subsection{Metodologia de Fabricação dos Laminados}

A fabricação dos laminados é realizada pelo empilhamento dos tecidos de fibra de vidro impregnados com PTFE em um molde metálico, seguido pelas etapas de prensagem e tratamento térmico (sinterização). Em todos os CDPs fabricados neste trabalho, as fibras do tecido bidirecional foram alinhadas a 0 e $90^{\circ} \mathrm{com}$ relação ao eixo longitudinal. A Figura (13) ilustra a sequência de passos para a fabricação do laminado.

Para a realização da etapa de prensagem foi construído um molde em aço inox 420 (Apêndice A), com superfícies retificadas, o qual foi temperado (com dureza resultante de $52 \mathrm{HRC}$ ) e cuja cavidade paralelepipédica possui $120 \mathrm{~mm}$ de comprimento, $15 \mathrm{~mm}$ de largura e $60 \mathrm{~mm}$ de altura. Estas dimensões foram esco- 


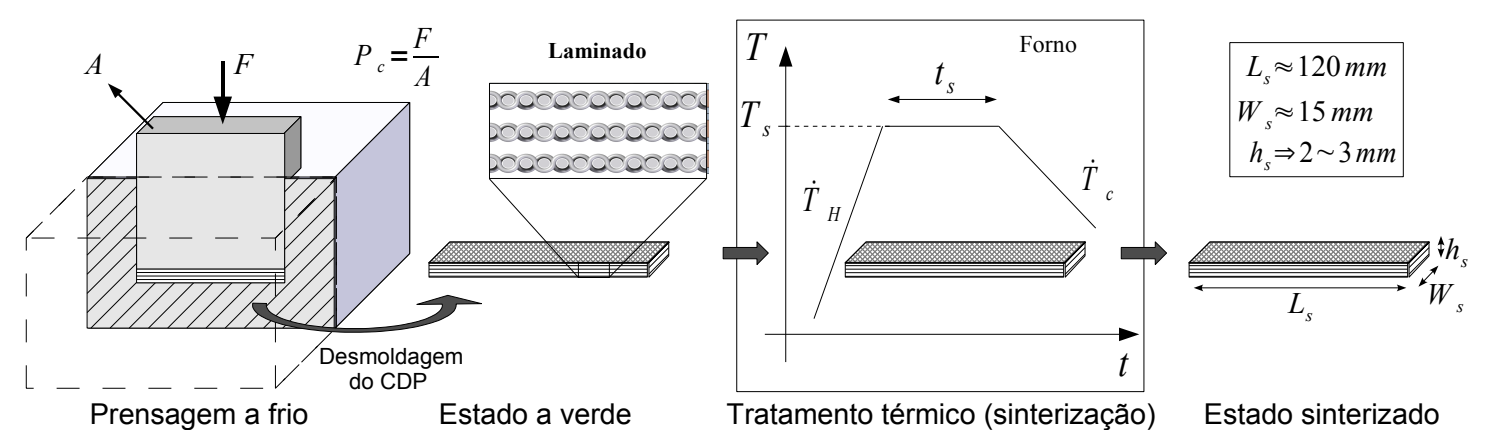

Figura 13: Processo de fabricação dos corpos-de-prova do compósito fabricado a partir de tecidos de fibra de vidro impregnados com PTFE.

lhidas por possibilitar a fabricação de CDPs para ensaios de flexão - com valores próximos aos dados pelas normas da American Society for Testing and Materials, ASTM D790 - 2 (2007) -, adesão interlaminar e tração. A etapa de prensagem foi realizada pela deposição das lâminas do tecido impregnado na cavidade do molde, cortadas em dimensões apropriadas para se ajustar a esta cavidade. A altura dos laminados fica dependente da quantidade e tipos das lâminas, além da pressão empregada na prensagem. Após o empilhamento das lâminas, os laminados foram prensados com uma pressão de conformação $\left(P_{c}\right)$ e mantidos a esta pressão por aproximadamente 5 min. Em seguida, eles foram lentamente descomprimidos e retirados do molde. Após este procedimento, foram levados a um forno para sinterização à pressão atmosférica, com exceção de um caso em que foi realizado um estudo complementar e o material prensado foi sinterizado sob pressão (ver seção 4.2.4 - página 96 .

O processo de sinterização foi realizado em forno com monitoramento computadorizado de temperatura, com variação máxima no controle de $\pm 1^{\circ} \mathrm{C}$ e circulação interna de ar para convecção forçada, garantindo uma variação menor que $\pm 2{ }^{\circ} \mathrm{C}$ na região onde foram dispostos os laminados, que foram sinterizados individualmente, para garantir uma maior homogeneidade no processo de fabricação. A sinterização consiste em submeter os laminados a um tratamento térmico conforme apresentado na Figura (13). Este tratamento térmico é realizado pela elevação da temperatura sob uma taxa de aquecimento constante $\left(\dot{T}_{H}\right)$ 
até um patamar superior à temperatura de fusão, denominada temperatura de sinterização $\left(T_{S}\right)$. A amostra permanece durante um determinado tempo neste patamar de temperatura, denominado tempo de sinterização $\left(t_{s}\right)$. Por fim, os laminados são resfriados até a temperatura ambiente sob uma taxa de resfriamento constante $\dot{T}_{C}$.

É bom ressaltar que, para a fabricação dos CDPs deste trabalho, tomaram-se os cuidados necessários para que a temperatura do ambiente de trabalho não se aproximasse dos limites inferior de $19{ }^{\circ} \mathrm{C}$ e superior de $30^{\circ} \mathrm{C}$. Esse procedimento teve como intuito evitar que o PTFE do tecido passasse pelas transições de fase que ocorrem para este polímero nestas temperaturas à pressão atmosférica, como anteriormente explicado na seção 2.2 (página 33).

\subsection{Metodologia de Avaliação das Propriedades Me- cânicas dos Laminados}

A avaliação das propriedades mecânicas dos laminados produzidos neste trabalho foi realizada pela execução e interpretação de ensaios mecânicos em CDPs elaborados a partir da matriz de prensagem mencionada na seção 3.2 (página 48). Foram realizados ensaios de flexão 3-pontos, adesão interlaminar e tração. O ensaio de flexão 3-pontos é de fácil execução, quando comparados aos ensaios de tração, e por isso foi escolhido para a execução do estudo de correlação das propriedades mecânicas dos laminados em relação aos parâmetros de processo, em que foram ensaiados uma quantidade muito grande de CDPs; o ensaio de adesão interlaminar foi realizado para se averiguar a natureza da adesão fibra matriz; e, o ensaio de tração buscou encontrar valores mais precisos das propriedades mecânicas do laminado. 


\subsubsection{Ensaio de flexão 3-pontos}

Os CDPs para a realização dos ensaios de flexão 3-pontos foram fabricados e submetidos ao ensaio (Figura 14), em que se utilizou uma distância entre os apoios inferiores - span $(S)$ - de $80 \mathrm{~mm}$. O controle foi feito pelo deslocamento do atuador da máquina de ensaios, sendo adotada a velocidade constante de 0,25 mm/min - correspondente à taxa de deformação máxima da ordem de $10^{-5} s^{-1}$ nas superfícies inferior e superior do CDP. Esta taxa foi verificada como sendo suficientemente baixa para se desprezar efeitos de viscosidade. Os ensaios foram realizados em ciclos de carregamento-descarregamento e as tensões e deformações nas faces calculadas, segundo a norma ASTM D790 - 2 (2007), pelas equações:

$$
\sigma^{f}=\frac{3 F S}{2 \omega_{s} h_{s}^{2}} \text { e } \varepsilon^{f}=\frac{6 y h_{s}}{S^{2}}
$$

sendo $\sigma^{f}$ a tensão de flexão calculada, $F$ a força de reação no atuador, $\varepsilon^{f}$ a deformação calculada e y o deslocamento aplicado. É importante ressaltar que estas expressões são baseadas na hipótese de que, durante o carregamento, as seções transversais, inicialmente planas, permanecem planas e ortogonais ao eixo de deslocamento do CDP, com $h<<S$, e sendo válidas para pequenas deformações e regime elástico-linear. Entretanto, essas relações foram utilizadas para descrever as tensões e deformações durante o ensaio, no qual o material é submetido a grandes deformações, apresentando comportamento não-linear (plasticidade). Assim, as relações são aceitáveis somente para fins comparativos entre os CDPs com diferentes condições de processamento.

A resistência máxima à flexão $\left(\sigma^{f(\max )}\right)$ é obtida da Eq. 3.1) para o maior valor de $\sigma^{f}$ aplicado durante um ensaio e o módulo de Young à flexão $\left(E^{f}\right)$ é dado pela Eq. (3.2) calculada no início do carregamento. 


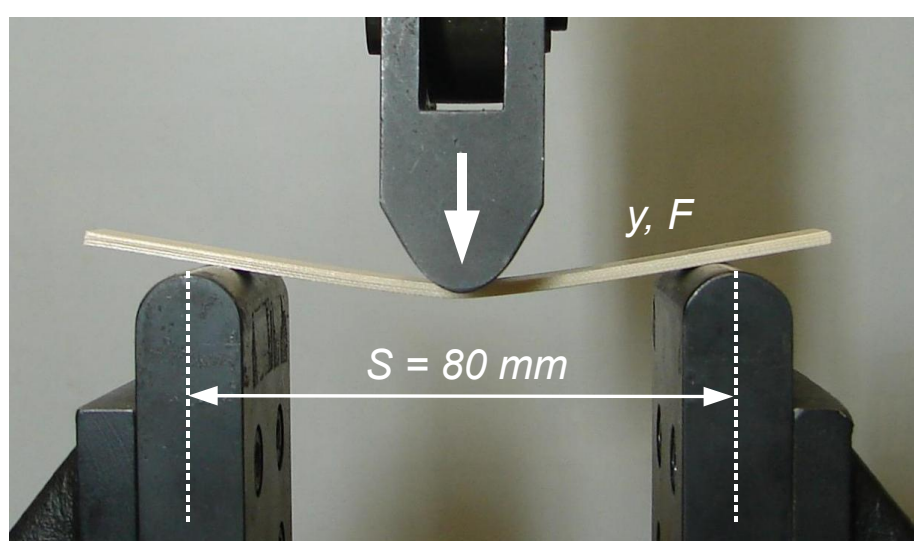

Figura 14: Ensaio de flexão 3-pontos em um CDP do compósito obtido pelos tecidos de fibra de vidro impregnados com PTFE.

$$
E^{f}=\frac{\sigma^{f}}{\varepsilon^{f}}
$$

\subsubsection{Ensaio de adesão fibra-matriz}

Para que se possa averiguar, isoladamente, a adesão fibra-matriz nos compósitos fabricados foi proposto um ensaio de adesão, com o auxílio de um dispositivo (Figura 15a) que foi confeccionado tendo como base a norma ASTM D316703a (2004) (Apêndice B). Esta norma é indicada para ensaios de adesão entre lâminas metálicas coladas por meio de adesivos específicos. Porém, ela foi adaptada para a realização de ensaios para os compósitos laminados propostos.

Os resultados deste ensaio são analisados observando-se a força aplicada para o descolamento da última lâmina (camada mais externa) de cada CDP, e uma análise comparativa pode ser estabelecida entre CDPs com diferentes condições de processamento.

Para a realização do ensaio foram fabricados CDPs (Figura 15p) com os mesmos comprimento e largura, da matriz de prensagem, da mesma forma que os CDPs elaborados para os ensaios de flexão 3-pontos. No entanto, para que fosse possível executar os ensaios de adesão, foi adicionada, antes da última camada, uma lâmina de alumínio de 0,01 mm de espessura, com mesma largura dos teci- 

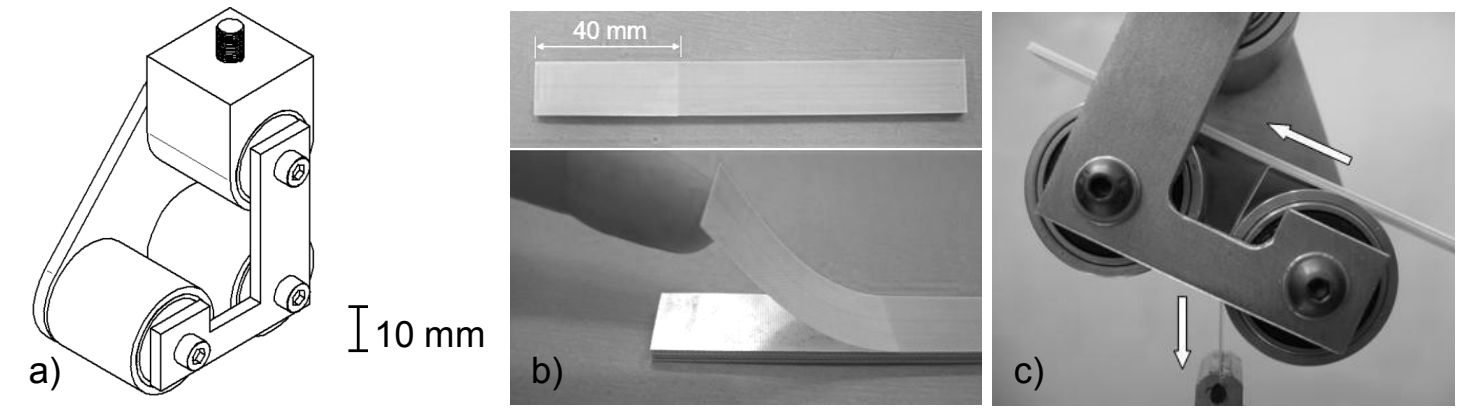

Figura 15: a) Dispositivo para ensaio de adesão; b) CDP para o ensaio de adesão; c) Execução do ensaio de adesão pelo arrancamento de uma lâmina de tecido.

dos e com comprimento de $40 \mathrm{~mm}$, posicionada a partir de uma das extremidades (Figura 15b) para impedir a adesão durante as etapas de prensagem e sinterização. Após a sinterização o CDP é colocado no dispositivo desenvolvido para o ensaio, como mostrado na Figura (15k), já acoplado à máquina universal de ensaios (EMIC, modelo DL-10000). A extremidade da lâmina inicialmente não aderida é fixada por uma garra. O tracionamento da lâmina provoca seu descolamento do restante do laminado a uma velocidade constante, fazendo com que o CDP se movimente girando os roletes do dispositivo, como indicado na Figura (15)). O descolamento se dá ao longo de um comprimento útil de pelo menos $60 \mathrm{~mm}$ (já descontados os $40 \mathrm{~mm}$ não aderidos). Para que permaneça rígido o suficiente para evitar oscilações causadas por flexão, o laminado é fabricado com uma espessura de aproximadamente $4 \mathrm{~mm}$.

\subsubsection{Ensaio de Tração}

Os CDPs para o ensaio de tração foram fabricados com os mesmos comprimento e largura que os CDPs dos ensaios anteriores, no entanto com uma região central mais estreita, formando um CDP do tipo gravata (Figura 16). Nestes CDPs é considerada para análise a região útil denotada por $A$ na Figura (16). Para a fabricação dos CDPs as lâminas foram cortadas no formato final do CDP e em seguida empilhadas e prensadas. Assim como na fabricação dos CDPs dos ensaios anteriores, cada CDP foi retirado do molde de prensagem e colocados em 
um forno para sinterização.

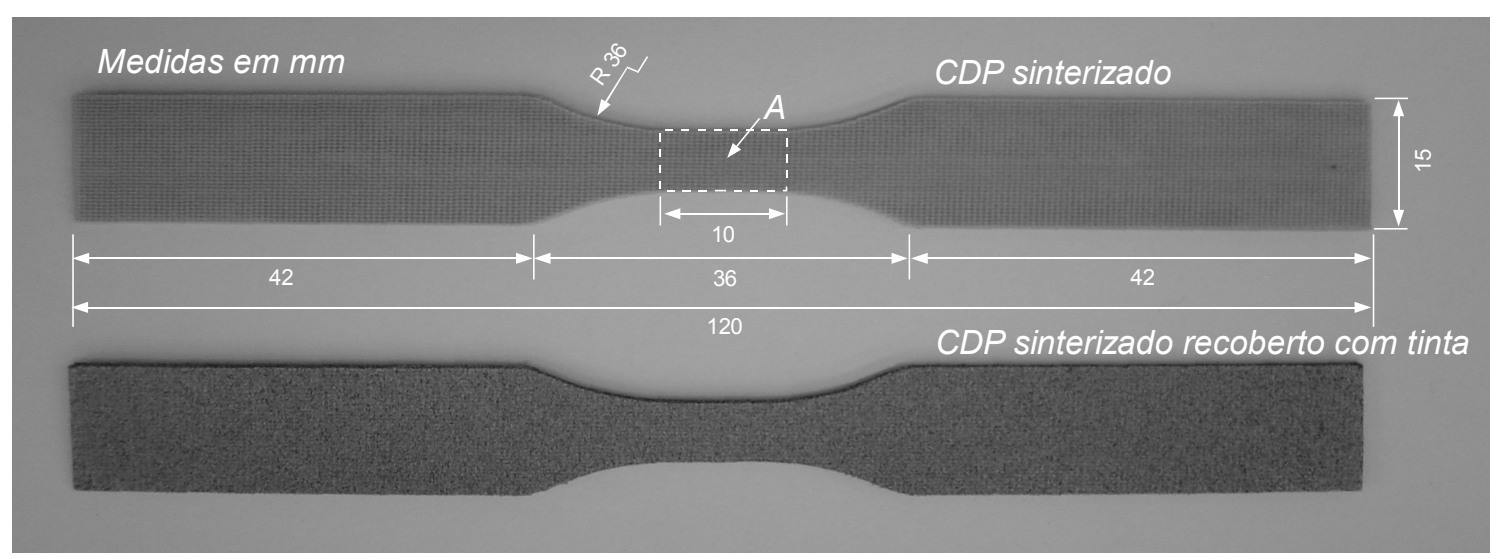

Figura 16: Medidas do CDP de tração e CDP recoberto com tinta para análise por correlação de imagens.

Os ensaios de tração foram realizados em uma máquina universal de ensaios, EMIC modelo DL-10000 com célula de carga de $5 \mathrm{kN}$, em ciclos de carregamento e descarregamento, com velocidade de deslocamento da garra superior de $0,025 \mathrm{~mm} / \mathrm{min}$, correspondente à taxa de deformação da ordem de $10^{-5} \mathrm{~s}^{-1}$. A tensão nominal é calculada pela força (medida pela célula de carga) dividida pela área inicial transversal da região $A$ do CDP e as deformações foram medidas por meio da técnica de correlação de imagens.

\subsubsection{Avaliação por correlação de imagens}

Os ensaios foram avaliados com ajuda do programa de correlação de imagens CORRELI, desenvolvido do LMT-Cachan, França. Para isso, no decorrer dos ensaios, foram capturadas imagens dos CDPs por meio uma câmera CANON EOS 50D, a uma taxa de aquisição de 4 fotos por minuto (Figura 17). Para a aquisição das fotos foi realizada uma iluminação artificial com LEDs para evitar o aquecimento dos CDPs. A partir de imagens consecutivas é possível obter o campo de deslocamentos da região fotografada, e, a partir deste, estabelecer campos de deformações no plano da região fotografada. Por meio destas análises é possível obter o módulo de elasticidade $(E)$ e o coeficiente de Poisson $(v)$. 




Figura 17: Ensaio de tração realizado em máquina universal de ensaio e equipamento para captura de imagens.

O programa CORRELI trabalha com o reconhecimento de pontos (pixels) em escala de cinza. Para que este reconhecimento seja possível, os CDPs passam por uma pintura que deixa sua superfície com pequenos pontos em diversas tonalidades que vão do preto ao branco, como mostrado na Figura (16). 


\section{Parâmetros de Fabricação e suas Influências nas Propriedades Finais dos Laminados}

Neste capítulo são apresentados os resultados referentes aos ensaios mecânicos realizados nos laminados fabricados segundo o processo proposto no capítulo anterior. Foram analisadas a resistência e a rigidez final do material em função da variação de valores dos parâmetros de fabricação. Buscou-se assim, encontrar uma dinâmica de processamento que levasse em conta a melhoria das propriedades mecânicas finais e custo operacional de fabricação. São discutidos no capítulo os fatores que levam a degradação da adesão fibra-matriz.

\subsection{Laminados de Tecido Comercial Chemfab ${ }^{\circledR} 013$}

\subsubsection{Avaliação por ensaio de flexão 3-pontos}

Inicialmente, para averiguar a possibilidade de sucesso em se produzir um laminado de PTFE e fibras de vidro contínuas a partir de um tecido impregnado comercial - material sinterizado -, foram construídos dois CDPs (Figura 18), um fabricado com o tecido impregnado Chemfab ${ }^{\circledR} 013$ STD e outro com PTFE puro 
granulado (pellets) Teflon ${ }^{\circledR}$ 6407. Esta etapa teve o intuito de verificar, por comparação, se há aumento considerável nas propriedades mecânicas do compósito estrutural frente ao material puro e, com isso, analisar a potencialidade do estudo proposto. Para isso, os dois CDPs foram sinterizados segundo o mesmo tratamento térmico, segundo os valores da Tabela (3).

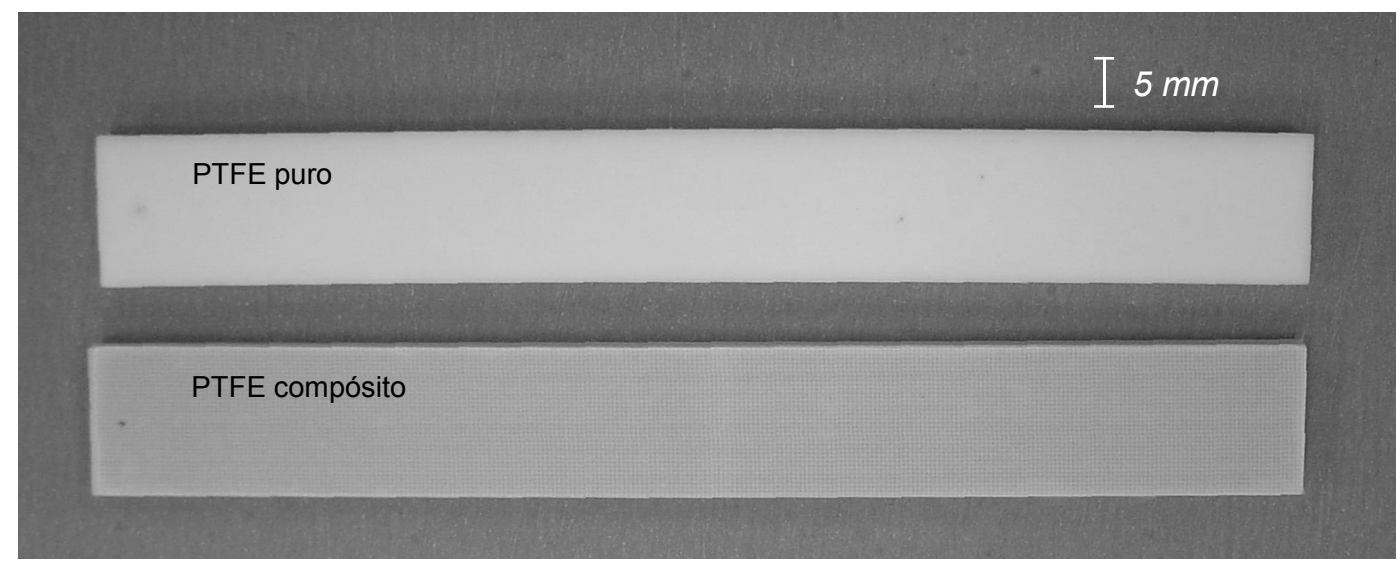

Figura 18: CDPs de PTFE puro (superior) e compósito de PTFE e fibras (inferior).

Tabela 3: Valores padrão dos parâmetros de fabricação para o desenvolvimento do trabalho ${ }^{1}$

\begin{tabular}{cccc}
\hline$\dot{T}_{H}\left[{ }^{0} \mathrm{C} / \mathrm{min}\right]$ & $T_{S}\left[{ }^{o} \mathrm{C}\right]$ & $t_{s}[\mathrm{~min}]$ & $\dot{T}_{\mathrm{C}}\left[{ }^{o} \mathrm{C} / \mathrm{min}\right]$ \\
\hline 2 & 365 & 100 & 0,6 \\
\hline
\end{tabular}

Os CDPs fabricados foram submetidos ao ensaio de flexão 3-pontos e os resultados são mostrados na Figura $(19$ a). A figura mostra os gráficos de tensão de flexão pela deformação nas superfícies inferiores $\left(\mathrm{em} L_{s} / 2\right)$ dos CDPs. Nos ensaios foram feitos carregamentos e descarregamentos iniciais com pequenos deslocamentos (domínio elástico) buscando separar respostas referentes às acomodações dos apoios e atuador da resposta do material. Os módulos de Young à flexão $\left(E^{f}\right)$ foram calculados tendo como base o segundo descarregamento de cada ensaio (Figura 19p) - este procedimento foi adotado também para a obtenção dos demais módulos de Young à flexão apresentados como resultados neste

\footnotetext{
${ }^{1}$ Dados fornecidos pela Tecnofluor Indústria e Comércio Ltda de Cotia-SP para a confecção de componentes de PTFE puro com dimensões aproximadas as dos corpos-de-prova deste trabalho.
} 
trabalho.
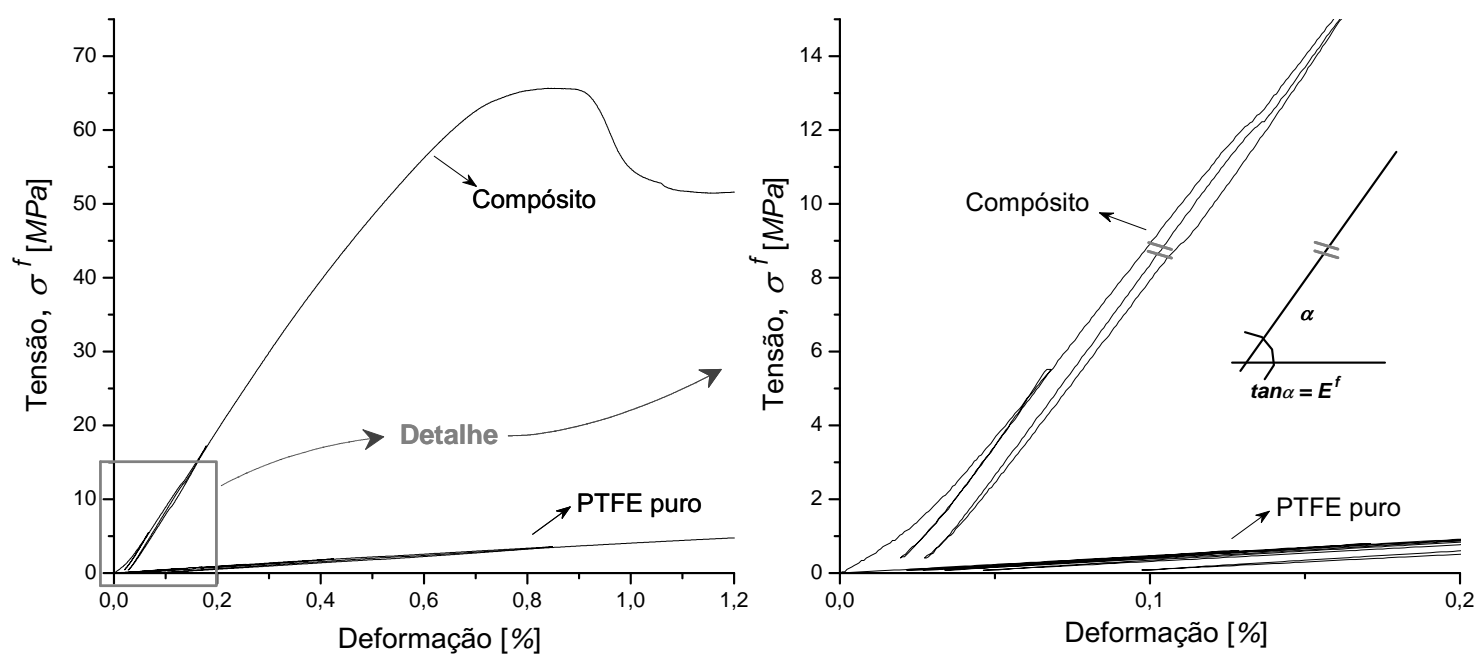

Figura 19: Comparação do ensaio de flexão 3-pontos dos CDPs de PTFE puro e compósito de PTFE e fibras: a) curvas de tensão pela deformação; b) detalhe para ilustrar o cálculo do módulo de Young à flexão.

O módulo de Young à flexão obtido para o compósito foi de aproximadamente $11 \mathrm{GPa}$, mais de 22 vezes maior que o módulo de Young à flexão do material puro $(\approx 0,5 \mathrm{MPa})$. A partir desta constatação, o trabalho foi direcionado ao estudo dos aspectos relativos à fabricação - prensagem e sinterização - relatados na sequência.

Para se investigar a influência do processo de fabricação no comportamento mecânico do material foram definidos como parâmetros de processo: $P_{c}, T_{s}, t_{S}$ e $\dot{T}_{C}$ (ver Figura 13 - página 49 ). Os valores dos parâmetros foram variados segundo o plano de ensaios da Figura (20). Neste plano, enquanto um parâmetro tem seus valores variados, os valores dos demais permanecem fixos. A sequência de execução é realizada como mostrada na Figura (20) (começando pela pressão, $\left.P_{C}\right)$.

Por falta de valores de referência adequados, os valores iniciais (Tabela 3 página 58) foram adotados por serem valores geralmente utilizados pela indústria para a fabricação de componentes de PTFE puro com dimensões próximas às 


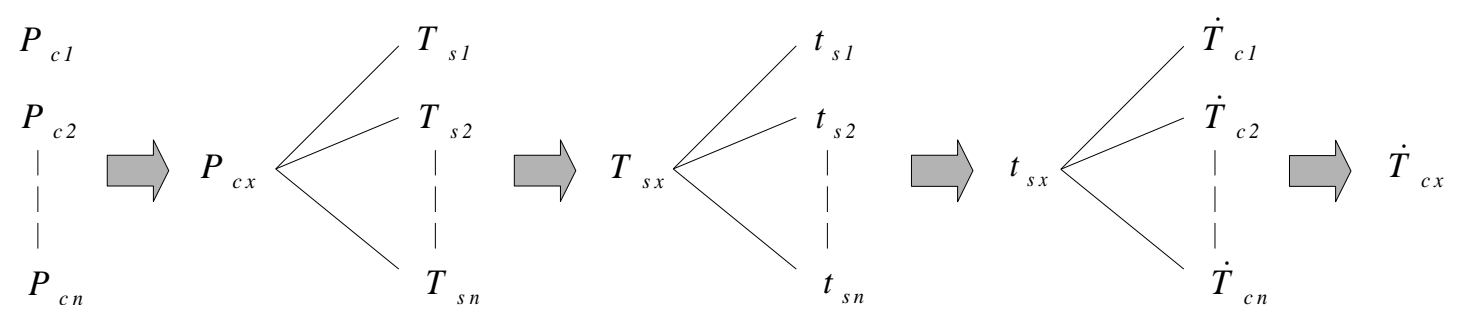

Figura 20: Plano de ensaios com variações dos parâmetros de prensagem e sinterização.

dos CDPs fabricados para este trabalho. Por esta razão, a cada variação de parâmetros é escolhido um novo valor (identificado pelo índice $x$ ), que corresponde à melhor performance no ensaio de flexão 3-pontos. A melhor performance é uma ponderação subjetiva que considera a tensão máxima à flexão, módulo de Young à flexão e custo operacional. Esta estratégia busca uma maneira rápida e eficaz de se obter valores mais aplicáveis à realidade de fabricação deste laminado. Para uma otimização do processo de fabricação do material seria preciso um cruzamento de todos os dados dos parâmetros de fabricação, o que acarretaria em uma quantidade muito grande de CDPs, sendo inviável dentro do presente trabalho.

Os CDPs para o ensaio de flexão 3-pontos foram fabricados como especificado na seção 3.2 (página 48 ), sendo que foram empilhadas 16 camadas de tecido com as fibras alinhadas a 0 e $90^{\circ}$ com o eixo longitudinal do CDP.

Para o estudo da influência da pressão de conformação foram fabricados CDPs com diferentes valores de $P_{c}$. Seguindo o plano de ensaios descrito anteriormente, os CDPs foram fabricados seguindo uma mesma curva de sinterização. Assim, a pressão de compactação foi a única variável a ser analisada nesta primeira sequência de ensaios. Os valores dos parâmetros de processo para estes ensaios são mostrados na Tabela (4).

As curvas de tensão pela deformação resultantes dos ensaios de flexão 3pontos e as tendências referentes às resistências máximas à flexão e aos módulos de Young à flexão em função da pressão de conformação são mostradas nos gráficos da Figura (21). As tendências revelam uma significativa melhora das 
Tabela 4: Parâmetros de fabricação - variação da pressão de conformação

\begin{tabular}{ccccc}
\hline$P_{c}[\mathrm{MPa}]$ & $\dot{\mathrm{T}}_{\mathrm{H}}\left[{ }^{\circ} \mathrm{C} / \mathrm{min}\right]$ & $T_{s}\left[{ }^{\circ} \mathrm{C}\right]$ & $t_{s}[\mathrm{~min}]$ & $\dot{T}_{\mathrm{C}}\left[{ }^{\circ} \mathrm{C} / \mathrm{min}\right]$ \\
\hline \hline 11 & & & & \\
22 & & & & \\
54 & 2 & 365 & 100 & 0,6 \\
98 & & & & \\
152 & & & & \\
\hline
\end{tabular}

propriedades mecânicas com o aumento da pressão de conformação. Para os CDPs submetidos às pressões de 11 e $22 \mathrm{MPa}$, os módulos de Young à flexão e resistências máximas à flexão ficaram bem abaixo dos valores encontrados para as demais pressões. Isso é atribuído a uma maior porosidade nestes laminados com relação aos fabricados com pressões maiores.
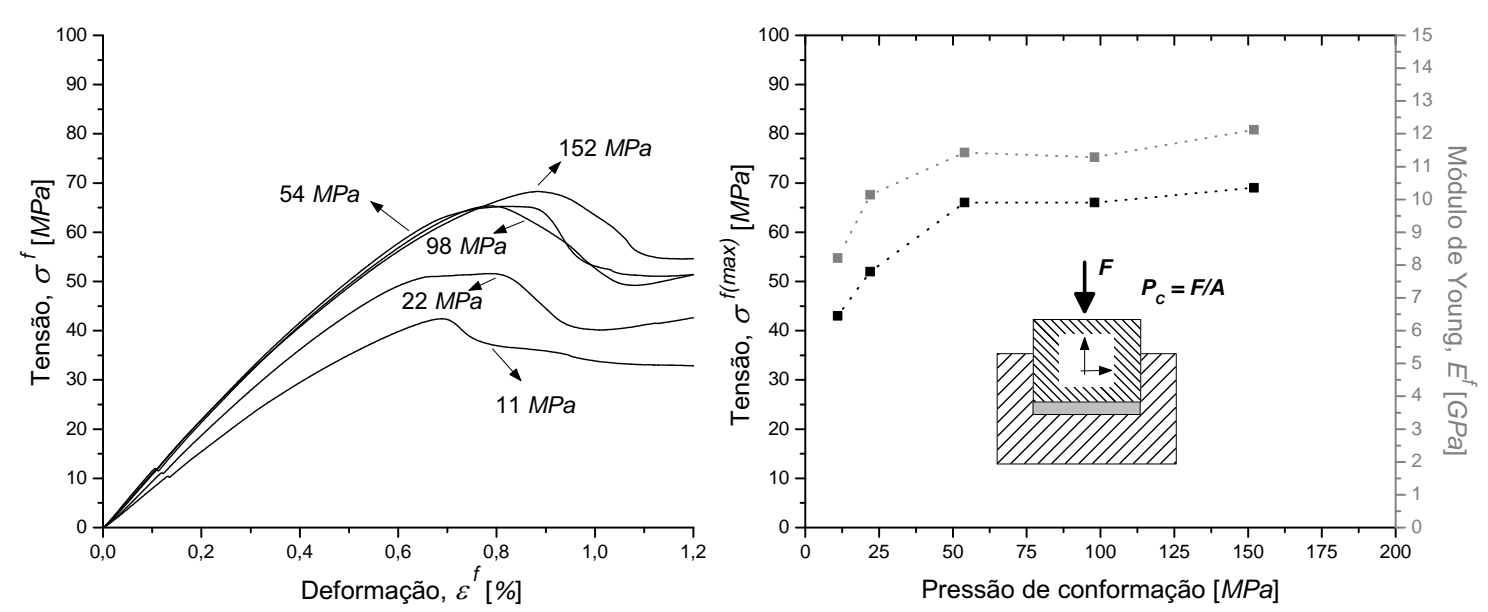

Figura 21: Análise da influência da pressão de compactação: Tensão pela deformação em ensaios de flexão 3-pontos (esquerda) e curvas de tendência da resistência máxima e módulo de Young à flexão em função da pressão de conformação.

Apesar de haver um aumento gradativo das propriedades mecânicas com o aumento da pressão aplicada, a partir da pressão de $54 \mathrm{MPa}$ ocorre uma relativa estabilização das propriedades mecânicas avaliadas. Como não há uma melhora evidente das propriedades mecânicas com relação às pressões acima de $54 \mathrm{MPa}$ (98 e $152 \mathrm{MPa}$ ), este valor foi escolhido - seguindo o plano de ensaios exposto 
na Figura (20) - como valor de pressão a permanecer fixo para o restante dos ensaios. Levou-se em conta o que foi chamado de custo operacional, uma vez que, pressões maiores são menos interessantes economicamente.

Os próximos parâmetros a serem avaliados são os referentes ao tratamento térmico. O único parâmetro entre estes a permanecer fixo é a taxa de aquecimento $\left(\dot{T}_{H}\right)$. Este parâmetro teria uma maior influência em corpos mais volumosos, devido à baixa condutividade térmica do PTFE (EBNESAJJAD, 2000).

A Tabela (5) mostra a variação dos valores da temperatura de sinterização e os valores dos parâmetros que permanecem fixos na fabricação dos CDPs usados no estudo deste parâmetro. Os gráficos da Figura (22) mostram uma tendência de aumento, tanto para o módulo de Young à flexão, quanto para a resistência máxima à flexão, com o aumento de $T_{S}$ até a temperatura de $380^{\circ} \mathrm{C}$. Os piores resultados são apresentados pela temperatura mais alta, de $395^{\circ} \mathrm{C}$. Esta temperatura fica próxima da temperatura de início de degradação do material (ver as TGAs da Figura 9- página 45), o que pode influenciar negativamente na adesão PTFE-PTFE e também na adesão interfacial fibra-matriz. O fato de as temperaturas mais baixas $\left(335^{\circ} \mathrm{C}\right.$ e $\left.350^{\circ} \mathrm{C}\right)$ também exibirem resultados inferiores, deve-se ao fato de estas temperaturas não serem suficientemente altas para permitir uma adesão satisfatória entre as camadas de PTFE.

Tabela 5: Parâmetros de fabricação - variação da temperatura de sinterização

\begin{tabular}{ccccc}
\hline$P_{C}[\mathrm{MPa}]$ & $\dot{\mathrm{T}}_{\mathrm{H}}\left[{ }^{\circ} \mathrm{C} / \mathrm{min}\right]$ & $T_{s}\left[{ }^{\circ} \mathrm{C}\right]$ & $t_{s}[\mathrm{~min}]$ & $\dot{\mathrm{T}}_{\mathrm{C}}\left[{ }^{0} \mathrm{C} / \mathrm{min}\right]$ \\
\hline \hline \multirow{5}{*}{54} & 335 & & \\
& & 350 & & \\
& 2 & 365 & 100 & 0,6 \\
& 380 & & \\
& & 395 & & \\
\hline
\end{tabular}

A temperatura em que se obteve o melhor resultado foi a de $380{ }^{\circ} \mathrm{C}$, com re- 

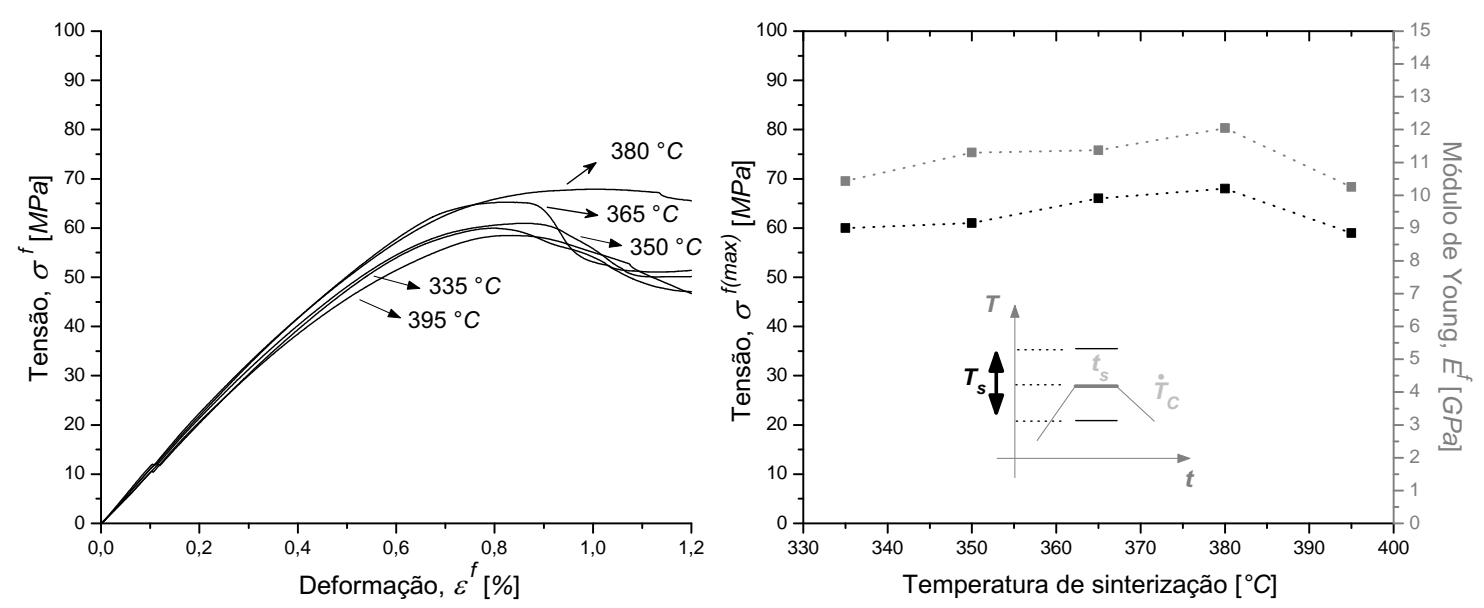

Figura 22: Análise da influência da temperatura de sinterização: Tensão pela deformação em ensaios de flexão 3-pontos (esquerda) e curvas de tendência da resistência máxima e módulo de Young à flexão em função da temperatura de sinterização.

sultados muito próximos ao CDP sinterizado no patamar de $365{ }^{\circ} \mathrm{C}$, cujo valor é usado como referência industrial para a fabricação de alguns dos CDPs deste trabalho. No entanto, para a continuação do plano de ensaios, o valor escolhido para a temperatura de sinterização é o de $380{ }^{\circ} \mathrm{C}$, para o qual se obteve os melhores valores associados de módulo de Young à flexão e resistência máxima à flexão.

Os valores adotados para a variação do tempo de permanência no patamar de sinterização são expostos na Tabela (6). Os gráficos da Figura (23) mostram que o melhor resultado em termos de módulo de Young à flexão e resistência máxima à flexão são para um $t_{s}$ de 5 min, havendo uma tendência de diminuição das propriedades mecânicas com o aumento do tempo de permanência no patamar de sinterização.

É conhecido que a interdifusão das cadeias poliméricas responsáveis pela adesão PTFE-PTFE é proporcional ao tempo de sinterização. Segundo Jahier (1992), o tempo ideal de sinterização para este CDP - com espessura menor que $3 \mathrm{~mm}$ - seria de aproximadamente $60 \mathrm{~min}$ caso fosse composto somente por PTFE. No entanto, ao se tratar do compósito com presença de uma considerável quan- 
Tabela 6: Parâmetros de fabricação - variação do tempo de sinterização

\begin{tabular}{|c|c|c|c|c|}
\hline$P_{C}[M P a]$ & $\dot{T}_{H}\left[{ }^{\circ} \mathrm{C} / \min \right]$ & $T_{S}\left[{ }^{\circ} \mathrm{C}\right]$ & $t_{s}[\mathrm{~min}]$ & $\dot{\mathrm{T}}_{\mathrm{C}}\left[{ }^{\circ} \mathrm{C} / \mathrm{min}\right]$ \\
\hline \multirow{5}{*}{54} & \multirow{5}{*}{2} & \multirow{5}{*}{380} & 5 & \multirow{5}{*}{0,6} \\
\hline & & & 25 & \\
\hline & & & 100 & \\
\hline & & & 400 & \\
\hline & & & 1000 & \\
\hline
\end{tabular}
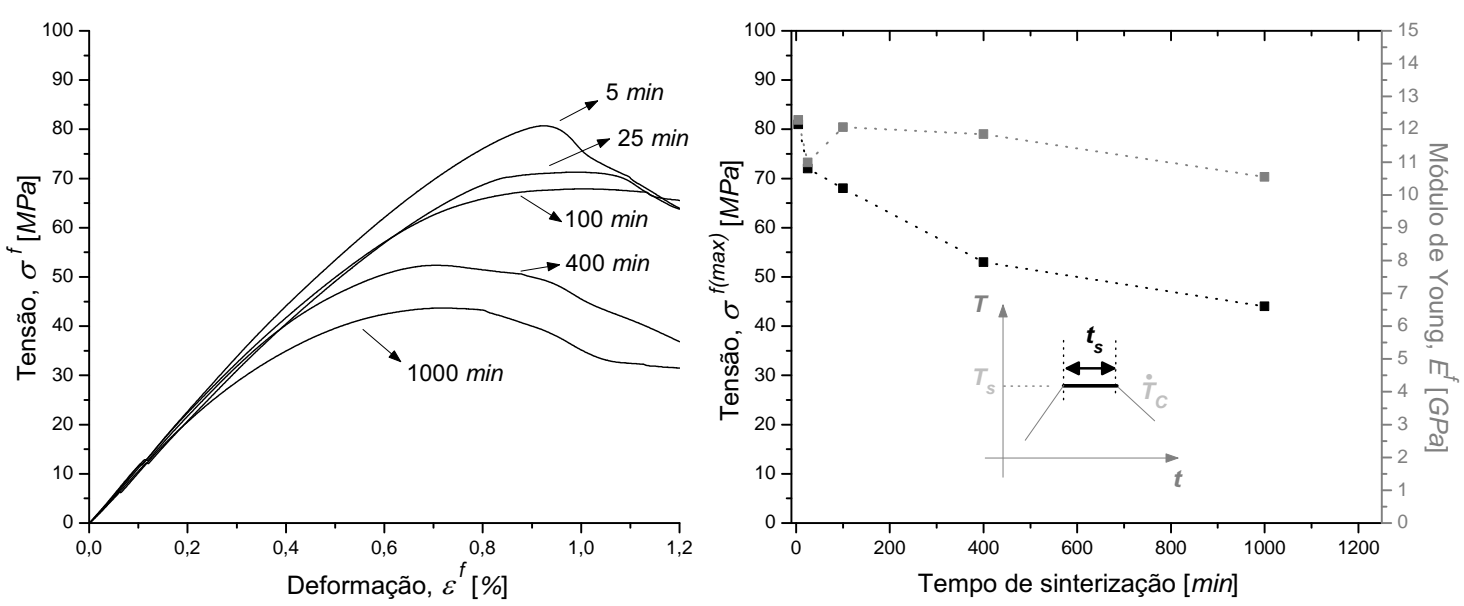

Figura 23: Análise da influência do tempo de sinterização: Tensão pela deformação em ensaios de flexão 3-pontos (esquerda) e curvas de tendência da resistência máxima e módulo de Young à flexão em função do tempo de sinterização.

tidade de fibras de vidro ( $\approx 38 \%$ em massa), um tempo de sinterização relativamente curto mostrou-se suficiente e, ainda, os resultados indicam piores desempenhos para tempos de sinterização maiores. Tal fato sugere a presença de um mecanismo de degradação da interface PTFE-fibra com o aumento do tempo de sinterização.

Na etapa inicial do ensaio, o CDP com $t_{s}$ de 25 min apresentou um desempenho abaixo do esperado, fato explicado por uma acomodação inicial do CDP, devido a este apresentar um empenamento (provavelmente induzido pelo processo de sinterização), já que a inclinação posterior da curva e a resistência máxima seguiram uma tendência coerente com os outros CDPs estudados. 
A velocidade de resfriamento durante o processo de sinterização influencia de forma determinante no grau de cristalinidade do PTFE e tem uma grande influência em seu comportamento mecânico. A Tabela (7) mostra as taxas que foram utilizadas para o resfriamento do material; os gráficos da Figura (24) mostram as curvas dos ensaios de flexão 3-pontos e suas tendências, referentes aos CDPs resfriados com estas taxas. Os resultados indicam que, quanto maior a velocidade de resfriamento adotada no ensaio, melhores são os valores de módulo de Young à flexão e resistência máxima à flexão. A maior taxa de resfriamento usada foi de $0,6{ }^{\circ} \mathrm{C} / \mathrm{min}$, próxima a taxa limite de resfriamento do forno (com tampa fechada) e para a qual se obteve os melhores resultados.

Tabela 7: Parâmetros de fabricação - variação da taxa de resfriamento

\begin{tabular}{ccccc}
\hline$P_{C}[\mathrm{MPa}]$ & $\dot{\mathrm{T}}_{H}\left[{ }^{\circ} \mathrm{C} / \mathrm{min}\right]$ & $T_{s}\left[{ }^{0} \mathrm{C}\right]$ & $t_{s}[\mathrm{~min}]$ & $\dot{T}_{\mathrm{C}}\left[{ }^{\circ} \mathrm{C} / \mathrm{min}\right]$ \\
\hline \hline & & & & 0,05 \\
54 & 2 & 380 & 5 & 0,2 \\
& & & & 0,6 \\
\hline
\end{tabular}
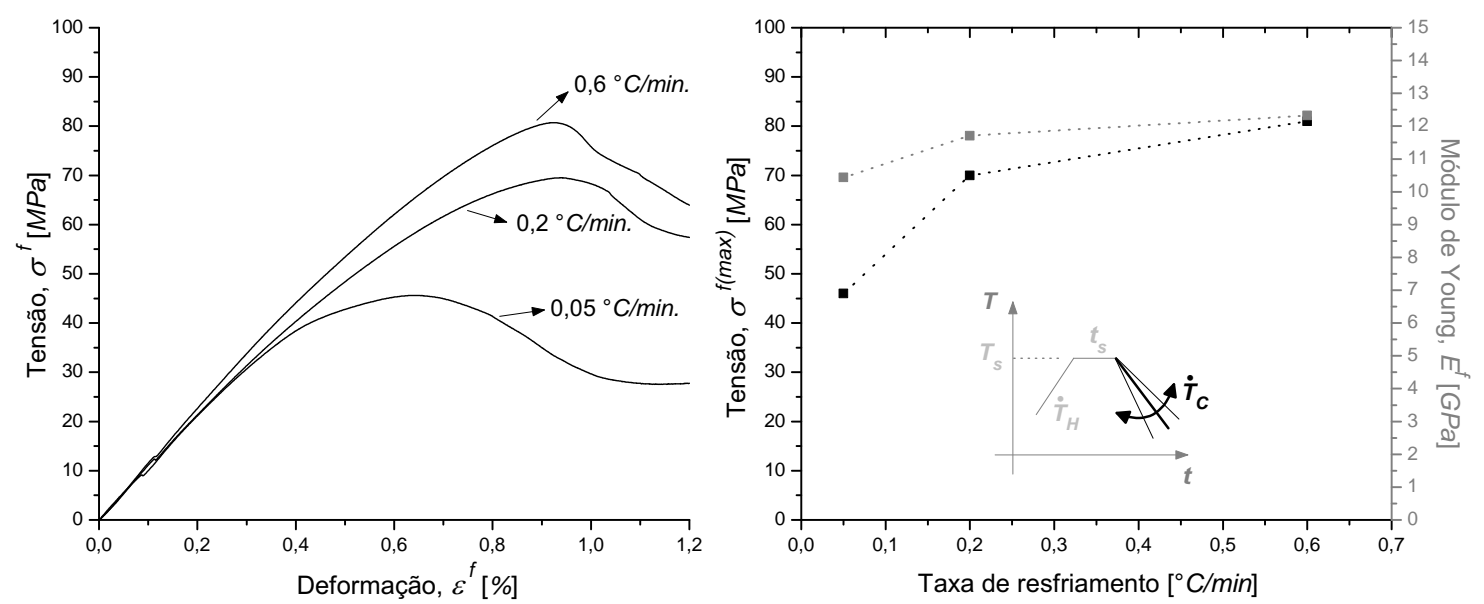

Figura 24: Análise da influência da taxa de resfriamento: Tensão pela deformação em ensaios de flexão 3-pontos (esquerda) e curvas de tendência da resistência máxima e módulo de Young à flexão em função da taxa de resfriamento.

O grau de cristalinidade do PTFE sinterizado diminui com o aumento da taxa de resfriamento durante a sinterização e o módulo de Young à flexão aumenta 
com o acréscimo no grau de cristalinidade - em um fator de 5 quando a cristalinidade passa de 50 para 90\%, com 0,2\% de vazios (GANGAL, 2001). Como visto na seção 2.1.1 (página 26), a transmissão do carregamento da matriz para fibra é melhor efetuado quanto menor o módulo de elasticidade da matriz (MAZUMDAR, 2002). Os resultados encontrados neste trabalho estão de acordo com estas informações, já que as propriedades mecânicas diminuem com o decréscimo na taxa de resfriamento, ou seja, diminuem com o aumento do grau de cristalinidade do PTFE. Outro fator que influencia neste resultado é, como mencionado anteriormente, uma degradação da interface fibra-matriz, já que quanto menor a taxa de resfriamento maior o tempo que o compósito permanecerá a altas temperaturas.

Um dos fatores que podem interferir de forma negativa na adesão entre fibra e matriz no compósito estudado é a degradação de aditivos que recobrem as fibras de vidro, adicionados durante seu processo de fabricação. Como visto na seção 2.1.2.2 (página 31), produtos que recobrem as fibras (sizing agent) são adicionados com propósitos que vão desde facilitar a confecção de tecidos (diminuindo o atrito entre as fibras), até melhorar a adesão entre fibra e matriz, como, por exemplo, os silanos (LAURA et al., 2002; PLUEDDEMANN, 1991) - usados amplamente e terras raras, muito usadas em compósitos de PTFE e fibras curtas (CHENG et al. 2002; XUE; CHENG, 2002; QIAN-QIAN; XIAN-HUA, 2006). Diferentemente dos silanos e terras raras, compostos orgânicos podem ser pirolizados durante a sinterização (OSHIMA et al., 2001a; OSHIMA et al., 2001c; EBNESAJJAD, 2000).

Oshima et al. (2001c) indicam a possibilidade de ocorrência de vazios entre a fibra e a matriz de PTFE devido à degradação dos aditivos que recobrem a fibra quando laminados de PTFE e fibras de carbono são expostos a altas temperaturas, o que causaria vazios (Figura 25) na interface fibra-matriz e, como consequência, interfeririam negativamente nas propriedades mecânicas finais destes compósitos. Este fato leva a crer que este fenômeno ocorra nos laminados fabricados a partir do tecido Chemfab ${ }^{\circledR} 013$ STD apresentados neste trabalho. 

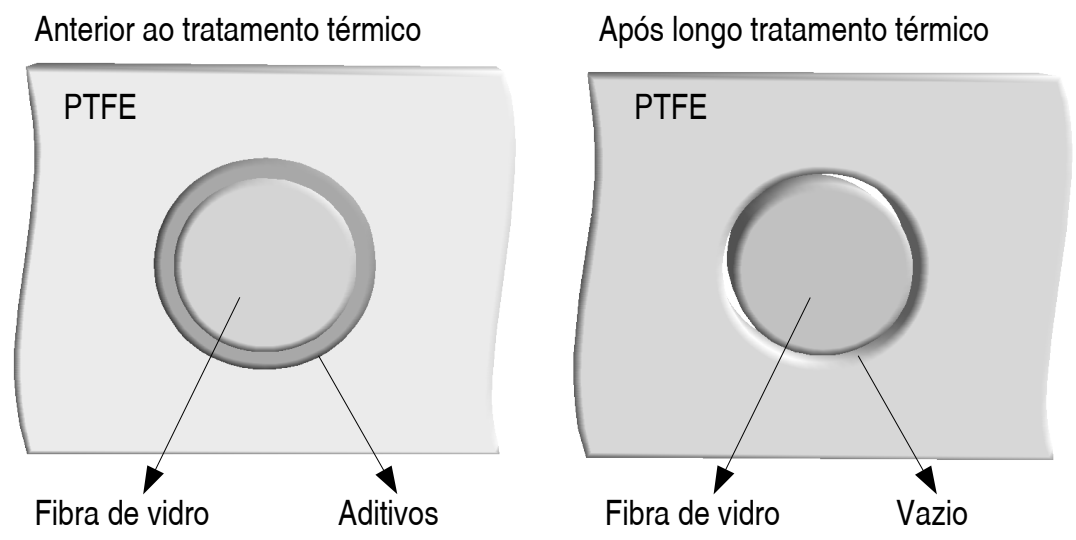

Figura 25: Ilustração: eliminação de aditivos da fibra de vidro e consequente formação de vazio entre fibra e matriz, durante tratamentos térmicos longos a altas temperaturas.

Para entender melhor o processo de degradação de aditivos, foi realizada uma TGA (Figura 26) na fibra de vidro utilizada na fabricação dos tecidos comerciais Chemfab ${ }^{\circledR} 013$ STD. Esta TGA, assim como as do capítulo 2, foi realizada em um equipamento TGA Q500 da TA instruments, também a uma taxa de aquecimento de $10{ }^{\circ} \mathrm{C} / \mathrm{min}$, porém, em atmosfera de ar sintético $\left(20 \% \mathrm{O}_{2}+80 \% \mathrm{~N}_{2}\right)$. A TGA mostra uma curva de degradação - de forma mais acentuada entre 160 e $490{ }^{\circ} \mathrm{C}$ em um tempo de aproximadamente $30 \mathrm{~min}$ - de aproximadamente $2 \%$ da massa inicial; esta massa é atribuida a composto(s) orgânico(s) que recobre(m) as fibras. Como dito anteriormente (seção 3.1.1 - página 44), o tecido Chemfab ${ }^{\circledR} 013$ STD passa algumas vezes (a cada impregnação) pelo processo de sinterização. No entanto, em cada camada, a aplicação dos tratamentos térmicos são rápidos, não sendo suficientes para degradar por completo os aditivos que recobrem as fibras de vidro. Um indicativo disto é a mudança de coloração do tecido.

Os tecidos comerciais Chemfab ${ }^{\circledR}$ apresentam uma coloração bronze, que é adquirida durante sua fabricação, por conta do tratamento térmico. Quando exposto novamente a altas temperaturas por um longo tempo, o tecido impregnado sofre um clareamento, chegando a ficar totalmente branco (cor natural do PTFE apresentada após a degradação total dos compostos orgânicos) dependendo do 


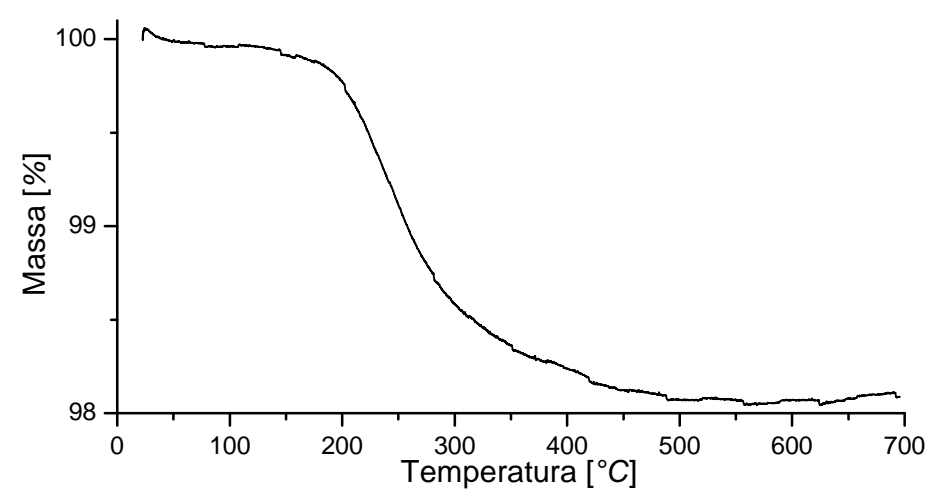

Figura 26: Análise de TGA feita em fibra de vidro usada na fabricação do tecido Chemfab ${ }^{\circledR} 013$ STD.

tempo e temperatura empregados (Figura 27). Ebnesajjad (2000) reporta este clareamento como um problema da fibra de vidro pela queima dos aditivos orgânicos e indica um tratamento térmico na fibra, anterior à impregnação por PTFE (24 horas a uma temperatura de $260{ }^{\circ} \mathrm{C}$ ), o que evitaria a formação de vazios na interface fibra-matriz. Outros autores também relatam a possibilidade de retirada dos aditivos das fibras por processo de queima (FRIEDRICH et al., 2002).

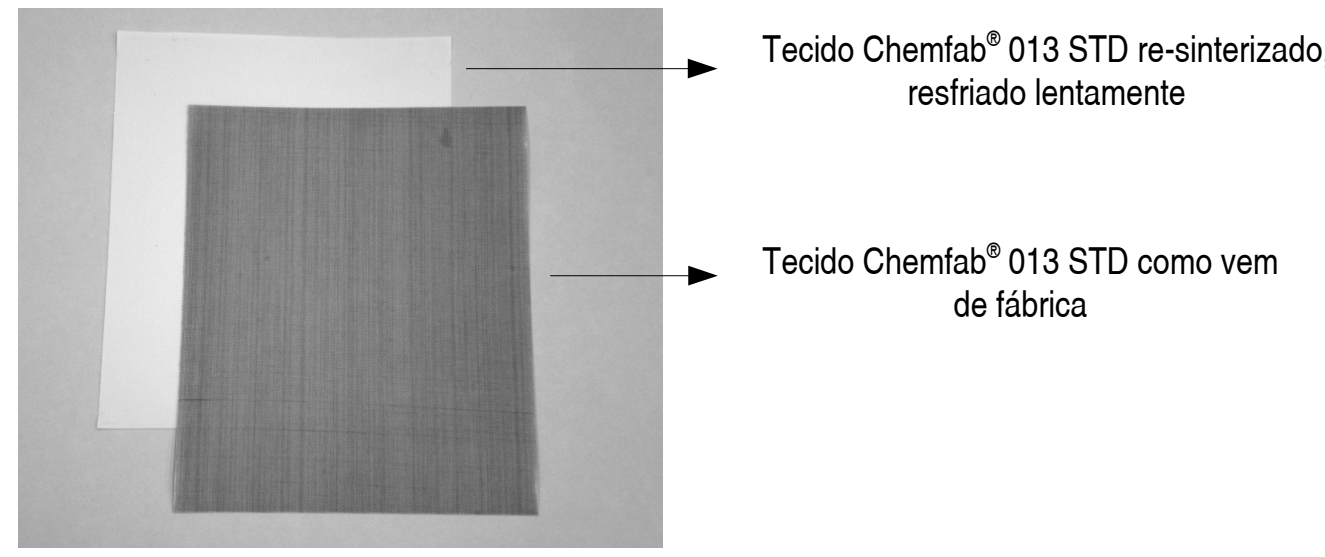

Figura 27: Diferença de tonalidade entre o tecido Chemfab ${ }^{\circledR} 013$ STD tratado termicamente em laboratório e o mesmo tecido como vem de fábrica.

Além da degradação pela taxa de resfriamento, para os CDPs em que se variaram os outros parâmetros de sinterização, $T_{s}$ e $t_{s}$, a queima dos aditivos podem também ter influenciado nos resultados, tanto no caso das temperaturas muito altas $\left(395{ }^{\circ} \mathrm{C}\right)$, em que a queima dos aditivos seria acelerada, como nos casos em 
que os CDPs ficam expostos a tempos muito longos, permitindo assim a queima gradual dos aditivos.

O plano de ensaios proposto no capítulo anterior (Figura 20 - página 60) pode ser agora visualizado com os valores adotados nos ensaios (Figura 28) de acordo com as variações de valores de parâmetros propostas nesta seção. São destacados na figura os melhores valores encontrados para cada parâmetro e que levam a uma melhoria estrutural do compósito. O módulo de Young à flexão para o CDP confeccionado segundo os valores escolhidos dos parâmetros de fabricação foi de 13, $6 \mathrm{GPa}$ - aproximadamente 28 vezes maior que o material puro - e a resistência máxima à flexão foi de $81 \mathrm{MPa}$.
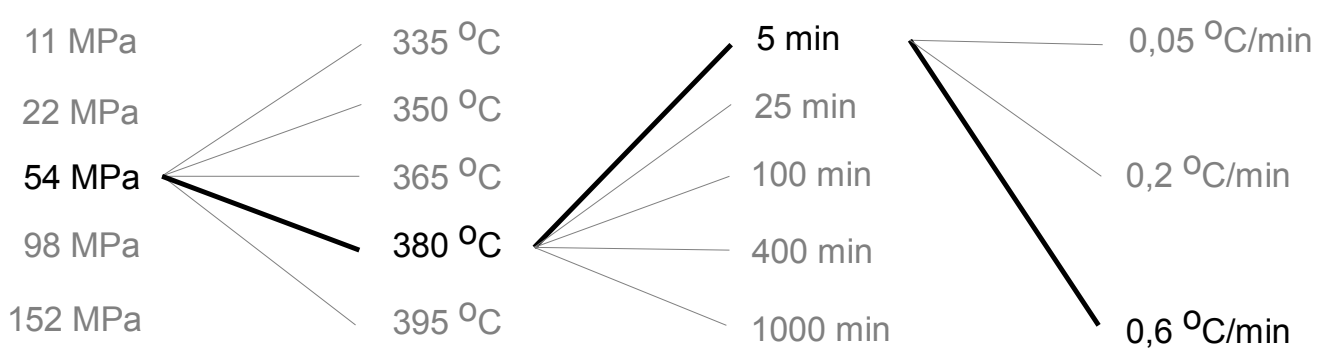

Figura 28: Plano de ensaios efetuado, destacando-se os parâmetros de processo que resultaram no melhor desempenho estrutural dentre os valores testados.

\subsubsection{Avaliação por ensaio de adesão fibra-matriz}

A foto da Figura (29) mostra um ensaio de flexão 3-pontos sendo realizado. Por esta foto é possível verificar o início de um descolamento das lâminas, ocasionado pela compressão longitudinal das lâminas superiores do CDP. Este descolamento caracteriza o momento em que os valores de tensão começam a diminuir. Tal fenômeno acontece em todos os CDPs laminados submetidos a este tipo de ensaio.

Levando-se em consideração a falha por compressão e o consequente descolamento das lâminas, juntamente com o exposto na seção anterior sobre adesão interfacial, decidiu-se realizar um estudo sobre a influência do processo de fabri- 

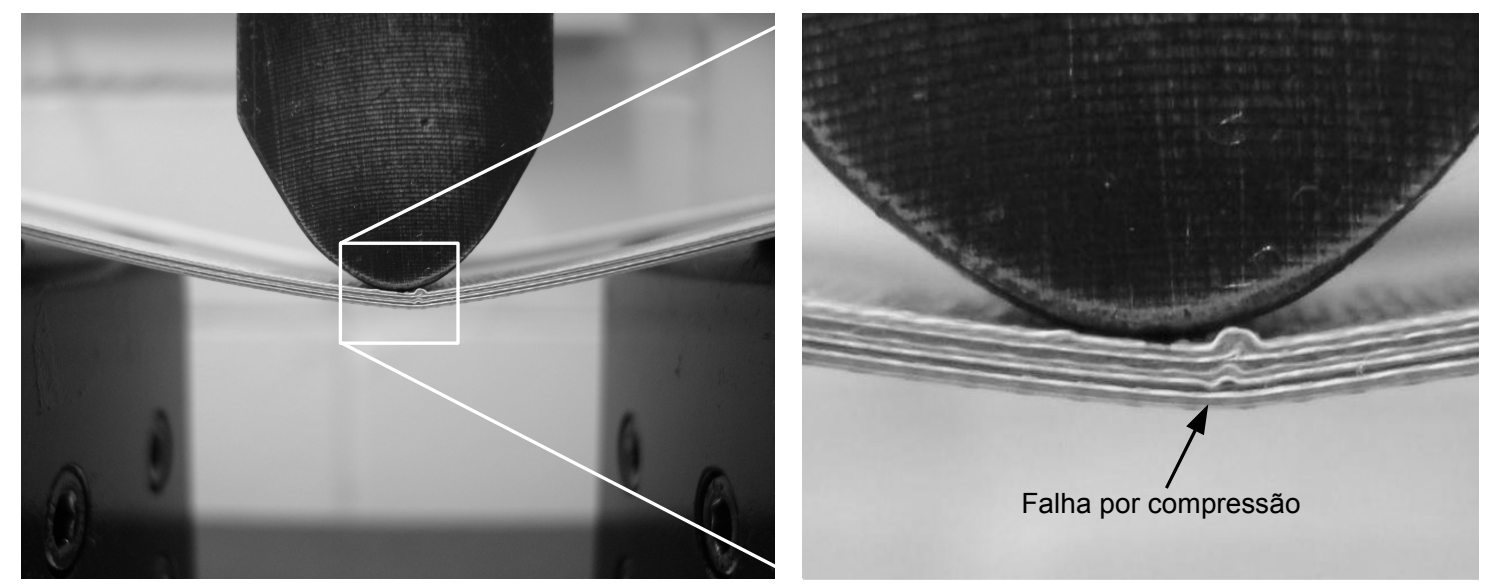

Figura 29: Falha por descolamento das lâminas durante ensaio de flexão 3-pontos dos laminados.

cação na adesão fibra-matriz.

Para averiguar isoladamente a influência da interação fibra-matriz nas propriedades mecânicas do laminado foram realizados ensaios de adesão e os resultados são expressos em um gráfico de força por deslocamento (descolamento da última lâmina) mostrados na Figura (30a). Os ensaios foram realizados em CDPs obtidos segundo os mesmos valores de parâmetros usados na fabricação dos CDPs para os ensaios de flexão 3-pontos, para os quais se obteve os piores e melhores desempenhos para as variações individuais de $T_{s}, t_{s}$, e $\dot{T}_{C}$. Os ensaios de flexão 3-pontos para estes valores de parâmetros estão reagrupados na Figura (30). Os resultados do ensaio de adesão estão especificados na Tabela (8), juntamente com os parâmetros de fabricação e resultados dos ensaios de flexão 3-pontos.

Pelos resultados, é reforçada a hipótese levantada para os ensaios de flexão 3-pontos, de que o tempo de permanência em temperaturas elevadas é o fator que mais contribui na degradação da interface fibra-matriz. Mesmo para o Caso 2 (ver Figura 30 e Tabela 8 , que tem a temperatura de sinterização mais baixa $\left(T_{S}\right.$ de $335^{\circ} \mathrm{C}$ ), em que $t_{s}$ é de $100 \mathrm{~min}$, a força necessária para o descolamento do tecido foi mais baixa que a exercida para o Caso 1, cuja temperatura de sinterização é 
maior $\left(T_{s}\right.$ de $\left.380^{\circ} \mathrm{C}\right)$, porém com um tempo de sinterização $t_{s}$ bem menor, 5 min. Para os demais casos, o tempo de permanência em altas temperaturas também é elevado, resultando num desempenho ainda pior para o ensaio de adesão. Isso reforça a hipótese de que tempos e temperaturas elevadas estejam influenciando na resistência da interface fibra-matriz.
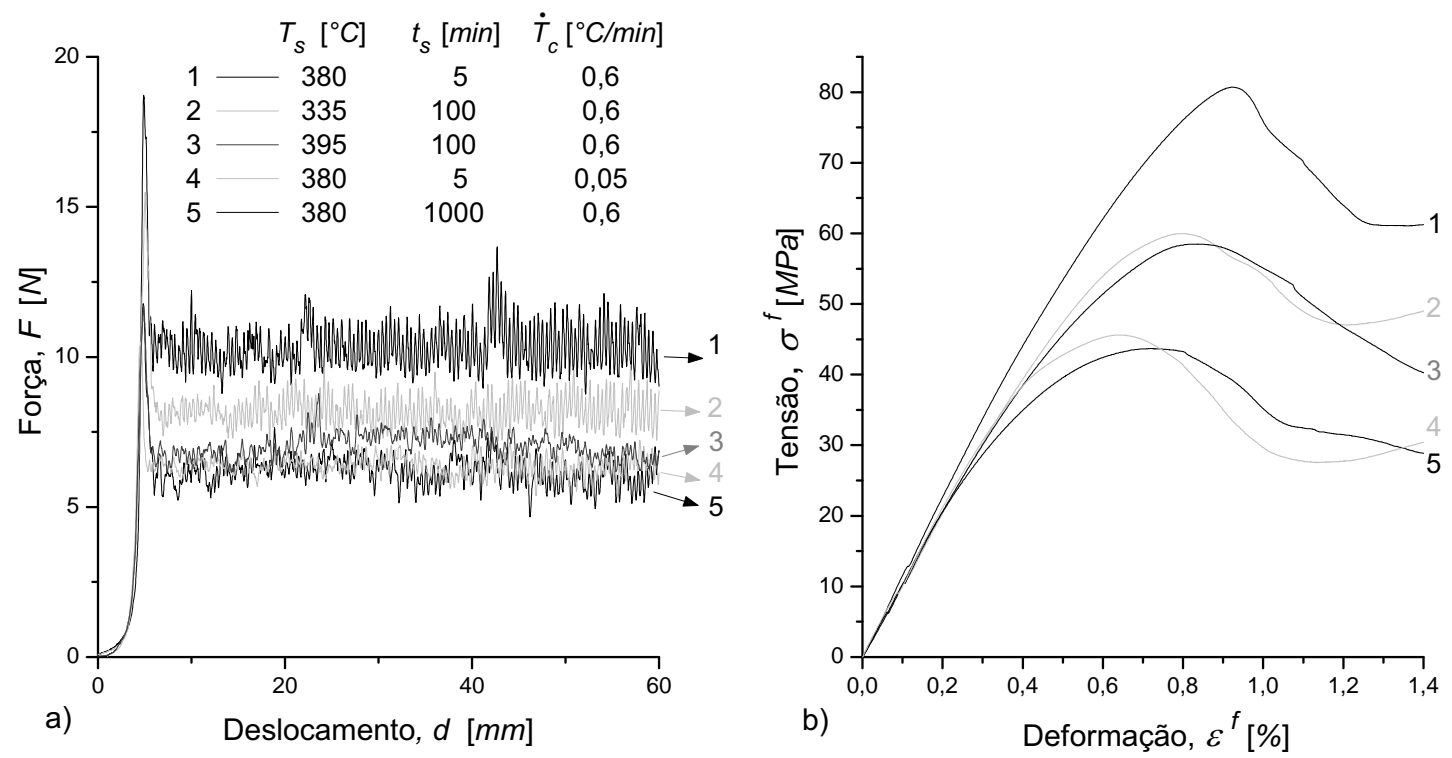

Figura 30: a) Curvas de força pelo deslocamento em ensaios de adesão; b) Curvas de tensão pela deformação em ensaios de flexão 3-pontos para os mesmos parâmetros usados no ensaio de adesão.

Tabela 8: Parâmetros de fabricação e valores de ensaios de flexão 3-pontos e adesão, para os melhores e piores valores para cada parâmetro de sinterização

\begin{tabular}{|c|c|c|c|c|c|c|c|}
\hline & \multicolumn{4}{|c|}{ Fabricação } & \multicolumn{2}{|c|}{ Flexão 3-pontos } & Adesão \\
\hline Caso & $P_{c}[M P a]$ & $T_{s}\left[{ }^{o} \mathrm{C}\right]$ & $t_{s}[\mathrm{~min}]$ & $\dot{T}_{C}\left[{ }^{o} \mathrm{C} / \mathrm{min}\right]$ & $E^{f}[G P a]$ & $\sigma^{f(\max )}[\mathrm{MPa}]$ & $\bar{F}[N]$ \\
\hline 1 & 54 & 380 & 5 & 0,6 & 12,3 & 81 & 10,3 \\
\hline 2 & 54 & 335 & 100 & 0,6 & 10,4 & 60 & 8,1 \\
\hline 3 & 54 & 395 & 100 & 0,6 & 10,2 & 59 & 6,7 \\
\hline 4 & 54 & 380 & 100 & 0,05 & 10,4 & 46 & 6,4 \\
\hline 5 & 54 & 380 & 1000 & 0,6 & 10,5 & 44 & 6,0 \\
\hline
\end{tabular}

A comparação entre os ensaios mostra uma correspondência entre os resultados dos ensaios de flexão 3-pontos e de adesão, indicando que a adesão fibra- 
matriz é a principal responsável na falha do material.

\subsubsection{Investigação do tempo e temperatura do tratamento tér- mico}

Com o intuito de investigar mais profundamente a influência do tempo e temperatura do tratamento térmico nas propriedades mecânicas dos laminados, elaborou-se uma estratégia de investigação que nos permite averiguar estes parâmetros isoladamente. A estratégia é baseada na interrupção temporária da curva de aquecimento durante a sinterização (Figura 31). Nesta interrupção, a temperatura $\left(T^{*} \leq T_{S}\right)$ é mantida constante por um longo tempo, seguindo, após isso, a curva normal de sinterização, ou seja, o material volta a ser aquecido à mesma taxa de aquecimento de antes da interrupção seguida do patamar sob a temperatura $\left(T_{S}\right)$ de sinterização e resfriamento. Esta estratégia visa encontrar uma temperatura crítica para a qual a degradação da interface fibra-matriz se torna mais acentuada.

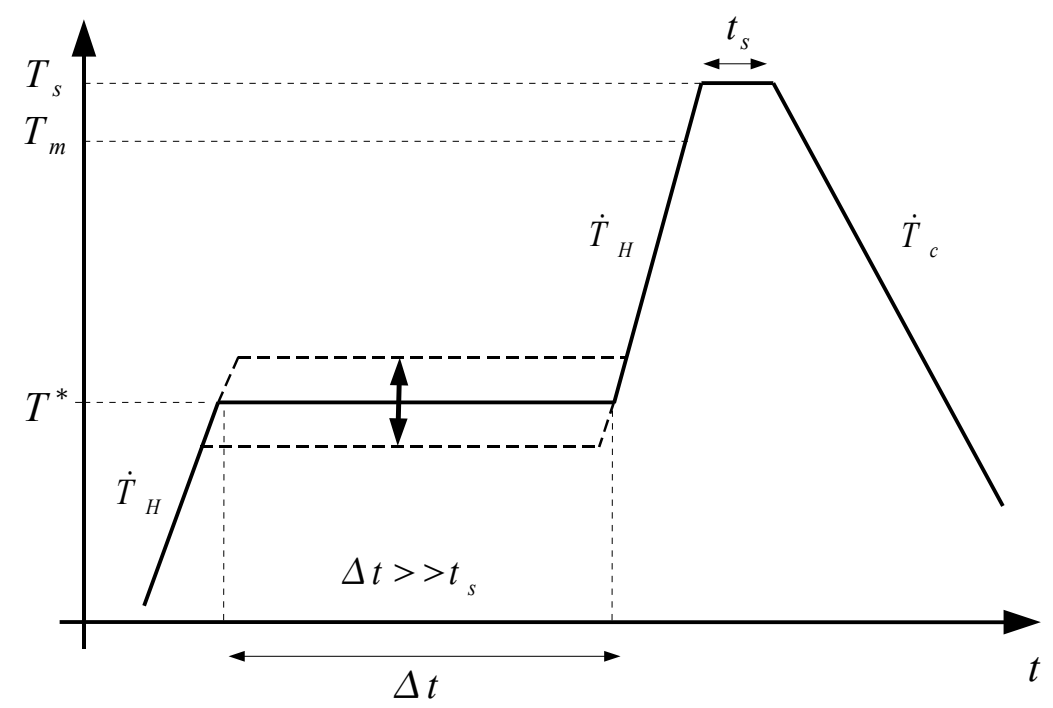

Figura 31: Estratégia para o estudo da influência do tempo e temperatura nas propriedades mecânicas dos laminados.

Para o desenvolvimento desta etapa foram fabricados sete CDPs cujos valores dos parâmetros de fabricação são expostos na Tabela (9). Todos os CDPs seguem a mesma curva de sinterização, entretanto, cada um permanece um tempo de 
$\Delta t=1000 \min$ em diferentes temperaturas, $T^{*}$.

Tabela 9: Parâmetros de fabricação e valores de ensaios de flexão 3-pontos para o estudo da influência do tempo e temperatura

\begin{tabular}{c||ccccccc}
\hline \multicolumn{1}{c||}{} & \multicolumn{7}{c}{ Parâmetros do processo de fabricação } \\
\hline \hline Caso & $P_{\mathrm{C}}[\mathrm{MPa}]$ & $\dot{\mathrm{T}}_{H}\left[{ }^{\circ} \mathrm{C} / \mathrm{min}\right]$ & $T_{s}\left[{ }^{\circ} \mathrm{C}\right]$ & $t_{s}[\mathrm{~min}]$ & $\dot{T}_{\mathrm{C}}\left[{ }^{\circ} \mathrm{C} / \mathrm{min}\right]$ & $\Delta t[\mathrm{~min}]$ & $T^{*}\left[{ }^{\circ} \mathrm{C}\right]$ \\
\hline 1 & 54 & 2 & 380 & 5 & 0,6 & 1000 & 25 \\
2 & 54 & 2 & 380 & 5 & 0,6 & 1000 & 50 \\
3 & 54 & 2 & 380 & 5 & 0,6 & 1000 & 150 \\
4 & 54 & 2 & 380 & 5 & 0,6 & 1000 & 310 \\
5 & 54 & 2 & 380 & 5 & 0,6 & 1000 & 335 \\
6 & 54 & 2 & 380 & 5 & 0,6 & 1000 & 365 \\
7 & 54 & 2 & 380 & 5 & 0,6 & 1000 & 380 \\
\hline
\end{tabular}

A Figura (32a) mostra as curvas de tensão pela deformação resultantes do ensaio de flexão 3-pontos dos CDPs da Tabela (9). A Figura (32p) indica as tensões à flexão máximas em função de $T^{*}$ e mostra uma queda acentuada destas tensões máximas para os CDPs que permaneceram em patamares com temperatura $T^{*}>335{ }^{\circ} \mathrm{C}$. A partir dos resultados foi adotado como temperatura crítica, $T_{\text {crit }}$ a temperatura de $350{ }^{\circ} \mathrm{C}$ (valor entre 335 e $365^{\circ} \mathrm{C}$ ). A partir desta temperatura, tem-se a possibilidade de verificar a influência do tempo de permanência acima da temperatura crítica na resistência máxima do material, como indicado pela Figura (33).

A Figura (34) mostra uma curva de interpolação dos pontos referentes a resistência máxima à flexão em função do tempo em que o material permaneceu acima da temperatura crítica durante o processo de fabricação. A figura mostra uma tendência de perda da resistência máxima em relação ao tempo de permanência acima da temperatura crítica. O processo que pode levar a essa degradação foi discutido nas seções anteriores (seção 4.1.1 - a partir da página 66). Apesar desta função não ter um bom ajuste para tempos curtos, ela é representativa da perda de resistência. 


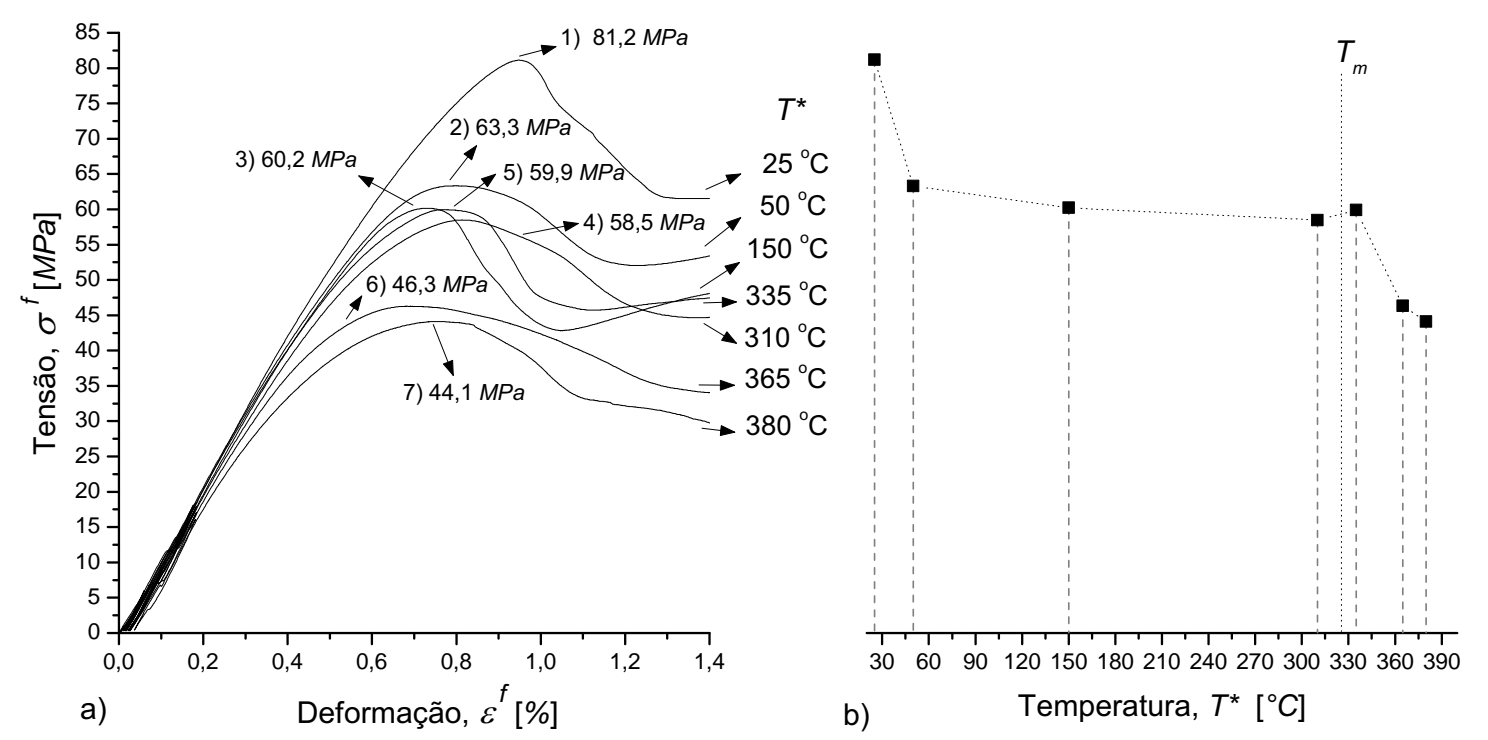

Figura 32: Resultados obtidos por ensaios de flexão 3-pontos para o estudo da influência do tempo e temperatura: a) Curva de tensão pela deformação em ensaios de flexão 3-pontos em CDPs obtidos a partir de diferentes patamares sob a temperatura $T^{*} ; b$ ) Tensões máximas das curvas de tensão pela temperatura $T^{*}$.

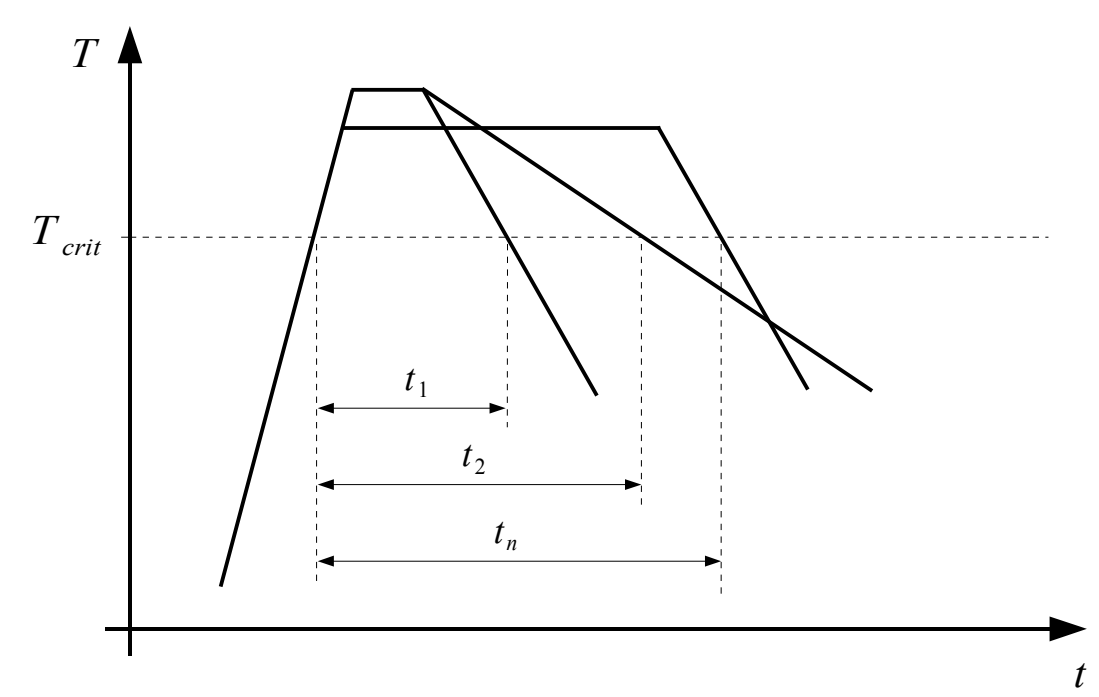

Figura 33: Verificação do tempo de permanência de cada CDP acima da temperatura crítica, $T_{\text {crit }}$, para diferentes curvas de tratamento térmico.

\subsubsection{Estudo sobre revestimento adicional de PTFE}

Com o objetivo de se estudar a viabilidade da fabricação de compósitos com camadas superficiais mais espessas de PTFE, nesta etapa do trabalho, foram fabricados compósitos pela deposição de camadas de PTFE granulado (Teflon ${ }^{\circledR}$ 6407) 


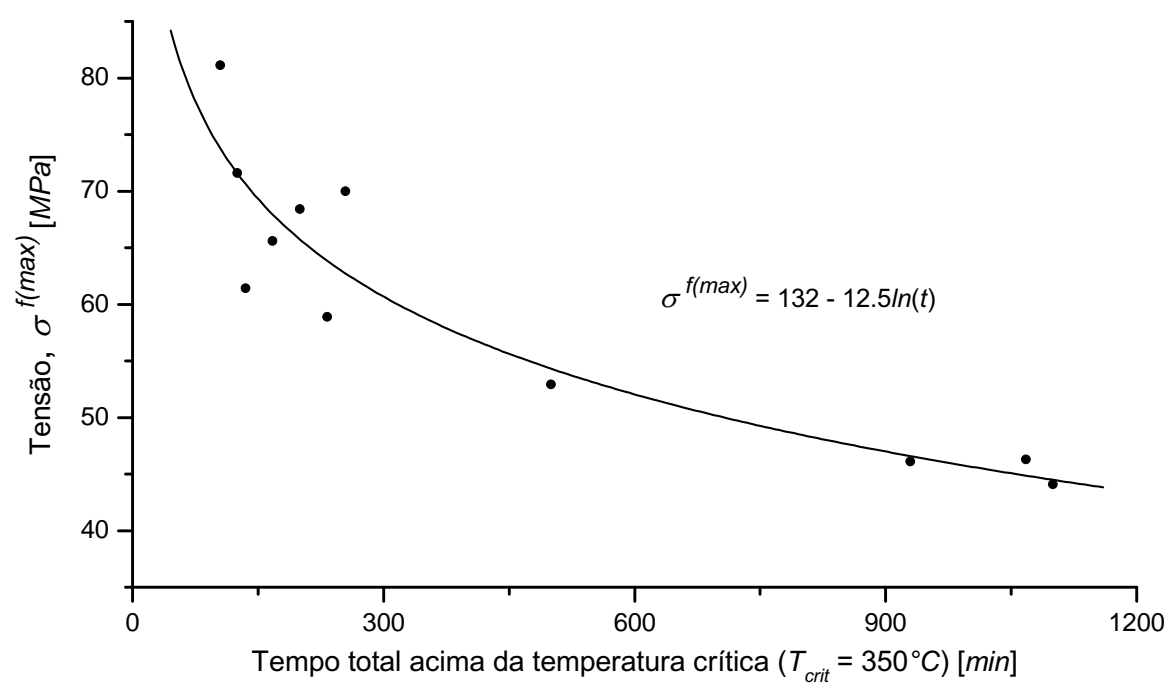

Figura 34: Curva de tendência da resistência máxima pelo tempo de permanência acima da temperatura crítica.

intercaladas com lâminas dos tecidos impregnados (Chemfab ${ }^{\circledR}$ 013). É levada em conta a necessidade de se construir um compósito com um revestimento externo contínuo de PTFE, como exemplificado na Figura (35), para que características como a resistência à corrosão sejam melhor aproveitadas em produtos para a indústria química, como, por exemplo, as válvulas propostas na seção 1.2 (página 22).

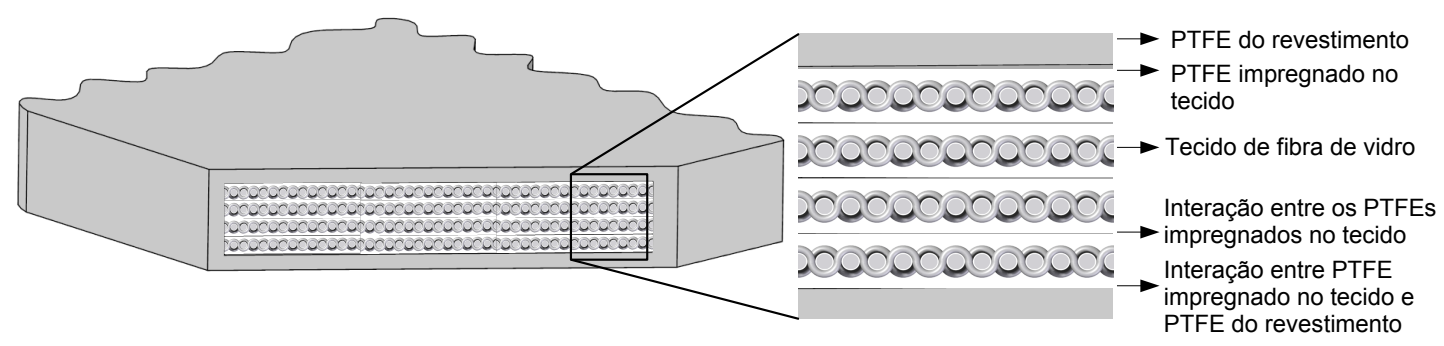

Figura 35: Revestimento contínuo de PTFE em laminados de PTFE e fibras.

Os compósitos elaborados desta forma, com a adição interlaminar e externa de PTFE, foram também avaliados por meio de ensaios de flexão 3-pontos, sendo analisada a adesão dessas camadas adicionais de PTFE ao PTFE impregnado nos tecidos, além das deformações residuais após sinterização. 
Os CDPs para os ensaios de flexão 3-pontos foram obtidos conforme esquematizado na Figura (36), que compreende a etapa de compactação seguida da etapa de sinterização, assim como o compósito anteriormente fabricado. Porém, para este compósito, os CDPs são fabricados pela deposição, na cavidade da matriz de moldagem, de lâminas do tecido impregnado cortados em dimensões apropriadas, intercaladas por camadas de PTFE granulado.

Para estes CDPs foi realizada uma pré-compactação com uma tensão de aproximadamente $5 \mathrm{MPa}$. Posteriormente, os CDPs foram compactados pela máquina universal de ensaios, com velocidade de compactação controlada de $0,5 \mathrm{~mm} / \mathrm{min}$, a uma força máxima de $72 k N$, que equivale a uma pressão na face superior de $40 \mathrm{MPa}$. O tipo de compactação diferenciada para os CDPs compostos de PTFE granulado e tecidos em relação aos CDPs fabricados apenas com tecido, devese ao fato da maior complexidade existente na prensagem do pó. Este procedimento foi adotado para se garantir uma maior homogeneidade na acomodação dos grãos e para promover a eliminação do ar presente no material em pó.

Devido ao complexo mecanismo de deformação do PTFE durante o processo de sinterização (CANTO et al., 2009), o CDP apresenta deformações residuais anisotrópicas, sendo que o material se expande na direção de compactação e se contrai nas direções perpendiculares a esta, conforme ilustrado na Figura (36), em que, $L_{g}, W_{g}$ e $h_{g}$ são respectivamente: comprimento, largura e altura do CDP no estado a verde e $L_{s}, W_{s}$ e $h_{s}$ são respectivamente, comprimento, largura e altura do CDP no estado sinterizado.

Com base nos resultados obtidos por Canto et al. (2009), pode-se considerar que amostras de PTFE, compactadas e sinterizadas nas condições descritas neste trabalho, possuem porosidade desprezível após sinterização. Desprezando-se o eventual aparecimento de novos vazios na sinterização dos CDPs reforçados, pode-se considerar que a fração volumétrica de fibras para os CDPs compostos por tecidos impregnados e PTFE granulado é definida por: 


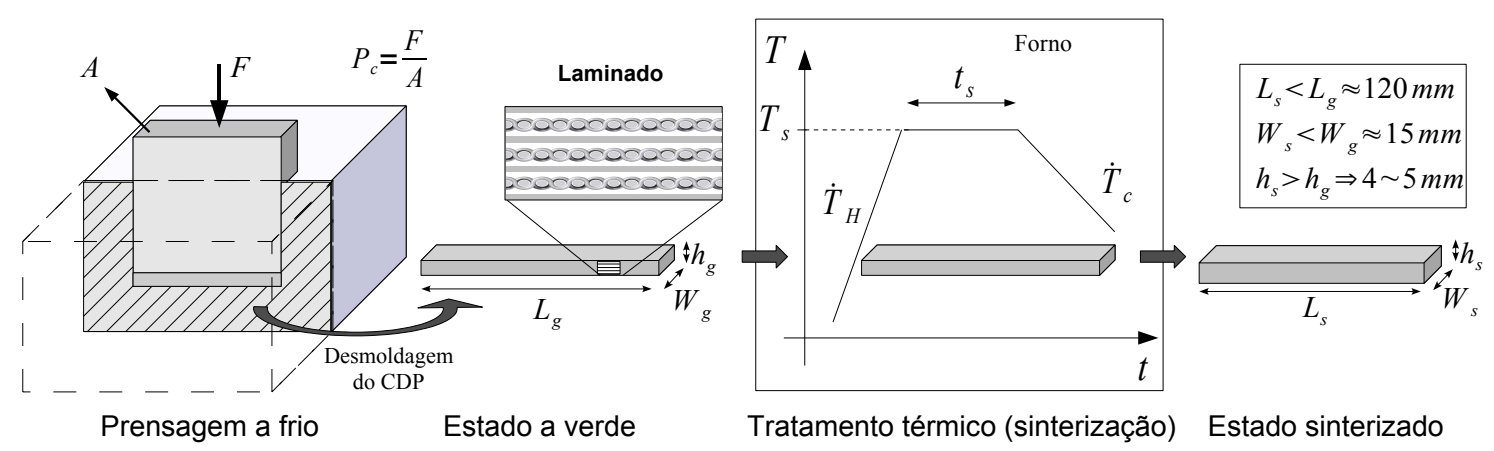

Figura 36: Processo de fabricação dos CDPs fabricados a partir do tecido comercial Chemfab ${ }^{\circledR} 013$ STD e PTFE granulado Teflon ${ }^{\circledR} 6407$.

$$
v_{f}=\frac{V_{f}}{V}=\frac{V_{f}}{V_{f}+V_{m}}
$$

em que $V_{f}$ o volume de fibras, $V$ representa o volume total do CDP, $V_{m}$ o volume de PTFE contido no tecido somado ao volume de PTFE adicionado para formar a matriz. A densidade $\left(\rho_{s}\right)$ dos CDPs após a sinterização pode ser calculada pela Eq. (4.2), sendo que $m$ é a massa do CDP. A densidade da fibra foi adotada da literatura como sendo de $2,5 \mathrm{~g} / \mathrm{cm}^{3}$ (tabela 1 - página 31 ).

$$
\rho_{s}=\frac{m}{V_{f}+V_{m}}
$$

Os CDPs foram fabricados seguindo os valores de parâmetros expostos na Tabela (3- página 58), em que o tempo de permanência no patamar de sinterização de 100 min é utilizado visando uma melhor coalescência dos grãos na sinterização do material e a temperatura de sinterização de $365^{\circ} \mathrm{C}$ é superior à temperatura de fusão, que é de aproximadamente $344^{\circ} \mathrm{C}$ para o material a verde, mas inferior à temperatura de início da degradação do material, que se dá a $390{ }^{\circ} \mathrm{C}$ (EBNESAJJAD, 2000: CANTO et al., 2009).

Para a fabricação dos CDPs deste tipo há uma maior complexidade no processo de prensagem, em que se faz a compactação conjunta das lâminas de tecido impregnados e das camadas de PTFE granulado. Apesar desta maior dificul- 
dade, o processo de compactação foi executado sem a ocorrência de problemas. No entanto, após o processo de sinterização foi verificado (visualmente) que não ocorre a aderência do PTFE adicionado ao PTFE impregnado no tecido, o que impossibilita a fabricação do compósito.

Para buscar entender o motivo desta falta de interação recorreu-se às análises de calorimetria exploratória diferencial (diferential scanning calorimetry - DSC), apresentadas nas Figura (37a) e Figura (37p). A diferença essencial entre os dois materiais evidenciada pelas análises de DSC está nos graus de cristalinidade. O grau de cristalinidade do PTFE puro (Teflon ${ }^{\circledR}$ 6407) é de $89 \%$ em massa e, após a primeira fusão, decresce para aproximadamente $23 \%$ quando submetido a uma taxa de resfriamento de $10{ }^{\circ} \mathrm{C} / \mathrm{min}$, de acordo com Canto et al. (2009). Estes diferentes graus de cristalinidade são representados nas análise de DSC pela considerável diferença entre as entalpias de fusão e cristalinização (áreas dos picos Figura 37a).

Analisando a diferença nas áreas de picos de fusão e cristalização no ensaio de DSC para o tecido impregnado (Figura 37b), deve ser observado que o grau de cristalinidade cresce após a fusão e recristalização - a uma taxa de resfriamento de $10{ }^{\circ} \mathrm{C} / \mathrm{min}$ - em aproximadamente 1,5 vezes. A partir destes dados pode-se inferir que o material, em seu processo de impregnação, é resfriado a uma taxa maior que $10^{\circ} \mathrm{C} / \mathrm{min}$, já que o grau de cristalinidade varia inversamente com a taxa de resfriamento.

No processo de impregnação (explicado na seção 2.3 - página 38), o tecido é resfriado rapidamente ao sair da torre de tratamento. Para simular este resfriamento em laboratório, o tecido impregnado foi aquecido em forno e retirado rapidamente à temperatura de $365{ }^{\circ} \mathrm{C}$, para que fosse resfriado à temperatura ambiente. Um termopar junto ao tecido fez o monitoramento deste resfriamento e indicou uma taxa de resfriamento mínima de aproximadamente $350{ }^{\circ} \mathrm{C} / \mathrm{min}$ à temperatura de $316^{\circ} \mathrm{C}$ (pico de cristalização). O que equivale a um grau de 


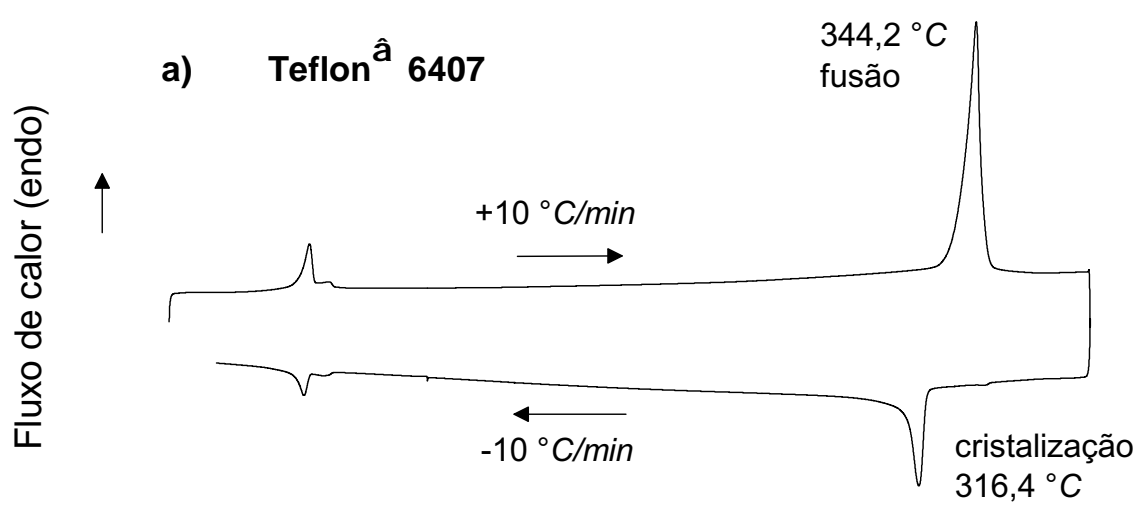

b) $\quad$ Chemfab $^{\circledR} 013$ STD

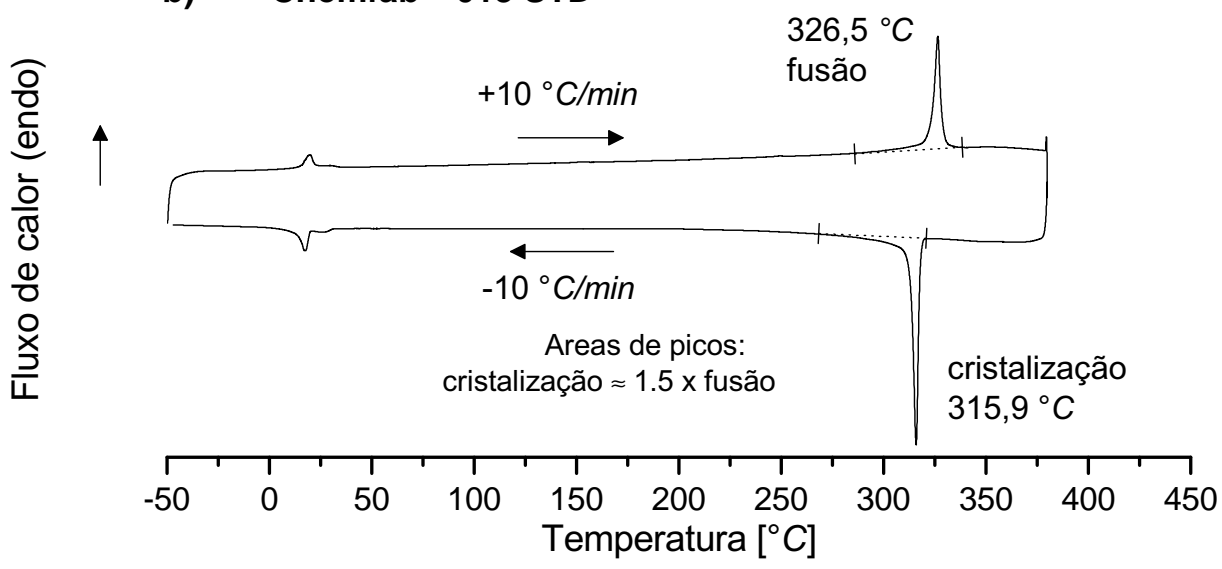

Figura 37: DSCs: a) PTFE - Teflon ${ }^{\circledR}$ 6407; b) tecido de fibra de vidro impregnado com PTFE - Chemfab ${ }^{\circledR} 013$ STD.

cristalinidade de no máximo 15\% em massa, segundo Canto et al. (2009) e considerando que as fibras do tecido não exercem influência no grau de cristalininade.

Segundo Canto (2007), o coeficiente de expansão térmica do PTFE varia inversamente com o grau de cristalinidade. Por este fato, como hipótese, o coeficiente de expansão com diferentes graus de intensidade para cada material tem um impacto negativo na adesão entre estes dois materiais durante o processo de sinterização.

Assim, um tratamento térmico $\left(T_{s}=365^{\circ} \mathrm{C}, \dot{T}_{C}=0,6{ }^{\circ} \mathrm{C} / \mathrm{min}\right)$ foi aplicado ao tecido impregnado anteriormente a fabricação dos laminados. Este tratamento térmico possibilitou a adesão entre o PTFE impregnado no tecido e o PTFE granular, tornando possível a fabricação deste tipo de compósito. A taxa de resfriamento de $0,6{ }^{\circ} \mathrm{C} / \mathrm{min}$ resultou num grau de cristalinidade de aproximadamente 
30\% em massa (CANTO et al., 2009) ao PTFE do tecido. Este aumento do grau de cristalinidade (aproximadamente de 15 para 30\%) pode ter influenciado positivamente facilitando a adesão. Seguindo a hipótese, o decréscimo da diferença entre o coeficiente de expansão do PTFE granular e o PTFE do tecido facilitaram a adesão entre eles.

Com a intenção de verificar a hipótese anteriormente levantada, foi confeccionado um CDP com o tecido tratado termicamente em laboratório, mas com resfriamento rápido $\left(T_{S}=365{ }^{\circ} \mathrm{C}, \dot{T}_{C}=350{ }^{\circ} \mathrm{C} / \mathrm{min}\right)$. Após este tratamento, foi fabricado um CDP nos mesmos moldes dos demais desta seção, tendo como resultado a não aderência entre o PTFE granular e o PTFE do tecido, como mostrado na Figura (38), reforçando a hipótese de que o grau de cristalinidade - e consequentemente o coeficiente de dilatação - influencia nesta adesão.

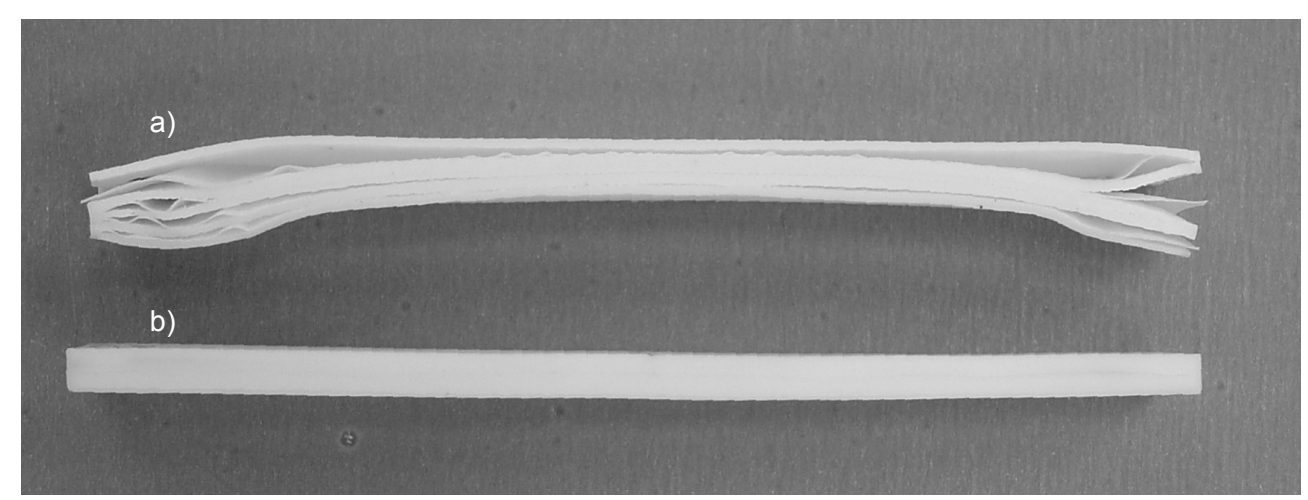

Figura 38: CDPs de PTFE granular e tecidos impregnados Chemfab ${ }^{\circledR}$ 013: a) CDP com tecido tratado termicamente com taxa de resfriamento rápida; b) CDP com tecido tratado termicamente com taxa de resfriamento lenta.

Portanto, para que fosse possível fabricar CDPs intercalados de PTFE granulado e tecidos de fibra de vidro com PTFE, os tecidos receberam o tratamento térmico com resfriamento de $0,6^{\circ} \mathrm{C} / \min$ antes de serem usados para a fabricação dos CDPs para os ensaios de flexão 3-pontos desta etapa. A Figura (38p) mostra um CDP fabricado com estes tecidos.

Os CDPs do compósito com os tecidos impregnados já tratados termicamente foram fabricados com diferentes frações volumétricas de fibras. Como exposto em Canto et al. (2009), quando submetido à temperatura de sinterização, o ma- 
terial se expande devido à dilatação térmica e à fusão cristalina. Após o resfriamento, o material se contrai devido à recristalização parcial e à contração térmica, apresentando deformação residual negativa na direção perpendicular à compactação e positiva na direção de compactação. Esta anisotropia é induzida pelo processo de compactação e causada por um outro mecanismo de deformação, chamado de recuperação por Canto et al. (2009). No entanto, a presença dos tecidos de fibra de vidro limita estas deformações e as dimensões finais dos CDPs dependem fortemente da fração volumétrica de fibras, conforme mostrado nos gráficos da Figura (39a) e Figura (39p) - a máxima fração de fibra no compósito é limitada em $34 \%$, que é a fração volumétrica do tecido utilizado.
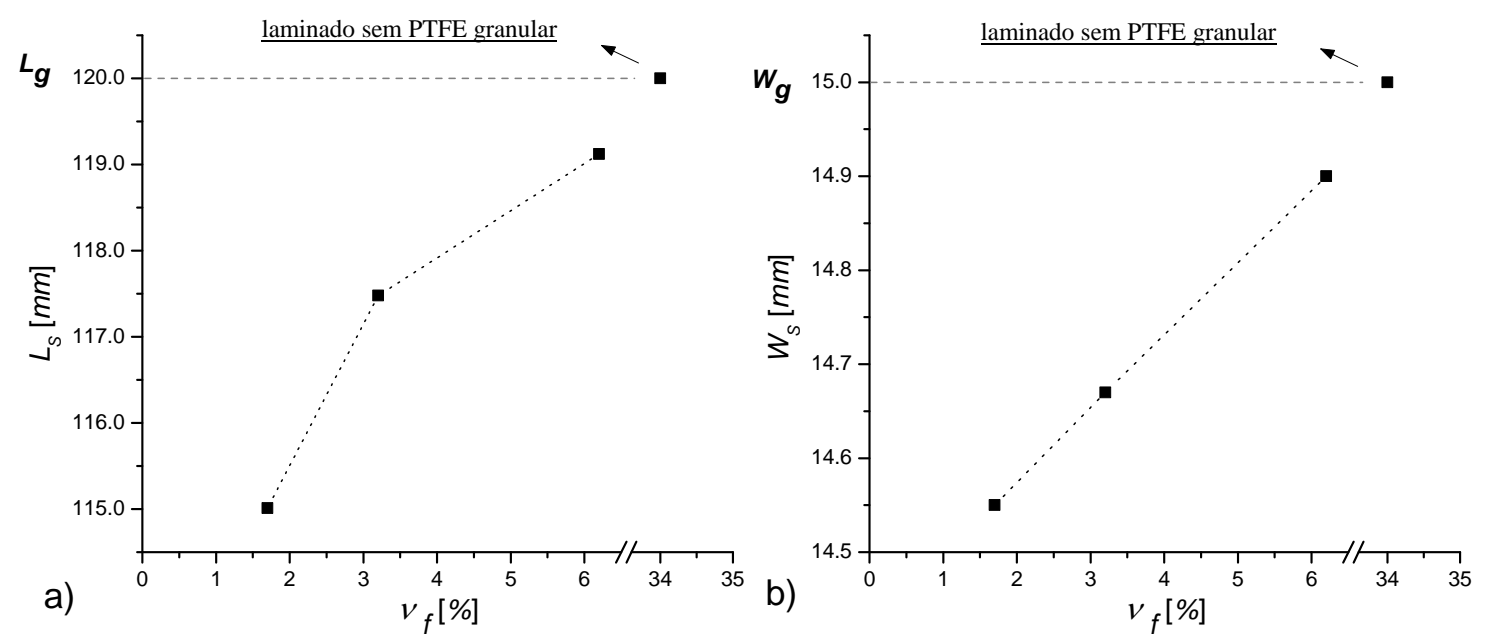

Figura 39: Dimensões finais dos CDPs após sinterização comparados com a dimensão no estado a verde para as diferentes frações volumétricas de fibras.

A Figura (40a) mostra a evolução do módulo de Young à flexão em função da fração volumétrica de fibra. Apesar da restrita quantidade de ensaios, foi possível concluir que há uma clara tendência do aumento do módulo de Young com o aumento da fração volumétrica de fibras. O mesmo acontece para o gráfico de tensão máxima na superfície inferior do CDP mostrado na Figura (40), onde se pode notar uma tendência do aumento dessa propriedade em função da fração volumétrica de fibras, porém seguindo uma evolução diferente.

Vale ressaltar que o aumento das propriedades mecânicas estudadas está re- 

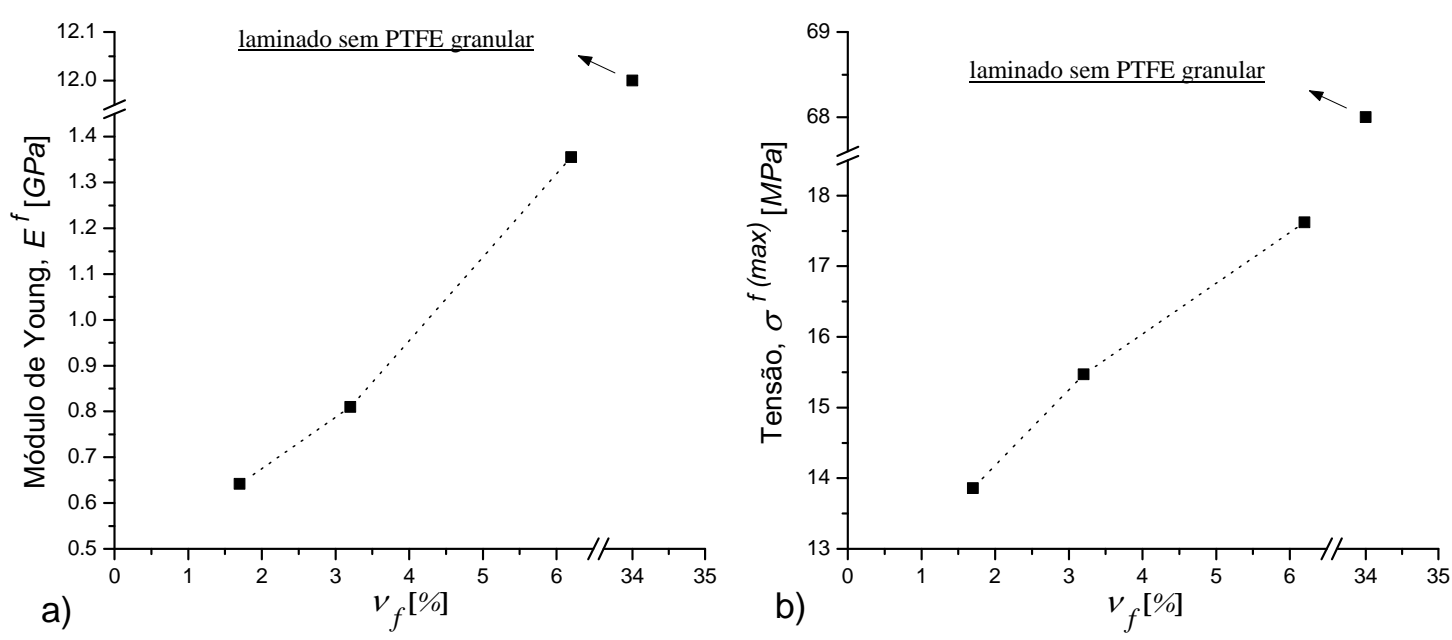

Figura 40: Curva de tendência: a) do módulo de Young à flexão em função da fração volumétrica de fibras; b) da tensão máxima em função fração volumétrica.

lacionado ao efeito da maior rigidez do reforço incorporado, mas também pode estar associado à diminuição da eventual micro-flambagem das fibras na direção longitudinal devido à menor contração induzida no processo de sinterização na medida em que a fração de fibras aumenta, conforme mostrado na Figura (39a).

\subsection{Laminados de Tecido Comercial Chemfab ${ }^{\circledR} 008$}

As diferenças básicas entre os tecidos comerciais estudados estão na espessura do tecido e no tipo de trama de fibra de vidro, como mostrado anteriormente na Figura (10) (página 46). O tecido Chemfab ${ }^{\circledR} 008$ tem uma espessura menor que a do tecido $\mathrm{Chemfab}^{\circledR} 013$ e maior espaçamento entre os feixes de fibras em relação ao tecido de fibra de vidro do Chemfab ${ }^{\circledR} 013$.

\subsubsection{Avaliação por ensaio de flexão 3-pontos}

Assim como para os laminados fabricados com tecido Chemfab ${ }^{\circledR} 013$, foi realizado um estudo da influência dos parâmetros de fabricação nas propriedades mecânicas finais dos laminados fabricados com o tecido Chemfab ${ }^{\circledR} 008$. Neste estudo, as propriedades finais dos laminados foram também avaliadas por meio de ensaios de flexão 3-pontos. 
Os melhores valores de parâmetros de fabricação, obtidos a partir do plano de ensaios (Figura 20 - página 60) realizado para o tecido Chemfab ${ }^{\circledR} 013$, serviram como base para a confecção dos CDPs de tecido Chemfab ${ }^{\circledR} 008$. Nesta nova estratégia os parâmetros foram variados individualmente (assim como para o Chemfab $\left.{ }^{\circledR} 013\right)$, no entanto, não foram feitas escolhas de melhores valores a cada passo. Os valores da Tabela (10) foram atribuídos aos parâmetros que não estavam sendo variados no momento. A mudança de estratégia leva em consideração o fato de que a Tabela (10) já fornece valores de parâmetros mais adequados para este tipo de compósito.

Devido à influência comprovada da exposição prolongada a altas temperaturas na adesão entre fibra e matriz nos compósitos fabricados com o tecido Chemfab $^{\circledR}$ 013, optou-se por estudar, também, o comportamento mecânico do laminado fabricado com tecido $C$ hemfab ${ }^{\circledR} 013$ com relação à variação da taxa de aquecimento $\left(\dot{T}_{H}\right)$, já que, no aquecimento, assim como no resfriamento, os CDPs estão sujeitos a permanecerem longos períodos a altas temperaturas, dependendo das taxas adotadas.

Os CDPs de tecidos Chemfab ${ }^{\circledR} 008$ para o ensaio de flexão 3-pontos foram fabricados segundo a metodologia apresentada na seção 3.2 (página 48). A fabricação se difere apenas no número de camadas, 20, em lugar das 16 camadas dos CDPs fabricados com o Chemfab ${ }^{\circledR} 013$.

Tabela 10: Valores de parâmetros de fabricação obtidos para o tecido Chemfab ${ }^{\circledR} 013$ e utilizados como referência para o estudo do Chemfab ${ }^{\circledR} 008$

\begin{tabular}{ccccc}
\hline$P_{C}$ & $\dot{T}_{H}\left[{ }^{o} \mathrm{C} / \mathrm{min}\right]$ & $T_{S}\left[{ }^{\circ} \mathrm{C}\right]$ & $t_{s}[\mathrm{~min}]$ & $\dot{T}_{\mathrm{C}}\left[{ }^{o} \mathrm{C} / \mathrm{min}\right]$ \\
\hline 54 & 2 & 380 & 5 & 0,6 \\
\hline
\end{tabular}

No estudo da pressão de conformação foram realizados ensaios de flexão 3pontos em CDPs cujos valores dos parâmetros de processamento estão indicados 
na Tabela (11) e os resultados são mostrados na Figura (41) - pelos gráficos de tensão por deformação e de evolução da tensão máxima à flexão e módulo de Young à flexão em função da pressão de conformação aplicada. As curvas de tendência de $E^{f}$ mostram haver uma queda no valor desta propriedade para o maior valor de $P_{c}$ aplicado, $174 \mathrm{MPa}$. O restante dos valores de $E^{f}$ permanecem próximos, não havendo uma variação considerável. A tendência apresentada para $\sigma^{f(\max )}$ em relação à pressão, indica que esta propriedade aumenta com a aplicação da pressão até um limite em torno de $142 \mathrm{MPa}$ - aumento esperado pela diminuição dos vazios do laminado - e que, a partir deste ponto, começa a diminuir.

Tabela 11: Parâmetros de fabricação - variação da pressão de conformação, $P_{C}$

\begin{tabular}{ccccc}
\hline$P_{C}[\mathrm{MPa}]$ & $\dot{\mathrm{T}}_{\mathrm{H}}\left[{ }^{\circ} \mathrm{C} / \mathrm{min}\right]$ & $T_{s}\left[{ }^{0} \mathrm{C}\right]$ & $t_{s}[\mathrm{~min}]$ & $\dot{T}_{\mathrm{C}}\left[{ }^{\circ} \mathrm{C} / \mathrm{min}\right]$ \\
\hline \hline 22 & & & & \\
54 & 2 & 380 & 5 & \\
109 & & & & \\
142 & & & & \\
152 & & & \\
174 & & & \\
\hline
\end{tabular}
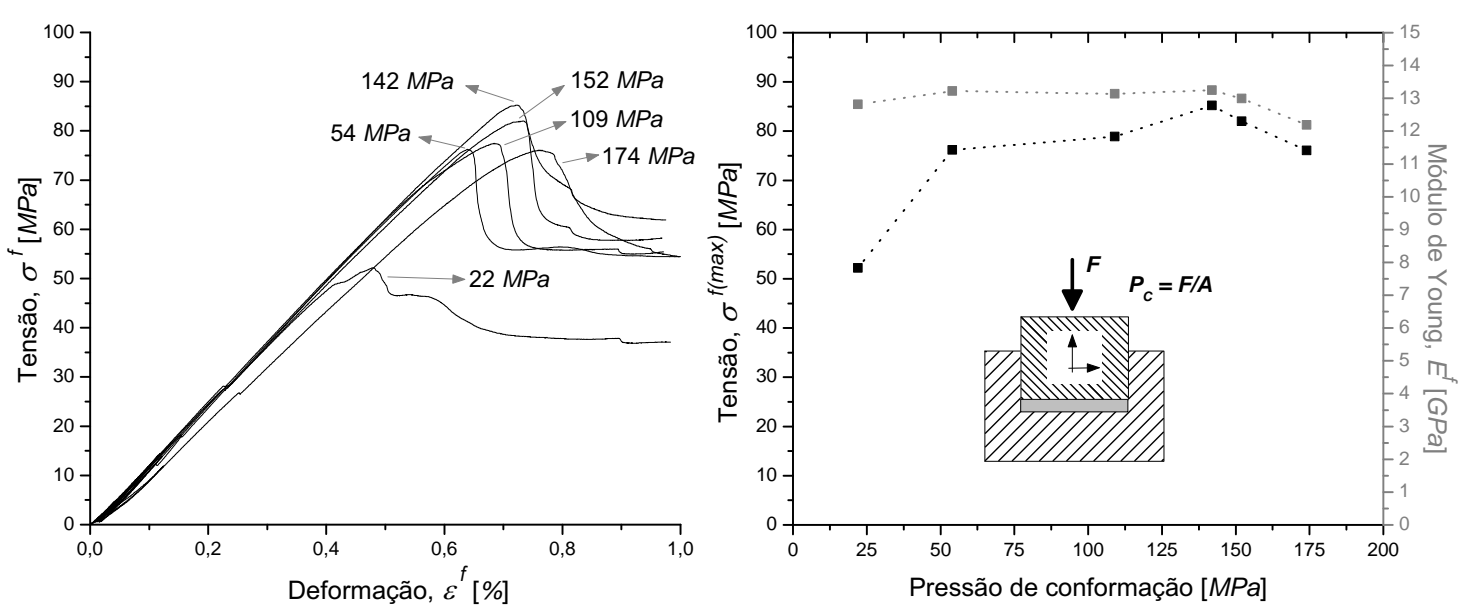

Figura 41: Análise da influência da pressão de conformação: Tensão pela deformação em ensaios de flexão 3-pontos (esquerda) e curvas de tendência da resistência máxima e módulo de Young à flexão em função da pressão de conformação. 
As quedas nos valores das propriedades mecânicas avaliadas para pressões altas sugerem que os laminados estão sendo danificados a estas pressões. Ebnesajjad (2000) relata o aparecimento de trincas na compactação do PTFE puro a altas pressões, que interferem negativamente nas propriedades mecânicas dos componentes fabricados com PTFE.

A Tabela (12) indica os valores para a variação da taxa de aquecimento $\left(\dot{T}_{H}\right)$ e, a Figura (42), os resultados dos ensaios de flexão 3-pontos. No estudo dos laminados feitos com Chemfab ${ }^{\circledR} 013$, constatamos que quanto maior o tempo em temperaturas elevadas, piores seriam as propriedades mecânicas do material salvo o tempo mínimo de permanência para que haja a adesão das lâminas -, porém, as curvas de tendência de $E^{f}$ e de $\sigma^{f(\max )}$, da Figura 42 , indicam que a taxa de aquecimento de $0,2{ }^{\circ} \mathrm{C} / \mathrm{min}$ proporciona melhores resultados que a taxa de $2{ }^{\circ} \mathrm{C} / \mathrm{min}$ anteriormente usada. Os gráficos de tendência indicam valores piores para a taxa de aquecimento mais baixa $\left(0,1^{\circ} \mathrm{C} / \mathrm{min}\right)$ e que os valores tendem a piorar para taxas de aquecimento muito elevadas.

Tabela 12: Parâmetros de fabricação - variação da taxa de aquecimento, $\dot{T}_{H}$

\begin{tabular}{ccccc}
\hline$P_{C}[\mathrm{MPa}]$ & $\dot{\mathrm{T}}_{\mathrm{H}}\left[{ }^{\circ} \mathrm{C} / \mathrm{min}\right]$ & $T_{s}\left[{ }^{\circ} \mathrm{C}\right]$ & $t_{s}[\mathrm{~min}]$ & $\dot{T}_{\mathrm{C}}\left[{ }^{o} \mathrm{C} / \mathrm{min}\right]$ \\
\hline \hline & 0,1 & & & \\
0,2 & & & \\
54 & 1 & & 5 & 0,6 \\
& 2 & 380 & & \\
\hline
\end{tabular}

Os valores para a variação da temperatura de sinterização $(T-s)$ estão expressos na Tabela (13). Os gráficos de tendência (Figura 43), apesar de pequena variação, mostram um aumento gradativo das propriedades mecânicas com o aumento da temperatura até o limite de $390^{\circ} \mathrm{C}$, para a qual se obtiveram os melhores valores de $E^{f}$ e $\sigma^{f(\max )}$. Vale lembrar que esta temperatura está próxima a temperatura de início de degradação do material, como pode ser visto pela TGA 

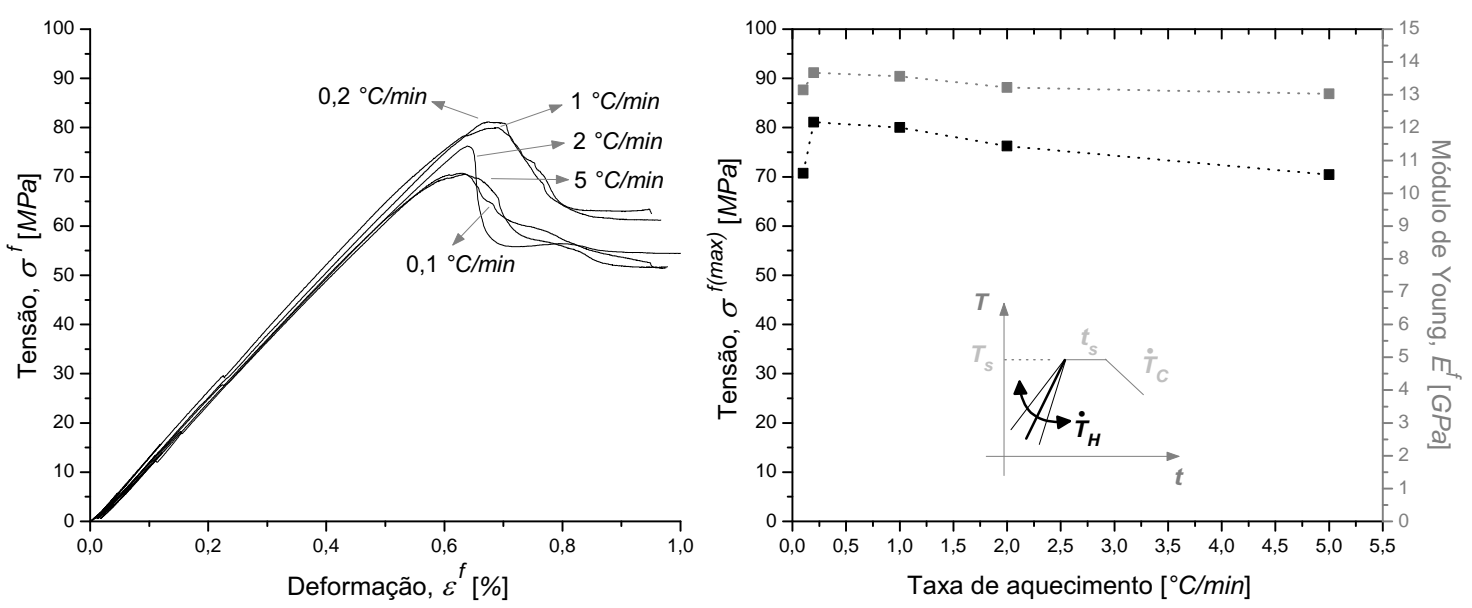

Figura 42: Análise da influência da taxa de aquecimento: Tensão pela deformação em ensaios de flexão 3-pontos (esquerda) e curvas de tendência da resistência máxima e módulo de Young à flexão em função da taxa de aquecimento.

dos tecidos utilizados (Figura 9- página 45).

Tabela 13: Parâmetros de fabricação - variação da temperatura de sinterização, $T_{S}$

\begin{tabular}{|c|c|c|c|c|}
\hline$P_{C}[M P a]$ & $\dot{\mathrm{T}}_{\mathrm{H}}\left[{ }^{\circ} \mathrm{C} / \mathrm{min}\right]$ & $T_{s}\left[{ }^{\circ} \mathrm{C}\right]$ & $t_{s}[\mathrm{~min}]$ & $\dot{T}_{C}\left[{ }^{o} \mathrm{C} / \min \right]$ \\
\hline \multirow{7}{*}{54} & \multirow{7}{*}{2} & 350 & \multirow{7}{*}{5} & \multirow{7}{*}{0,6} \\
\hline & & 365 & & \\
\hline & & 375 & & \\
\hline & & 380 & & \\
\hline & & 385 & & \\
\hline & & 390 & & \\
\hline & & 395 & & \\
\hline
\end{tabular}

A Tabela (14) traz os valores referentes à variação do tempo de sinterização $\left(t_{s}\right)$. Os resultados são mostrados na Figura (44), em que os gráficos de tendências de $E^{f}$ e $\sigma^{f(\max )}$ em função do tempo mostram não haver uma variação considerável destas propriedades mecânicas com a variação deste parâmetro. No entanto, diferentemente ao realizado no $\mathrm{Chemfab}^{\circledR} 013$, não foi analisado o comportamento para tempos mais longos como 400 min e 1000 min, por ter sido considerado os resultados anteriores e o custo operacional. 

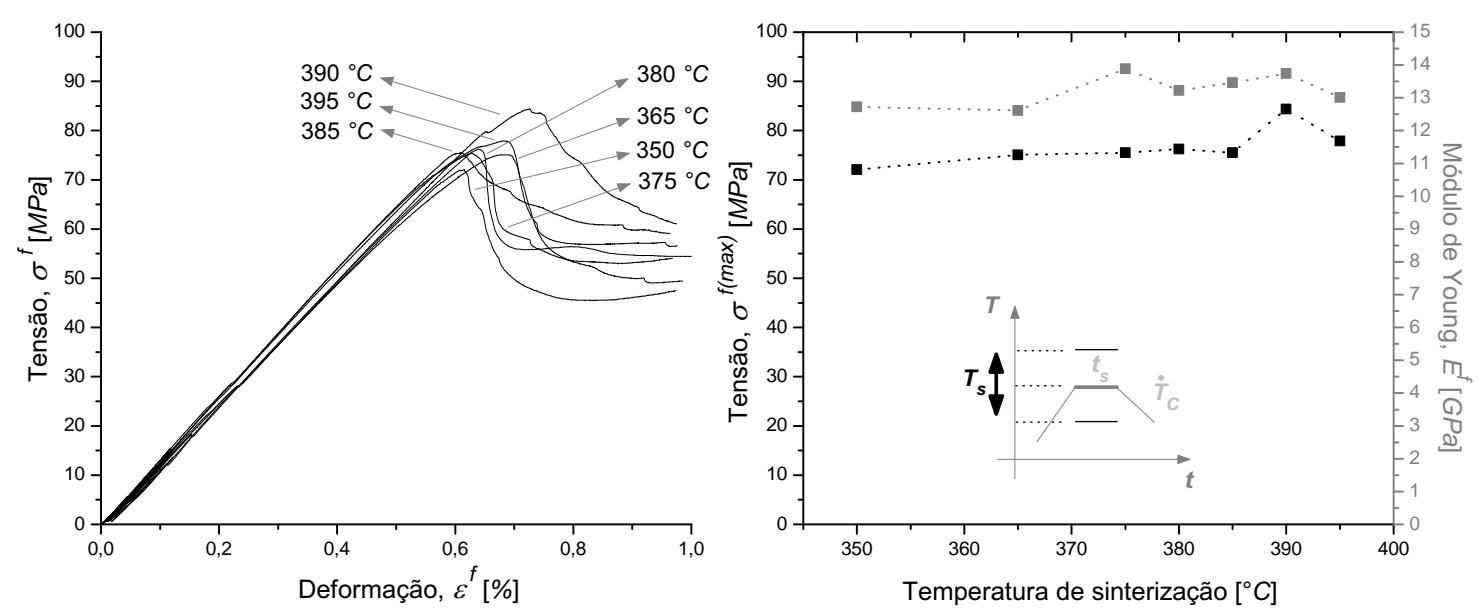

Figura 43: Análise da influência da temperatura de sinterização: Tensão pela deformação em ensaios de flexão 3-pontos (esquerda) e curvas de tendência da resistência máxima e módulo de Young à flexão em função da temperatura de sinterização.

Tabela 14: Parâmetros de fabricação - variação do tempo de sinterização, $t_{s}$

\begin{tabular}{|c|c|c|c|c|}
\hline$P_{C}[M P a]$ & $\dot{\mathrm{T}}_{H}\left[{ }^{o} \mathrm{C} / \mathrm{min}\right]$ & $T_{S}\left[{ }^{o} \mathrm{C}\right]$ & $t_{s}[\mathrm{~min}]$ & $\dot{\mathrm{T}}_{\mathrm{C}}\left[{ }^{\circ} \mathrm{C} / \mathrm{min}\right]$ \\
\hline & & & 0 & \\
\hline \multirow[t]{6}{*}{54} & 2 & 380 & 5 & 0,6 \\
\hline & & & 10 & \\
\hline & & & 20 & \\
\hline & & & 50 & \\
\hline & & & 100 & \\
\hline & & & 200 & \\
\hline
\end{tabular}

O fato das melhores propriedades mecânicas encontradas, pela variação da taxa de aquecimento, terem sido para baixos valores, poderia indicar uma necessidade de um tempo maior de sinterização para a fabricação do laminado. No entanto, as variações da temperatura e tempo de sinterização não foram conclusivas a este respeito, indicando que uma taxa de aquecimento mais baixa é necessária para um aumento nas propriedades estruturais do laminado fabricado pelo tecido Chemfab ${ }^{\circledR}$ 008. Este fato pode estar ligado a baixa condutividade térmica do PTFE, mesmo havendo uma considerável quantidade de fibra de vidro - cuja 

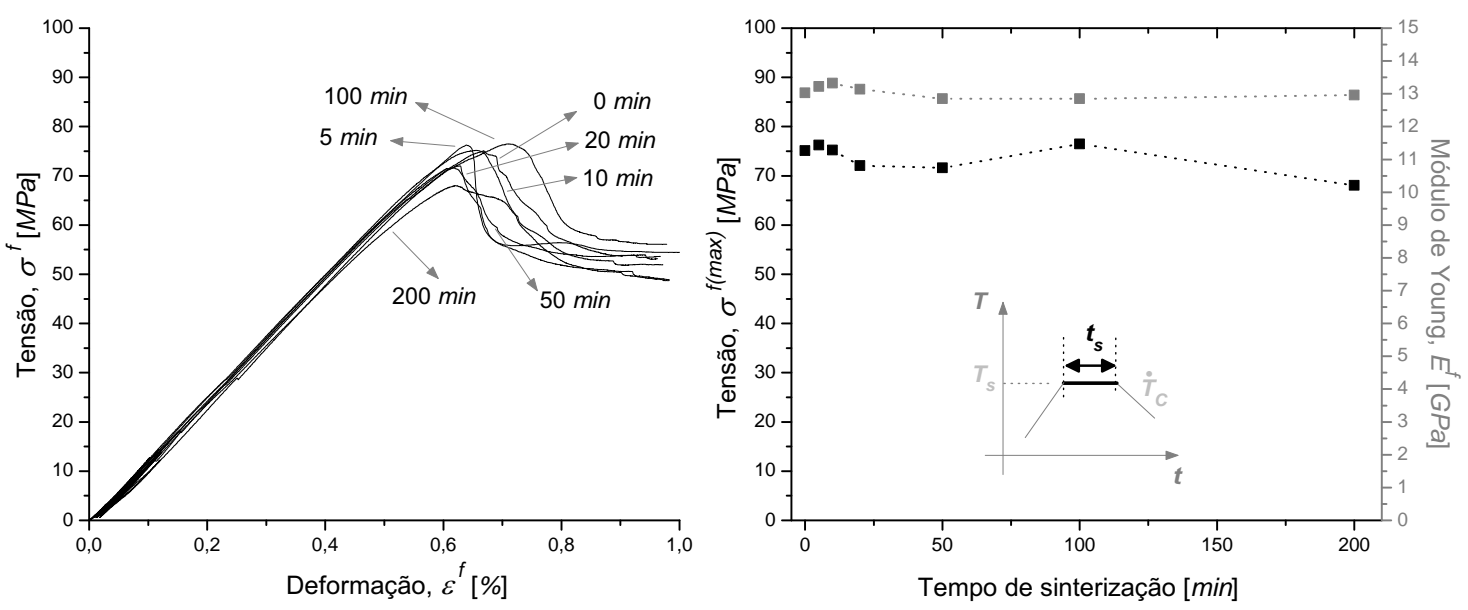

Figura 44: Análise da influência do tempo de sinterização: Tensão pela deformação em ensaios de flexão 3-pontos (esquerda) e curvas de tendência da resistência máxima e módulo de Young à flexão em função do tempo de sinterização.

condutividade térmica é muito maior que a do PTFE.

Os dados de variação da taxa de resfriamento são mostrados na Tabela (15), e, os resultados, nos gráficos da Figura (45). A variação do módulo de elasticidade foi novamente muito pequena para ser levada em conta. Porém, a resistência máxima se comportou melhor para a taxa de resfriamento de $1^{\circ} \mathrm{C} / \mathrm{min}$, obtendo valores inferiores para taxas de resfriamento muito baixas e muito altas.

Tabela 15: Parâmetros de fabricação - variação da taxa de resfriamento, $\dot{T}_{C}$

\begin{tabular}{|c|c|c|c|c|}
\hline$P_{C}[M P a]$ & $\dot{\mathrm{T}}_{H}\left[{ }^{\circ} \mathrm{C} / \mathrm{min}\right]$ & $T_{S}\left[{ }^{o} \mathrm{C}\right]$ & $t_{s}[\min ]$ & $\dot{\mathrm{T}}_{\mathrm{C}}\left[{ }^{\circ} \mathrm{C} / \mathrm{min}\right]$ \\
\hline & & & & 0,2 \\
\hline \multirow[t]{4}{*}{54} & 2 & 380 & 5 & 0,6 \\
\hline & & & & 1 \\
\hline & & & & $\approx 2,3$ \\
\hline & & & & $\approx 21$ \\
\hline
\end{tabular}

A ausência de grandes diferenças entre os resultados de módulo de Young à flexão e resistência máxima à flexão pela variação de tempo e temperatura parâmetros considerados como mais relevantes para os CDPs fabricados com o tecido Chemfab ${ }^{\circledR} 013$ - pode ser explicada pela existência de dois fenômenos 

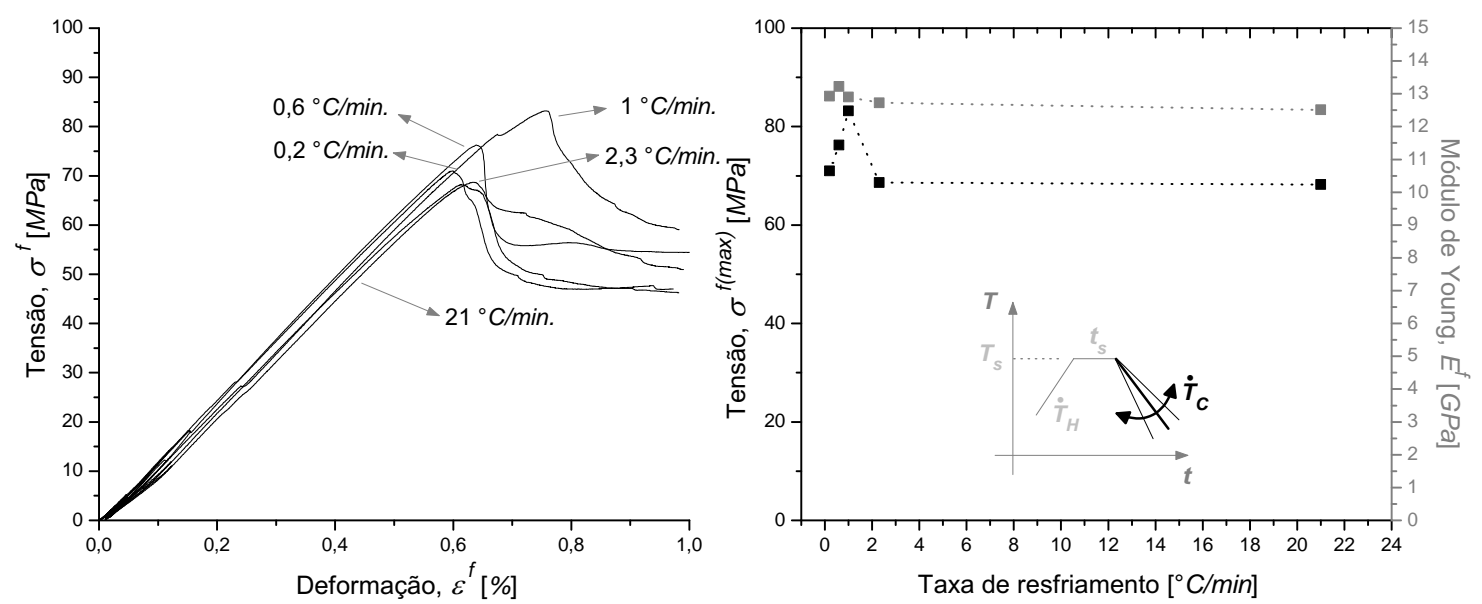

Figura 45: Análise da influência da taxa de resfriamento: Tensão pela deformação em ensaios de flexão 3-pontos (esquerda) e curvas de tendência da resistência máxima e módulo de Young à flexão em função da taxa de resfriamento.

concorrentes: o primeiro, já amplamente discutido, seria a degradação da interface fibra-matriz, e, o segundo, seria que um tempo elevado de permanência a altas temperaturas pudesse levar a uma melhor interdifusão das cadeias de PTFE de uma camada para outra.

A trama mais aberta do tecido Chemfab ${ }^{\circledR} 008$ traz uma característica diferente para a fabricação dos laminados deste tecido. Este espaçamento pode levar a uma interdifusão entre as cadeias poliméricas de tecidos vizinhos. $\mathrm{O}$ fato da adesão entre fibra e matriz ser muito fraca faz com que a interdifusão das cadeias poliméricas para os compósitos do tecido Chemfab ${ }^{\circledR} 013$ seja pouco relevante, já que uma baixa adesão entre duas superfícies seria suficiente para a fabricação dos compósitos. Ou seja, mesmo que a aderência entre as superfícies de PTFE seja fraca, será ainda bem mais forte que a aderência entre PTFE e fibra - a falha sempre ocorrerá primeiramente na interface fibra-matriz. Por outro lado, esta difusão se torna importante para os compósitos feitos com Chemfab ${ }^{\circledR} 008$. Acredita-se que possa continuar havendo a degradação da interface fibra-matriz, o que piora a adesão química; entretanto, a interdifusão das cadeias pode estar melhorando a adesão mecânica, mantendo próximos os valores das propriedades mecânicas avaliadas. 
Como parte final da avaliação por ensaio de flexão 3-pontos dos laminados fabricados com tecido Chemfab $^{\circledR}$ 008, foram escolhidos valores de parâmetros baseados nos melhores desempenhos obtidos pelos estudos apresentados nesta seção, levando em conta ainda um menor custo operacional. Foram fabricados e ensaiados 4 CDPs, cujos valores de processamento, módulo de Young à flexão médio, $\bar{E}^{f}$, e resistência máxima à flexão média, $\bar{\sigma}^{f(\max )}$, são apresentados na Tabela (16). Os valores das propriedades mecânicas são os melhores apresentados até aqui, o que configura os valores de parâmetros de fabricação apresentados na tabela, como os indicados neste trabalho para a metodologia de fabricação de laminados proposta.

Tabela 16: Valores de parâmetros de fabricação e propriedades mecânicas obtidas em ensaios de flexão 3-pontos para 4 CDPs

\begin{tabular}{c||ccccc|cc}
\hline \multicolumn{1}{l||}{} & \multicolumn{5}{c}{ Fabricação } & \multicolumn{2}{c}{ Flexão 3-pontos } \\
\hline \hline $\mathrm{CDPs}$ & $P_{\mathrm{C}}[\mathrm{MPa}]$ & $\dot{\mathrm{T}}_{H}\left[{ }^{\circ} \mathrm{C} / \min \right]$ & $\mathrm{T}_{S}\left[{ }^{\circ} \mathrm{C}\right]$ & $t_{s}[\mathrm{~min}]$ & $\dot{T}_{\mathrm{C}}\left[{ }^{\circ} \mathrm{C} / \min \right]$ & $\bar{E}^{f}[G P a]$ & $\bar{\sigma}^{f(\max )}[\mathrm{MPa}]$ \\
\hline 4 & $\approx 140$ & 1 & 380 & 5 & 1 & $13,37( \pm 0,08)^{1}$ & $89( \pm 2)$ \\
\hline
\end{tabular}

\subsubsection{Avaliação por ensaio de adesão fibra-matriz}

Seguindo a mesma ideia adotada na seção 4.1.2 (página 69), foram fabricados dois CDPs para o ensaio de adesão, com valores de parâmetros de fabricação diferentes entre si. Estes valores foram também usados em ensaios de flexão 3pontos realizados anteriormente e são expostos na Tabela (17), juntamente com os resultados levantados pelos dois ensaios.

Assim como na comparação entre os ensaios de adesão e flexão 3-pontos feita para o tecido Chemfab ${ }^{\circledR} 013$ STD, a comparação dos dois ensaios feita para o tecido Chemfab ${ }^{\circledR} 008$ STD (Figura 46) mostrou haver uma correspondência entre eles, indicando que a degradação entre fibra e matriz é, também, o principal mecanismo de falha do laminado fabricado com este tecido.

\footnotetext{
${ }^{1}$ Desvio padrão.
} 
Tabela 17: Parâmetros de fabricação e valores de ensaios de flexão 3-pontos e adesão, para os melhores e piores valores para cada parâmetro de sinterização

\begin{tabular}{c||cccc|cccc}
\hline \multicolumn{1}{l||}{} & \multicolumn{4}{c}{ Fabricação } & \multicolumn{2}{c}{ Flexão 3-pontos } & \multicolumn{2}{c}{ Adesão } \\
\hline \hline Caso & $P_{C}[\mathrm{MPa}]$ & $\dot{T}_{H}\left[{ }^{\circ} \mathrm{C} / \mathrm{min}\right]$ & $T_{S}\left[{ }^{\circ} \mathrm{C}\right]$ & $t_{s}[\mathrm{~min}]$ & $\dot{T}_{\mathrm{C}}\left[{ }^{\circ} \mathrm{C} / \mathrm{min}\right]$ & $E^{f}[G P a]$ & $\sigma^{f(\max )}[\mathrm{MPa}]$ & $\bar{F}[N]$ \\
\hline 1 & 54 & 1 & 380 & 5 & 1 & 13,3 & 83 & 14 \\
2 & 54 & 1 & 390 & 100 & 1 & 12,3 & 77 & 11 \\
\hline
\end{tabular}
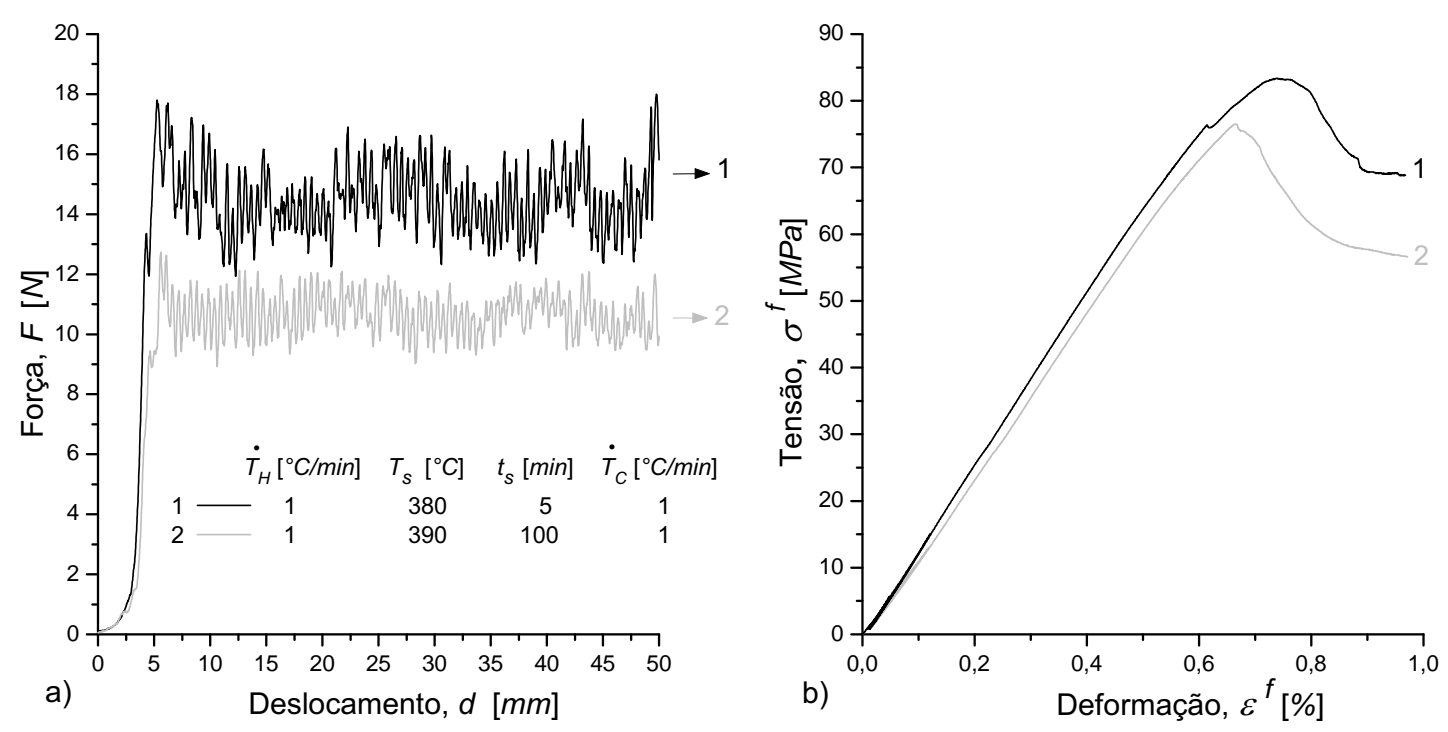

Figura 46: a) Curvas de força pelo deslocamento em ensaios de adesão; b) Curvas de tensão pela deformação em ensaios de flexão 3-pontos para os mesmos parâmetros usados no ensaio de adesão.

A fotomicrografia de MEV apresentada na Figura (47) mostra a superfície de um CDP feito a partir do tecido Chemfab ${ }^{\circledR} 013$ que passou por um ensaio de adesão. Nesta foto é possível observar as fibras de vidro da região de onde o PTFE foi arrancado (à esquerda na figura) e a parte do CDP em que o revestimento de PTFE permanece sobre a fibra devido a separação pela Lâmina de alumínio. A nítida fronteira entre as duas regiões é a responsável pelos picos iniciais de força (Figura 30- página 71) no ensaio de adesão para os compósitos fabricados tendo como base o tecido Chemfab ${ }^{\circledR}$ 013. Estes picos representam a força necessária para o rompimento da camada de PTFE, maior que a força usada para o descolamento do PTFE das fibras, que se mantém oscilante em um patamar mais baixo 
durante o restante do ensaio.

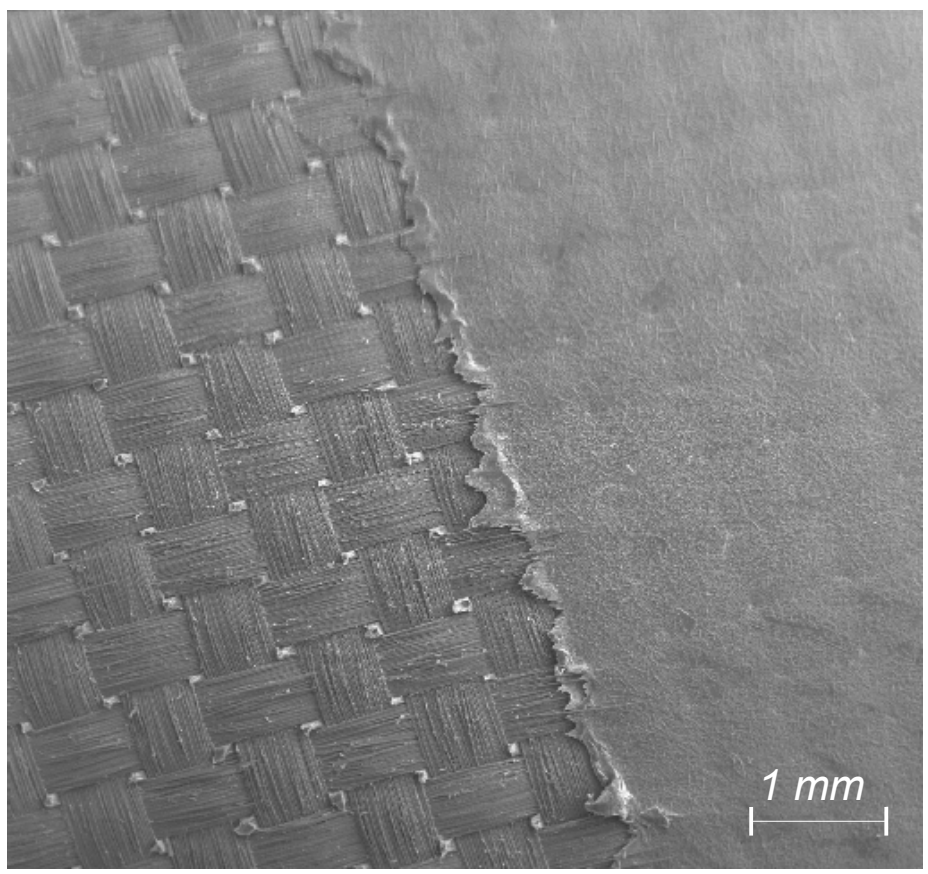

Figura 47: Fotomicrografia de microscopia eletrônica de varredura da superfície do CDP de adesão após ensaio: tecido de fibra de vidro a mostra (parte esquerda da foto) após arrancamento do revestimento de PTFE.

Os picos iniciais de força não aparecem nos ensaios de adesão para os CDPs fabricados com o tecido Chemfab ${ }^{\circledR}$ 008. Este fato pode ser explicado pela diferença das tramas dos tecidos, como comentado na seção anterior. A trama mais espaçada do tecido Chemfab ${ }^{\circledR} 008$ faz com que o arrancamento da última lâmina seja mais próximo da força inicial de rompimento do PTFE, pois, com este maior espaçamento entre os feixes de fibras, há uma maior região de contado entre o PTFE de um lado do tecido com o PTFE do lado oposto, fazendo com que o rompimento do PTFE aconteça durante todo o ensaio, como mostrado na Figura 48. Os pequenos pontos cinza claro entre a trama da Figura (47) indicam também este tipo de rompimento para o tecido Chemfab $^{\circledR} 013$, mas em uma escala muito menor que para o Chemfab ${ }^{\circledR} 008$.

A fração volumétrica dos dois tecidos comerciais aqui usados são relativamente próximas, como mostrado anteriormente pelas análises de TGA da Figura (9) (página 45), o que possibilita uma comparação direta dos resultados finais. 


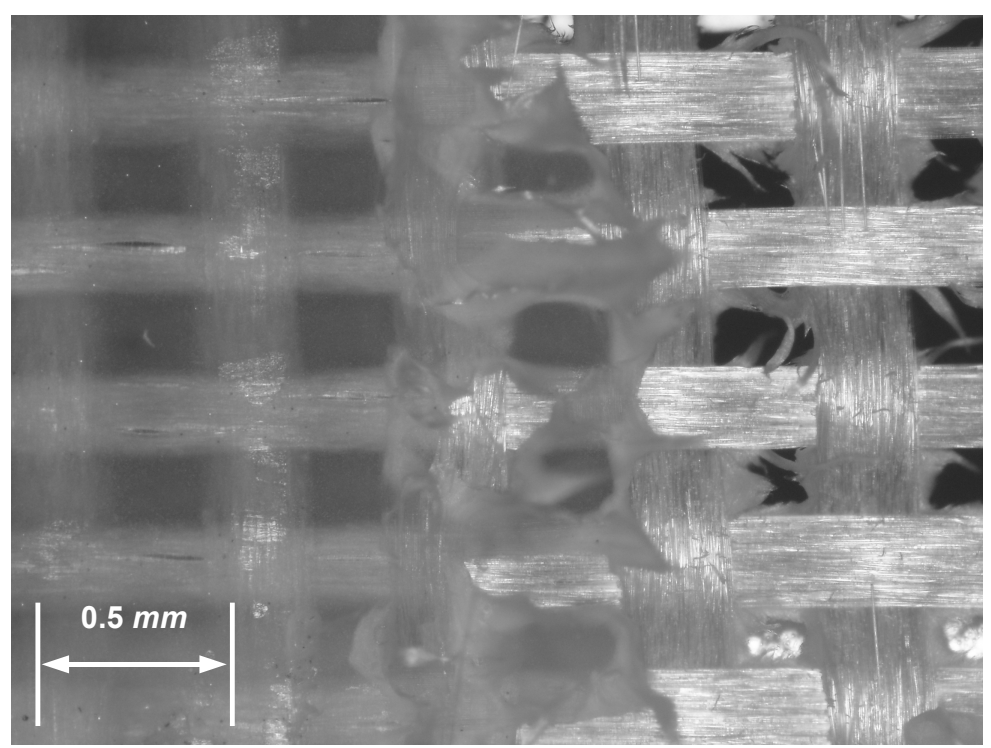

Figura 48: Fotomicrografia de microscopia eletrônica de varredura do tecido Chemfab ${ }^{\circledR}$ 008 arrancado durante ensaio de adesão.

Dentro desta comparação, é possível dizer, em termos dos módulos de Young à flexão alcançados, que o tecido com trama mais espaçada, ou seja, o Chemfab ${ }^{\circledR}$ 008, oferece, em média, melhores resultados que o tecido Chemfab ${ }^{\circledR} 013$. Na Figura (49) é mostrado um gráfico comparativo dos módulos de Young à flexão para três conjuntos de parâmetros com valores comuns entre os dois tecidos. Este gráfico comprova o melhor desempenho do tecido Chemfab ${ }^{\circledR}$ 008. O maior espaçamento entre os feixes de fibras faz com que estes feixes sejam melhor envolvidos pelo PTFE, o que se mostra mais vantajoso para a fabricação dos laminados.

\subsubsection{Avaliação por ensaio de tração}

O ensaio de tração foi realizado em 4 CDPs fabricados com os mesmos valores de parâmetros de fabricação que proporcionaram as melhores propriedades mecânicas aos CDPs avaliados pelo ensaio de flexão 3-pontos (Tabela 16). Foi utilizada a técnica de correlação de imagens, por meio do programa CORRELI, para a medição do campo de deslocamentos e deformações durante os ensaios.

Na Figura (50) é mostrada uma região de análise discretizada por uma malha 


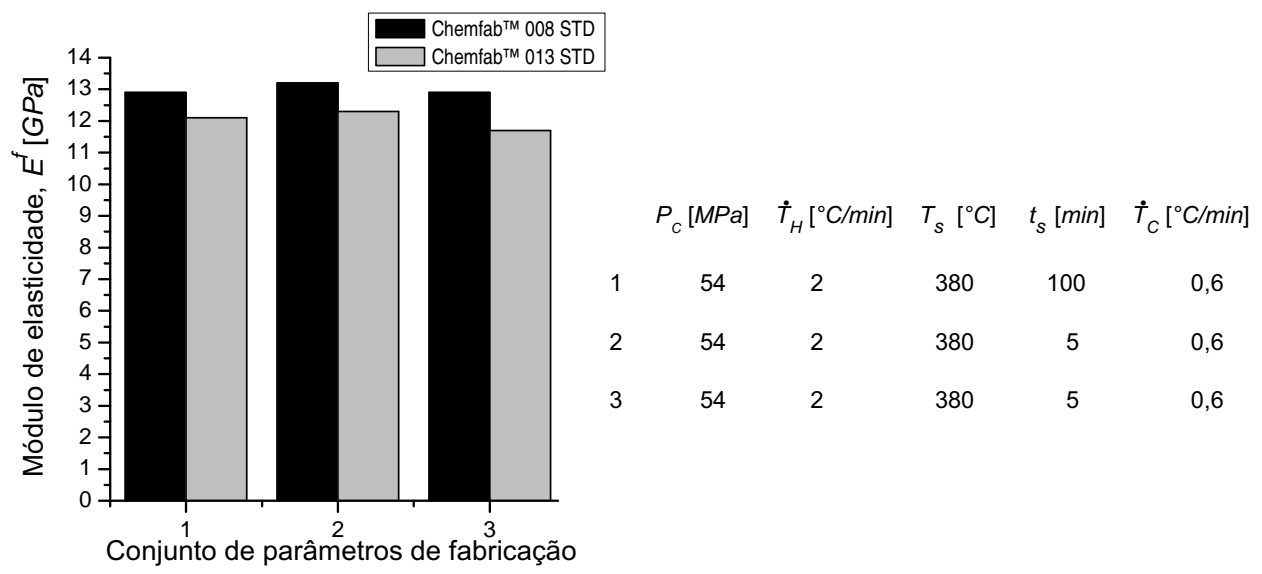

Figura 49: Comparação entre os módulos de Young à flexão para os tecidos Chemfab $^{\circledR}$ 008 e Chemfab ${ }^{\circledR}$ 013, para valores de parâmetros comuns entre os dois.

composta de elementos de $32 \times 32$ pixels $^{2}$, e resultados obtidos para um determinado estado do ensaio em relação ao estado de referência, dado pela foto inicial obtida antes do início do ensaio. Da esquerda para a direita, os resultados são: o campo de deslocamentos na direção 1 em pixels - com a desconsideração do movimento de corpo rígido calculada diretamente pelo programa -; o campo de deformações na direção 1 (longitudinal); e, o campo de deformações na direção 2 (transversal).

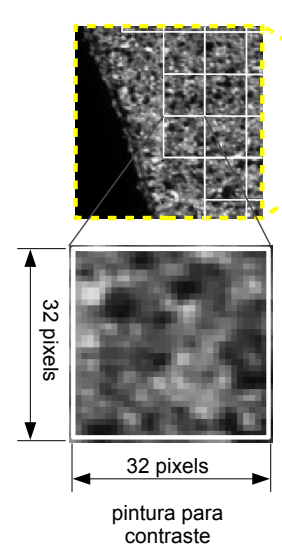

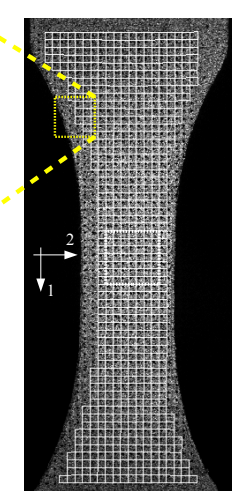

discretização da região de análise

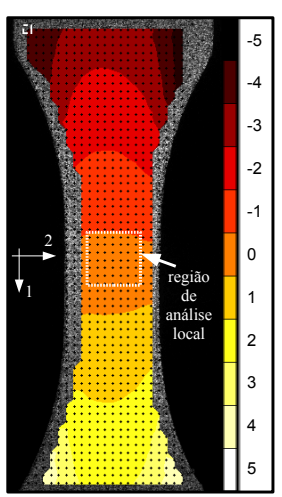

deslocamento na direção 1 [pixels]

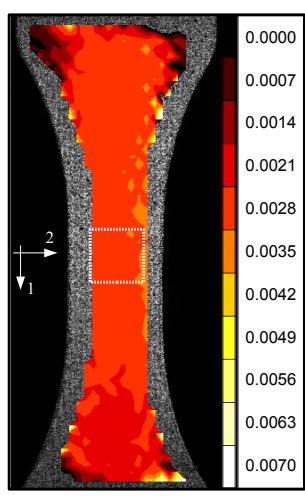

deformação na direção 1

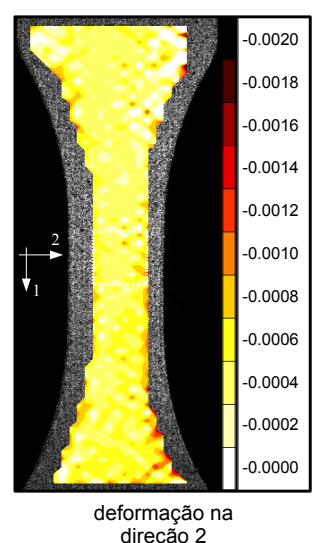

direção 2

Figura 50: Campos de deslocamentos e deformações analisados pelo programa CORRELI em CDP de tração.

Pela análise dos resultados apresentados na Figura (50), observa-se um estado homogêneo de deformações na região central do CDP onde uma região foi selecionada para análise local. Para cada fotografia obtida no ensaio, as deformações $\left(\varepsilon_{1}\right)$ e $\left(\varepsilon_{2}\right)$ foram calculadas pela média dos valores na região local de análise. Os 
gráficos da Figura 51 mostram as curvas de deformação longitudinal (esquerda) e transversal pelo tempo de ensaio; cada ponto do gráfico representa uma fotografia tirada. Para os instantes correspondentes às fotografias, calculou-se a tensão nominal $\left(\sigma_{1}\right)$ obtida pela razão entre a força de reação medida na célula de carga da máquina universal e a área da seção transversal da região central do CDP no estado de referência (inicial). Assim, as curvas da Figura (52) podem ser traçadas e exemplificam um dos ensaios realizados. O gráfico menor na figura mostra a curva referente a deformação transversal $\left(\varepsilon_{2}\right)$ pela deformação longitudinal $\left(\varepsilon_{1}\right)$.
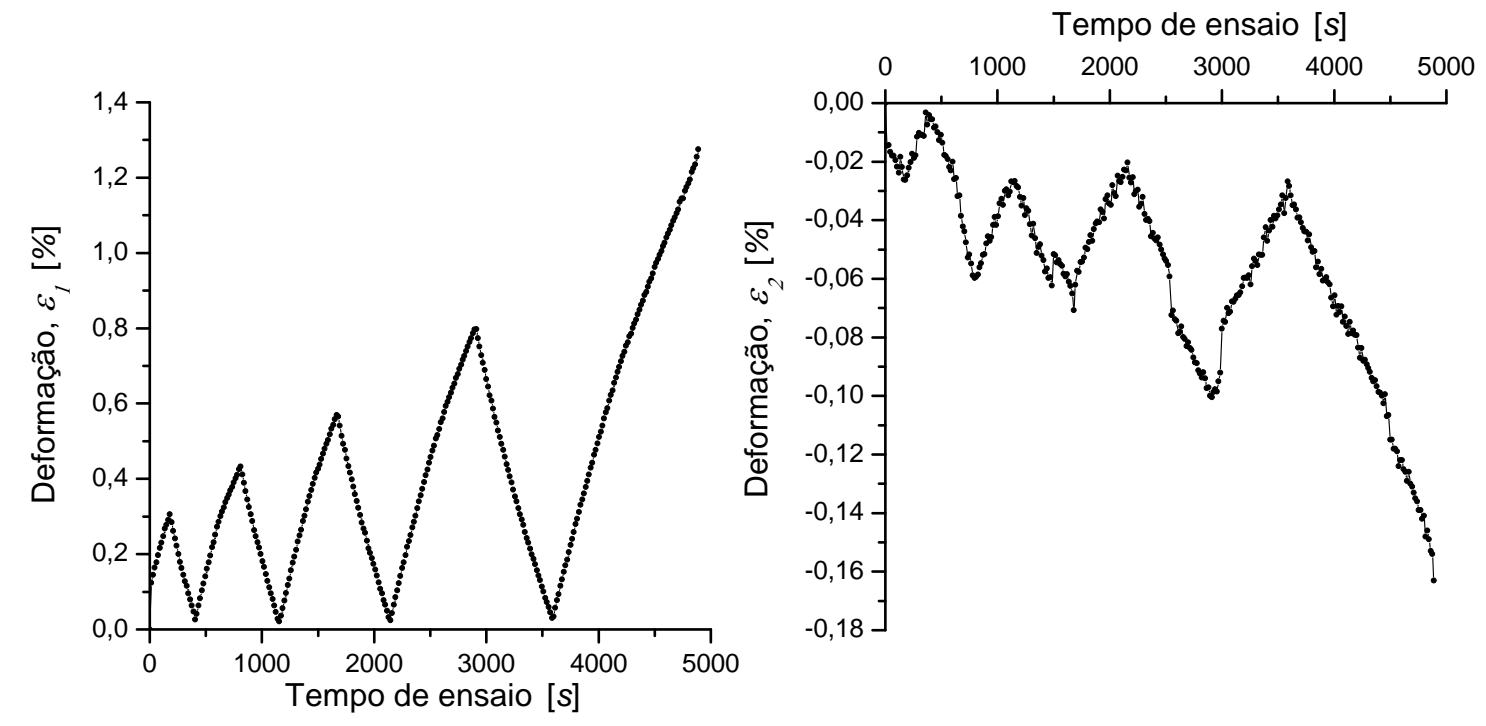

Figura 51: Curvas de deformações longitudinal (esquerda) e transversal em função do tempo para o ensaio cíclico de tração.

Para o cálculo do módulo de elasticidade foi tomada a inclinação da curva $\left(\sigma_{1}\right)$ vs. $\left(\varepsilon_{1}\right)$ no segundo descarregamento do ensaio cíclico. Para o cálculo do coeficiente de Poisson $\left(v_{12}\right)$ foi tomada a média das inclinações da curva $\left(\varepsilon_{2}\right)$ vs. $\left(\varepsilon_{1}\right)$ nos dois primeiros descarregamentos do ensaio cíclico. Os valores médios obtidos dos ensaios nos 4 CDPs são apresentados na Tabela (18).

O valor da resistência máxima à tração média, $\bar{\sigma}^{\text {max }}$, obtido dos 4 CDPs, é de quase duas vezes o valor médio obtido para a resistência máxima à flexão $\bar{\sigma}^{f(\max )}$. Esta grande diferença se deve, principalmente à diferença no mecanismo de falha que ocorre no CDP de flexão, que como discutido na 4.1.2 (página 69), se dá pela 


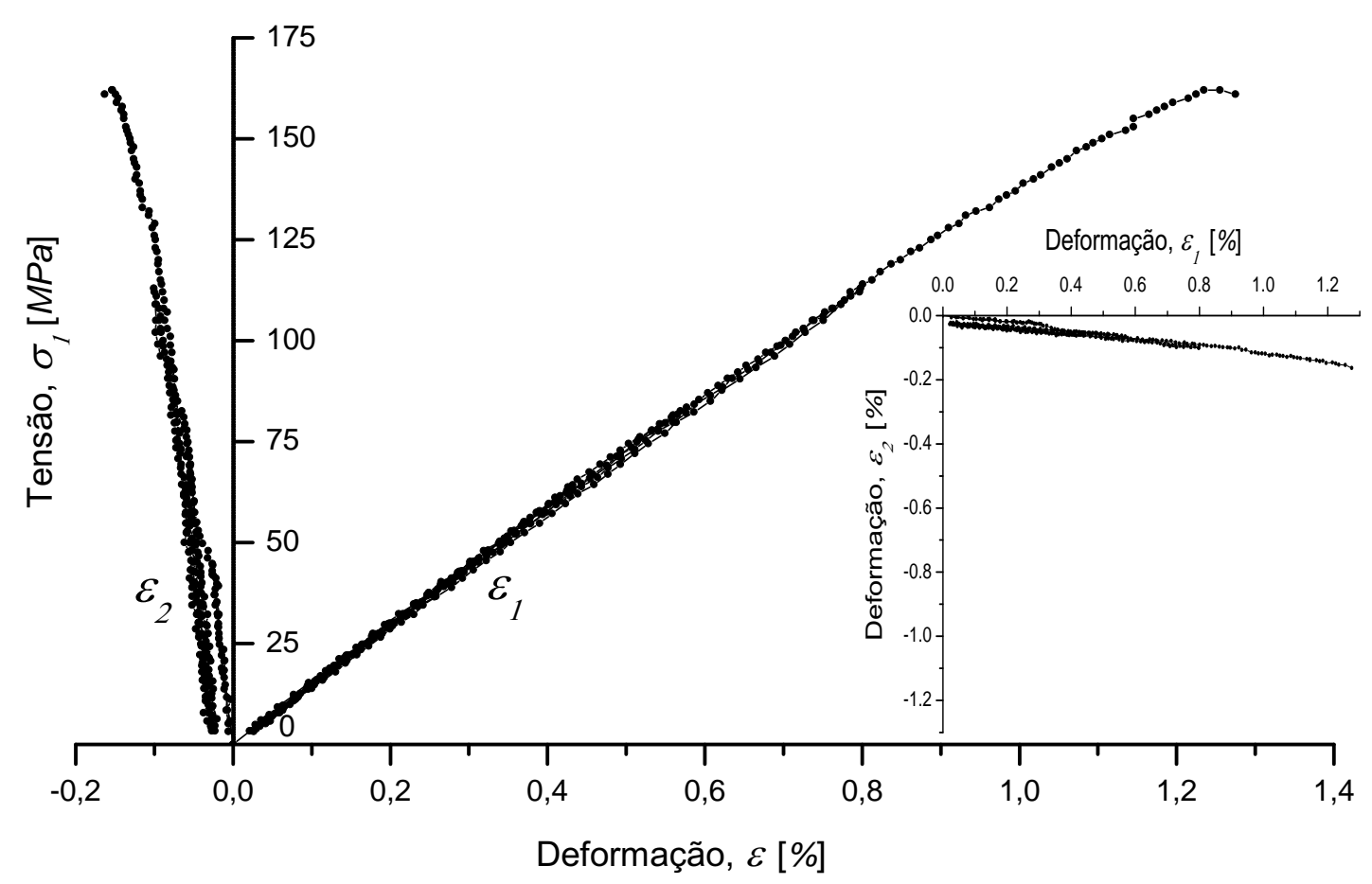

Figura 52: Tensão nominal $\left(\sigma_{1}\right)$ pelas deformações longitudinal $\left(\varepsilon_{1}\right)$ e transversal $\left(\varepsilon_{2}\right)$ num ensaio de tração cíclico

Tabela 18: Propriedades mecânicas obtidas em ensaios de tração para 4 CDPs

\begin{tabular}{c||ccc}
\hline & \multicolumn{3}{c}{ Ensaio de tração } \\
\hline \hline $\mathrm{CDPs}$ & $\bar{E}[G P a]$ & $\bar{\sigma}^{\text {max }}[M P a]$ & $\bar{v}$ \\
\hline 4 & $14,2( \pm 0,3)$ & $165( \pm 8)$ & $0,09( \pm 0,02)$ \\
\hline
\end{tabular}

baixa adesão entre fibra e matriz que gera uma instabilidade local na região sob compressão (face superior do CDP).

\subsubsection{Laminado sinterizado sob pressão}

Apesar de ter um custo operacional maior que o padrão de sinterização usado até aqui, a sinterização sob pressão pode ser uma alternativa visando a obtenção de propriedades mecânicas ainda melhores para os laminados de PTFE e fibras contínuas. 
Para testar este tipo de fabricação, foi fabricado um CDP com o tecido $\mathrm{Chemfab}^{\circledR}$ 008, segundo os valores de parâmetros da Tabela 10 (página 83). O CDP foi sinterizado sob uma pressão de $35 \mathrm{kPa}$, que segundo (EBNESAJJAD, 2000), é suficiente para a realização da soldagem do PTFE à temperatura usada $\left(380^{\circ} \mathrm{C}\right)$. Para estabelecer uma comparação, este CDP foi fabricado com o mesmo tecido e com os mesmos parâmetros de um caso anterior, sinterizado sob pressão atmosférica. A comparação é mostrada na Figura (53), sendo que não houve um aumento significativo do módulo de Young à flexão (aproximadamente 4\%), mas sim um aumento relativamente alto, 33\%, na resistência máxima à flexão.

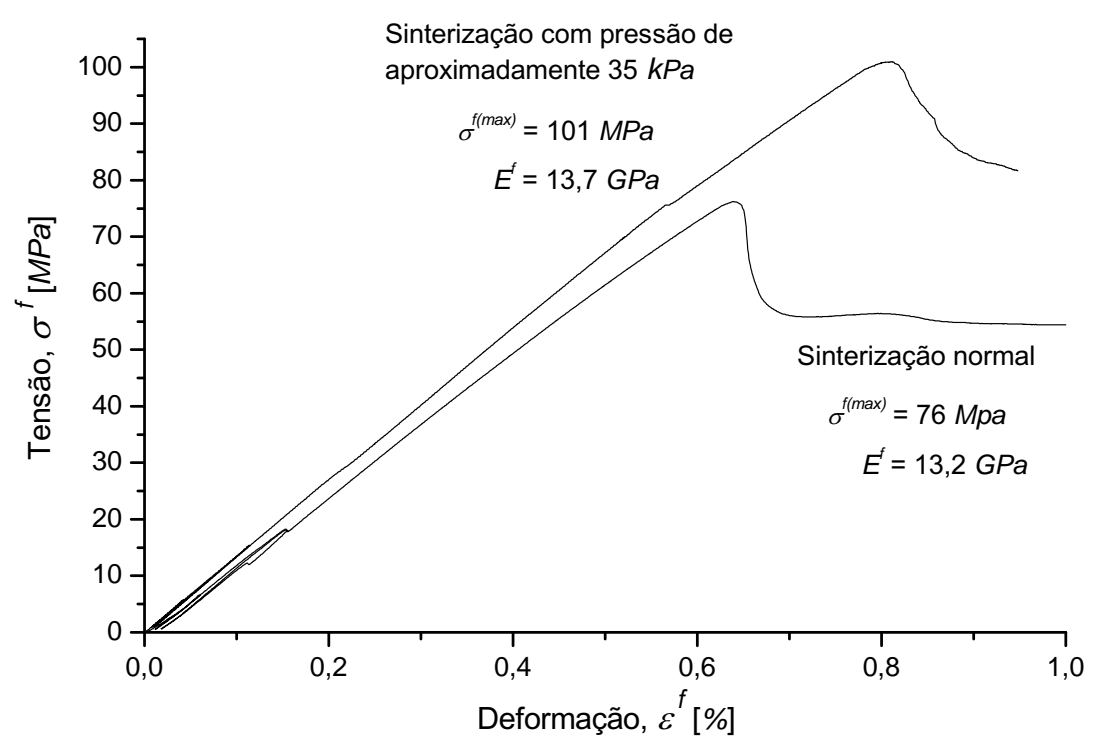

Figura 53: Curva de tensão pela deformação em ensaios de flexão 3-pontos em CDPs obtidos pelos mesmos valores de parâmetros de fabricação, com e sem aplicação de pressão durante a sinterização.

Os CDPs sinterizados sem adição de pressão sofrem, em média, um aumento no volume de aproximadamente $2 \%$. Este aumento de volume, atribuído à formação de vazios no material, não ocorreu para o CDP sinterizado sobre pressão, o que ajuda a entender o grande aumento na resistência máxima. 


\subsection{Análise por fotomicrografias de MEV}

A Figura (54) mostra a fotomicrografia de MEV da superfície de um CDP que passou por um ensaio de adesão. A foto mostra a camada de PTFE sendo arrancada do tecido de fibra de vidro. Mostra também pequenas porções de PTFE que permaneceram aderidas às fibras. O PTFE aderido à fibra é melhor visualizado na Figura (55). Em detalhe, é possível ver o PTFE envolvendo a fibra (adesão mecânica) e o PTFE que permanece colado nas fibras, indicando a presença de uma pequena adesão química (quando comparada à adesão das resinas termofixas às fibras) à fibra de vidro.

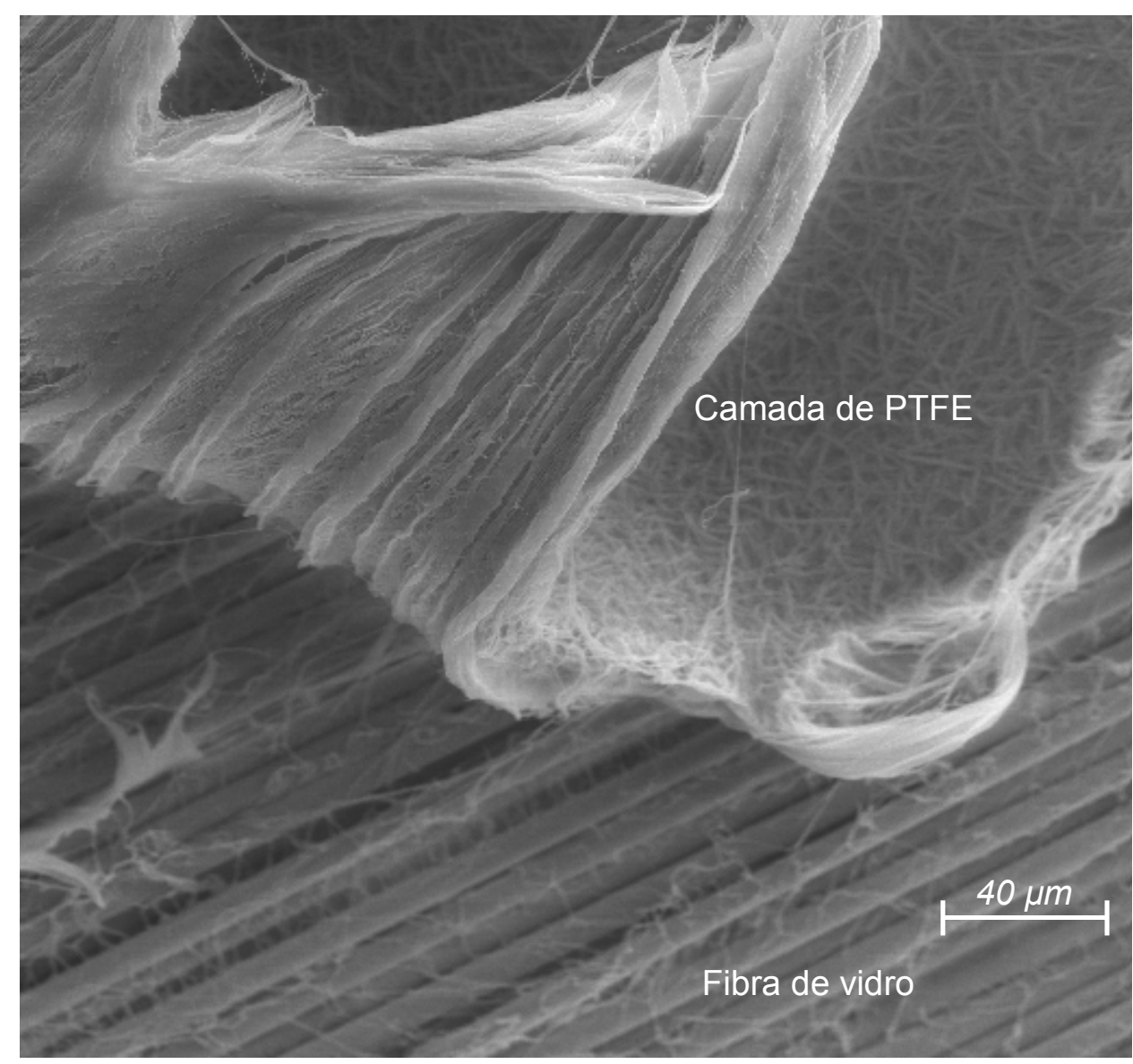

Figura 54: Fotomicrografia de MEV de CDP de adesão fabricados com o tecido Chemfab ${ }^{\circledR}$ 008: descolamento do PTFE impregnado do tecido e fibra de vidro. 

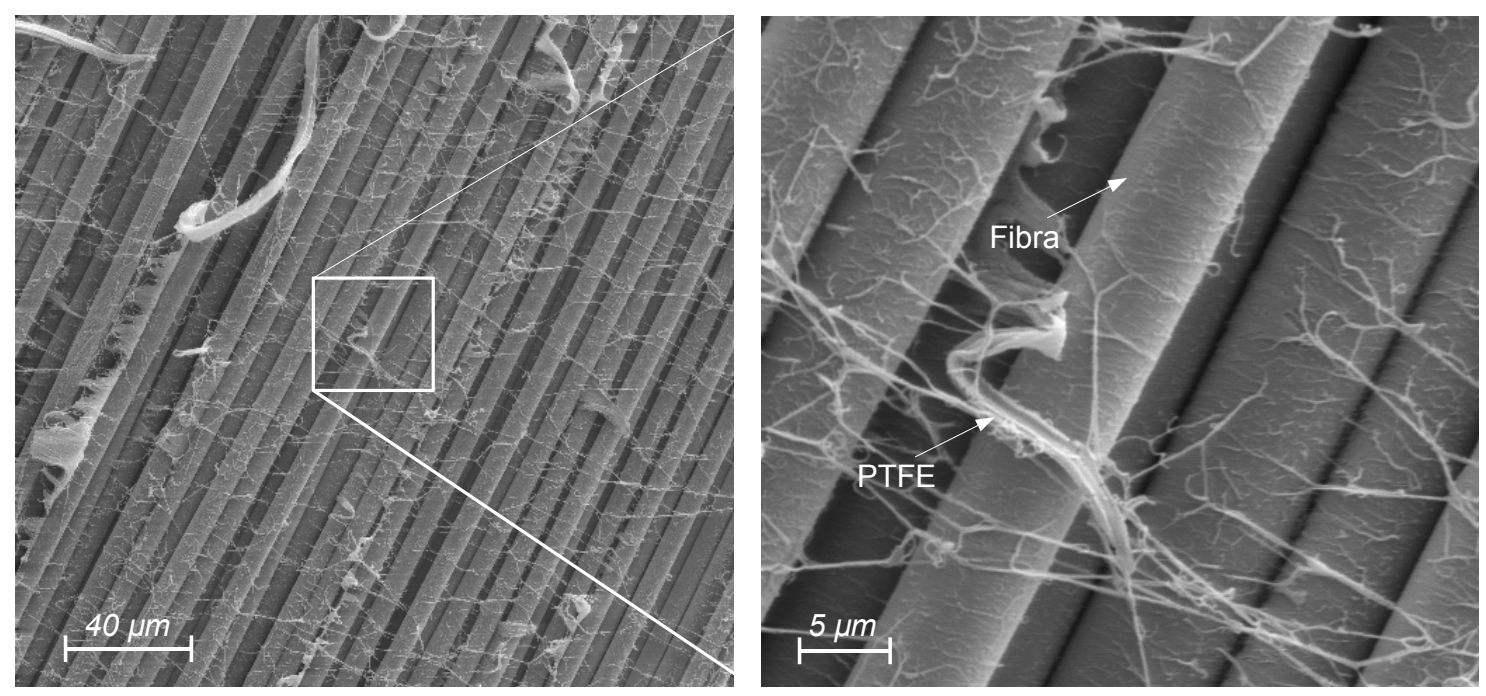

Figura 55: PTFE aderido à fibra de vidro (tecido Chemfab ${ }^{\circledR} 008$ ) após o ensaio de adesão evidenciando a adesão química do PTFE à fibra.

\subsection{Laminados de Tecido Impregnado em Laborató- rio}

O estudo com os laminados obtidos com o tecido de fibra de vidro e PTFE impregnado em laboratório é um estudo preliminar. Dada a dificuldade de executar o processo de impregnação em laboratório, essa etapa visa estudar a possibilidade de produção de laminados com tecido impregnado de PTFE a verde. Como explicado na seção 3.1 .2 (página 46), o tecido foi apenas seco, o que diferencia o processo de fabricação, já que há uma compactação do PTFE a verde no momento da conformação das lâminas

Foram confeccionados ao todo quatro CDPs, dois de cada tipo de impregnação, cujos parâmetros de fabricação estão expressos na Tabela (19). Os resultados do ensaio de Flexão 3-pontos são mostrados na Figura (56).

O primeiro CDP foi fabricado levando em conta os parâmetros da Tabela (10). Para efeito comparativo, o segundo CDP foi fabricado seguindo valores de parâmetros de fabricação mais próximos aos usados para o PTFE puro. Foi considerado que o PTFE que recobre o tecido ainda não foi sinterizado e, por isso, poderia necessitar de um tempo maior no patamar de sinterização para que haja 
Tabela 19: Parâmetros de fabricação e valores de ensaios de flexão 3-pontos dos CDPs fabricados com tecido impregnado em laboratório

\begin{tabular}{c||ccccc|c}
\hline \multicolumn{1}{c||}{} & \multicolumn{5}{c}{ Fabricação } & Propriedades \\
\hline \hline $\mathrm{CDP}$ & $P_{\mathrm{C}}[\mathrm{MPa}]$ & $\dot{\mathrm{T}}_{H}\left[{ }^{\circ} \mathrm{C} / \mathrm{min}\right]$ & $T_{s}\left[{ }^{\circ} \mathrm{C}\right]$ & $t_{s}[\mathrm{~min}]$ & $\dot{T}_{\mathrm{C}}\left[{ }^{\circ} \mathrm{C} / \mathrm{min}\right]$ & $v_{f}[\%]$ \\
\hline 1 & 54 & 2 & 380 & 5 & 0,6 & $\approx 60$ \\
2 & 54 & 2 & 375 & 100 & 0,6 & $\approx 60$ \\
3 & 54 & 2 & 375 & 100 & 0,6 & $\approx 43$ \\
4 & 54 & 2 & 375 & 100 & 0,6 & $\approx 36$ \\
\hline
\end{tabular}

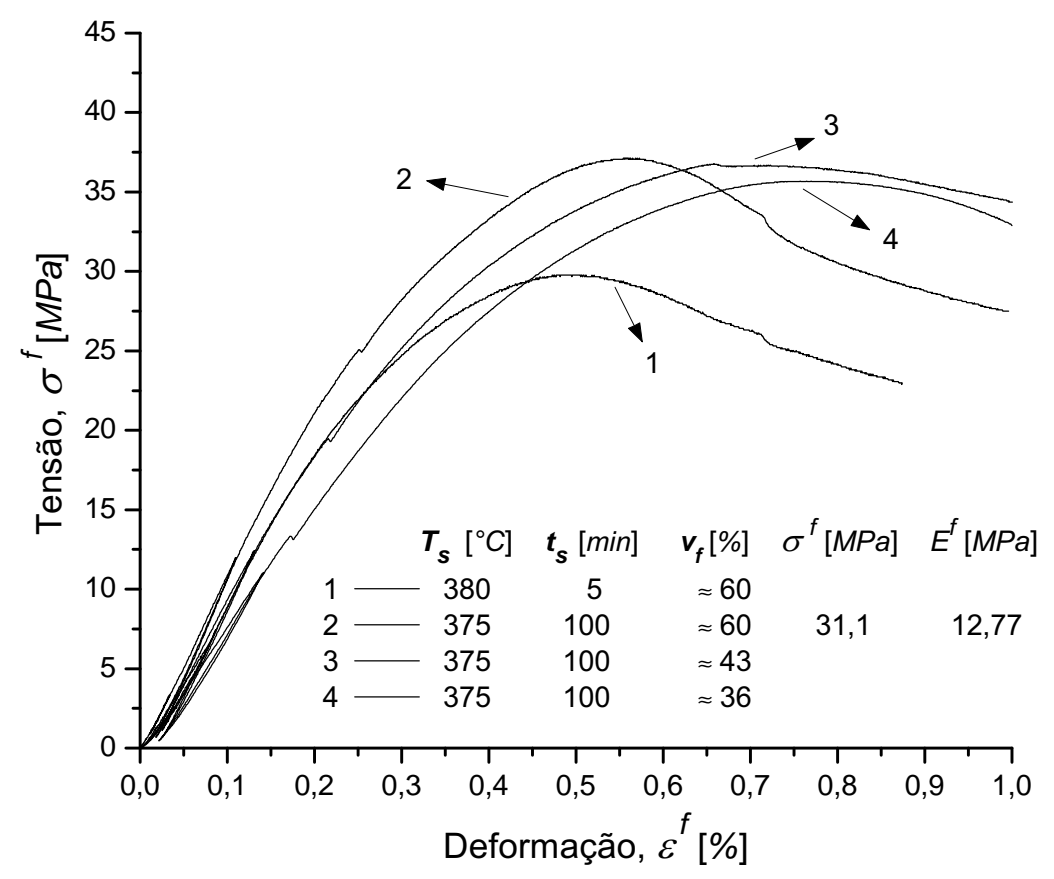

Figura 56: Curva de tensão pela deformação em ensaios de flexão 3-pontos em CDPs feitos com tecido impregnado em laboratório.

a coalescência do material.

Os resultados mostraram que realmente houve uma melhora nas propriedades mecânicas para o segundo CDP (com tempo de patamar maior). Por este motivo, os outros dois CDPs foram feitos com os tecidos obtidos da segunda seção de impregnação. Dentre os resultados obtidos, pode-se dizer que houve uma sensível melhora das propriedades mecânicas do material com o aumento da fra- 
ção mássica de fibra.

Apesar do módulo de elasticidade ter alcançado um valor próximo aos dos tecidos comerciais - 12,77 GPa-, o mesmo não ocorreu com a resistência máxima, que foi de apenas de 37,1 $\mathrm{MPa}$ (menos da metade do melhor valor obtido para os tecidos comerciais).

São poucos os resultados para poder se tirar maiores conclusões desta etapa do trabalho. No entanto, este estudo indica a possibilidade de se fabricar um tecido voltado para a fabricação de laminados, diferentemente dos tecidos comerciais usados neste trabalho, podendo-se, por exemplo, reduzir o tempo que o material fica exposto a altas temperaturas. 


\section{Conclusões}

O presente trabalho mostrou a viabilidade na fabricação de compósitos estruturais de PTFE com fibras de vidro contínuas a partir de tecidos impregnados sinterizados. Pelo processo de fabricação adotado foram obtidos valores expressivos de rigidez e de resistência mecânica para o compósito - módulo de elasticidade de elasticidade de aproximadamente 14,2 GPa e resistência máxima de aproximadamente $165 \mathrm{MPa}$-, frente ao PTFE puro. Os valores das propriedades mecânicas citadas são da mesma ordem de grandeza, ou de ordem superior, aos de polímeros estruturais de engenharia sem reforços. Como as camadas de PTFE mais externas dos laminados podem ter espessura controlada, pode-se garantir que algumas importantes características deste polímero - tais como: resistência à corrosão e propriedades tribológicas - possam ser aproveitadas normalmente num projeto de um produto estrutural.

O estudo referente a influência dos parâmetros de fabricação (prensagem e sinterização) nas propriedades mecânicas do laminado mostrou a necessidade de encontrar um processamento específico para este material, com valores de parâmetros de fabricação distintos dos geralmente usados pela indústria na fabricação de componentes de PTFE puro. Ficou evidenciada que as propriedades mecânicas finais são influenciadas por um mecanismo de degradação do laminado, que é dependente diretamente da temperatura e do tempo de sinterização. A avaliação do laminado por ensaio de flexão 3-pontos indicou como principal mecanismo de falha o descolamento das lâminas superiores ocasionado pela flambagem destas 
quando sujeitas à compressão, indicando uma fraca adesão interlaminar, que é diretamente relacionada à degradação da interface fibra-matriz constatada. Neste sentido, o estudo da variação dos parâmetros de fabricação levaram a valores de processo que degradassem pouco o material e pelos quais se obteve um aumento ainda maior de rigidez e resistência mecânica, sem que houvesse um aumento do custo operacional de fabricação.

A constatação da baixa adesão fibra-matriz levou a estudos dirigidos à adesão interlaminar. Ensaios de adesão fibra-matriz reforçaram a ideia da ocorrência da degradação desta interface, além de mostrar uma correspondência com ensaios de flexão 3-pontos realizados com mesmos valores de parâmetros o que comprovou a baixa adesão como principal mecanismo de falha. Fotomicrografias de MEV após o ensaio de adesão fibra-matriz evidenciaram a fraca interação química entre PTFE e fibra de vidro.

Por meio de uma investigação separada do tempo e temperatura na análise da degradação do laminado, pode-se concluir que: fica evidenciada a relação entre a perda de resistência em função do tempo de permanência sob uma temperatura acima de uma temperatura crítica, e que a metodologia utilizada (Figuras 31 e 33) pode ser eficaz para a determinação desta temperatura; porém, uma quantidade maior de ensaios deve ser realizada caso se necessite identificar com maior precisão esta temperatura crítica.

Os estudos feitos com laminados fabricados com tecido Chemfab ${ }^{\circledR} 008$ mostraram diferenças de respostas mecânicas quando comparados aos laminados fabricados com tecido Chemfab ${ }^{\circledR} 013$, indicando vantagens dos tecidos com trama mais espaçadas na fabricação de laminados de PTFE e fibra de vidro contínuas. É possível inferir que a trama mais espaçada do tecido de fibra de vidro auxilia na adesão interlaminar, graças ao maior envolvimento dos feixes de fibra pela matriz. O ganho de propriedades mecânicas dos laminados mostra que a adesão mecânica, somada a adesão química (mesmo esta sendo baixa), torna possível a 
utilização deste material como material estrutural - com melhores desempenhos a esforços de tração.

Os estudos preliminares de sinterização sob pressão e desenvolvimento de tecido impregnado com PTFE a verde para a fabricação de compósitos mostram formas alternativas de fabricação que podem ser mais profundamente estudas. A pressão usada durante a sinterização faz com que seja diminuída a porosidade do material, além de poder forçar um preenchimento dos eventuais vazios ocasionados pela queima dos aditivos orgânicos durante a sinterização dos laminados. Os tecidos impregnados com PTFE a verde teriam que trazer aumentos ainda maiores das propriedades mecânicas para que se pudesse justificar seu uso, já que proporciona uma dificuldade maior de manipulação, transporte e acondicionamento, comparado ao tecido sinterizado.

Os tecidos comerciais aqui utilizados são produtos finais desenvolvidos para serem usados para outros fins que não o proposto para este trabalho, no entanto se adequaram muito bem à fabricação dos laminados. O tecido é de fácil manuseio e os laminados fabricados apresentaram um desempenho superior ao esperado.

Como sugestões para trabalhos futuros pode-se citar:

- Estudo de impregnação com diferentes frações volumétricas de fibras, além de diferentes tratamentos térmicos, gerando um tecido com potencialidade ainda maior para a fabricação de laminados. Para tanto, uma associação com uma empresa do ramo de fabricação destes tecidos seria fundamental;

- Aplicações do laminado em peças estruturais. Um exemplo poderia ser a fabricação de válvulas para a indústria química, que poderiam substituir válvulas feitas de metal com revestimento de PTFE;

- Estudo mais aprofundado da ensimagem e de técnicas que melhorem a ade- 
são química entre fibra e matriz, visando melhorar ainda mais as propriedades mecânicas dos laminados. 



\section{Referências}

ASTM D3167 - 03a. Standard Test Method for Floating Roller Peel Resistance of Adhesives. 2004. West Conshohocken.

ASTM D790 - 2. Standard test methods for flexural properties of unreinforced and reinforced plastics and electrical insulating materials. 2007. Annual Book of ASTM Standards, West Conshohocken, PA.

BIRCH, J.; NICOL, E.; STREET, R. New near-millimeter wavelength radome material. Applied Optics, OSA, v. 22, n. 19, p. 2947-2949, 1983.

BONNET, J.-F. Polymères Fluorés. [S.1.]: Techniques de l'Ingénieur, 2004.

BRIAN, S. M. An Introduction to Materials Engineering and Science for Chemical and Materials Engineers. [S.1.]: A John Wiley \& Sons, inc., 2004. 107 p.

BROWN, E. N.; DATTELBAUM, D. M. The role of crystalline phase on fracture and microstructure evolution of polytetrafluoroethylene (ptfe). Polymer, v. 46, n. 9 , p. $3056-3068,2005$. ISSN 0032-3861.

CALLISTER, W. D. Fundamentals of Materials Science and Engeneering: An Integrate Approach. 2. ed. [S.1.]: John Wiley \& Sons, Inc., 2005. 702 p.

CANEVAROLO, S. Ciência dos polimeros: um texto básico para tecnólogos e engenheiros. [S.1.]: Artliber, 2002.

CANTO, R. et al. Experimental analysis to identify the deformation mechanisms during sintering of cold compacted polytetrafluoroethylene (ptfe) powders. 2009. A ser publicado em Polymer Engineering and Science.

CANTO, R. B. Estudo teórico e experimental dos processos de compactação e sinterização do politetrafluoretileno (PTFE). Tese (Doutorado) - Universidade de São Paulo Brasil/École Normale Supérieure de Cachan - França, 2007.

CHENG, X.; XUE, Y.; XIE, C. Friction and wear of rare-earth modified glass-fiber filled PTFE composites in dry reciprocating sliding motion with impact loads. Wear, Elsevier, v. 253, n. 7-8, p. 869-877, 2002.

COOMBS, C. Printed circuits handbook. [S.1.]: McGraw-Hill Professional, 2007.

EBNESAJJAD, S. Fluoroplastics, volume 1-Non-Melt Processible Fluoroplastics: The Definitive User's Guide and Databook. [S.1.]: Plastics Design Library, 2000. 360 p.

EBY, R. et al. Crystal Structure of Poly (Tetrafluoroethylene) Homo- and Copolymers in the High Pressure Phase. Polymer, v. 31, n. 12, p. 2227-2237, 1990. 
FRIEDRICH, K.; REINICKE, R.; ZHANG, Z. Wear of polymer composites. Proceedings of the Institution of Mechanical Engineers, Part J: Journal of Engineering Tribology, Prof Eng Publishing, v. 216, n. 6, p. 415-426, 2002.

GANGAL, S. V. Encyclopedia of Polymer Science and Technology: Perfluorinated Polymers, Polytetrafluoroethylene. [S.1.]: John Wiley \& Sons, Inc., 2001. 378-402 p.

GAY, D. Composite Materials: Design and Applications. [S.1.]: CRC Press, 2003.

GU, A.; LIANG, G. New approach to fabricate densificated continuous fiber reinforced polytetrafluoroethylene composites with significantly improved interfacial bonding and mechanical properties. Journal of Applied Polymer Science, v. 104, n. 6, p. 3588-3591, 2007.

GU, A.; LIANG, G.; YUAN, L. Novel preparation of glass fiber reinforced polytetrafluoroethylene composites for application as structural materials. Polymers for Advanced Technologies, John Wiley \& Sons, Ltd. Chichester, UK, v. 20, n. 1, 2009.

HARPER, C. Modern Plastics Handbook. [S.1.]: McGraw-Hill Professional, 2000.

HOUGHAM, G. et al. Fluoropolymers 2: Properties. [S.1.]: Kluwer Acdemic Publishers, New York, 2002. 427 p.

HYER, M. W.; WHITE, S. Stress Analysis of Fiber-reinforced Composite Materials. [S.l.]: WCB McGraw-Hill, 1998.

JAHIER, D. Le PTFE (polytétrafluoroéthylène): présentation et applications. [S.1.]: Publications CETIM, 1992. 102 p.

JAWITZ, M. Printed Circuit Board Materials Handbook. [S.1.]: McGraw-Hill, 1997.

JAWITZ, M.; JAWITZ, M. Materials for rigid and flexible printed wiring boards. [S.1.]: CRC Press, 2006.

KERBOW, D. Poly (tetrafluoroethylene). Polymeric Materials Encyclopedia', JC Salamone, Ed., CRC Press, Boca Raton, p. 6884, 1996.

KUTZ, M. Handbook of materials selection. [S.1.]: Wiley, 2002.

LAURA, D. et al. Effect of glass fiber surface chemistry on the mechanical properties of glass fiber reinforced, rubber-toughened nylon 6. Polymer, Elsevier, v. 43, n. 17, p. 4673-4687, 2002.

LEVY, F.; PARDINI, L. C. Compósitos Estruturais: Ciência e Tecnologia. [S.l.]: Editora Blücher, 2006.

MAZUMDAR, S. Composites Manufacturing: Materials, Product, and Process Engineering. [S.1.]: CRC Press, 2002.

MCCRUM, N. An internal friction study of polytetrafluoroethylene. Journal of Polymer Science, Interscience Publishers, Inc. New York, v. 34, n. 127, 1959. 
MENDONÇA, P. T. Materiais Compostos E Estruturas-Sanduíche. [S.1.]: Manole. Brasil, 2005.

OSHIMA, A.; UDAGAWA, A.; MORITA, Y. Application of radiation-crosslinked polytetrafluoroethylene to fiber-reinforced composite materials. Radiation Physics and Chemistry, Elsevier, v. 60, n. 4-5, p. 467-471, 2001.

OSHIMA, A.; UDAGAWA, A.; MORITA, Y. Radiation processing for carbon fiber-reinforced polytetrafluoroethylene composite materials. Radiation Physics and Chemistry, Elsevier, v. 60, n. 1-2, p. 95-100, 2001.

OSHIMA, A.; UDAGAWA, A.; TANAKA, S. Fabrication of polytetrafluoroethylene/carbon fiber composites using radiation crosslinking. Radiation Physics and Chemistry, Elsevier, v. 62, n. 1, p. 77-81, 2001.

PENGGANG, R.; GUOZHENG, L.; ZENGPING, Z. Study on Glass Fabric Reinforced Polytetrafluoroethylene Composites Infused with Melted Cyanate Ester Resin. Journal of Reinforced Plastics and Composites, 2008.

PIGGOT, M. R. Load Bearing Fibre Composites. [S.1.]: Kluwer Academic Publishes, 2002. $496 \mathrm{p}$.

PLUEDDEMANN, E. Reminiscing on silane coupling agents. Journal of Adhesion Science and Technology, VSP, an imprint of Brill, v. 5, n. 4, p. 261-277, 1991.

QIAN-QIAN, S.; XIAN-HUA, C. On the friction and wear behavior of PTFE composite filled with rare earths treated carbon fibers under oil-lubricated condition. Wear, Elsevier, v. 260, n. 11-12, p. 1243-1247, 2006.

ROESLER, J.; HARDERS, H.; BäKER, M. Mechanical Behaviour of Engineering Materials: Metals, Ceramics, Polymers, and Composites. [S.1.]: Springer, 2007. 534 p.

SHAEFFER, R. Tensioned fabric structures: a practical introduction. In: AMERICAN SOCIETY OF CIVIL ENGINEERS. [S.1.], 1996.

SHI, Y. et al. Tribological and mechanical properties of carbon-nanofiber-filled polytetrafluoroethylene composites. Journal of Applied Polymer Science, v. 104, n. 4, p. 2430-2437, 2007.

TERVOORT, T. A.; VISJAGER, J. F.; SMITH, P. Melt-processable poly(tetrafluoroethylene)-compounding, fillers and dyes. Journal of Fluorine Chemistry, v. 114, n. 2, p. 133 - 137, 2002. ISSN 0022-1139.

THIERAUF, S. High-speed circuit board signal integrity. [S.1.]: Artech House Publishers, 2004.

TSAI, S. W. Theory of composites design. Think Composites. [S.1.]: Palo Alto, 1992.

VICK, L.; KANDER, R. Ambient temperature compaction of polycarbonate powder. Polymer Engineering $\mathcal{E}$ Science, Wiley Subscription Services, Inc., A Wiley Company Hoboken, v. 37, n. 1, 1997.

VINSON, J. R.; SIERAKOWSKI, R. L. The Behavior of Structures Composed of Composite Materials. [S.1.]: Springer, 2002. 323 p. 
WILLIAM, D.; CALLISTER, J. Materials science and engineering: an introduction. [S.1.]: John Wiley \& Sons, 2000.

WU, J. J.; BUCKLEY, C. P.; O'CONNOR, J. J. Mechanical integrity of compressionmoulded ultra-high molecular weight polyethylene: effects of varying process conditions. Biomaterials, v. 23, n. 17, p. 3773 - 3783, 2002. ISSN 0142-9612.

XUE, Y.; CHENG, X. Effect of rare earth elements' surface treatment on tensile properties and microstructure of glass fiber-reinforced polytetrafluoroethylene composites. Journal of Applied Polymer Science, Wiley Subscription Services, Inc., A Wiley Company New York, v. 86, n. 7, 2002. 


\section{APÊNDICE A - Molde de Prensagem}

Molde de prensagem fabricado para a fabricação dos laminados do trabalho.

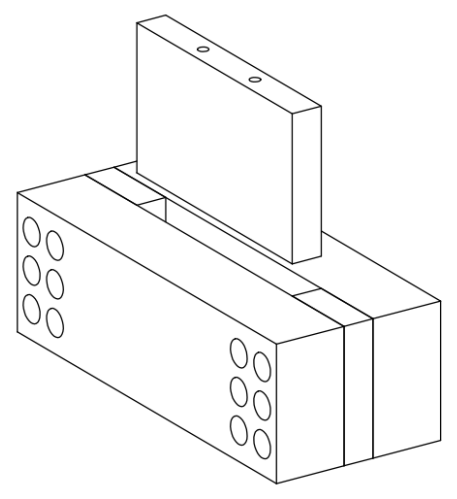

Matriz montada

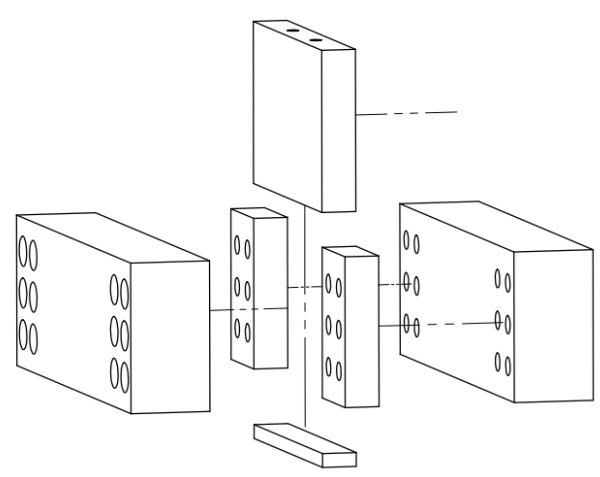

Vista explodida

Figura 57: Vistas do projeto do molde de prensagem.

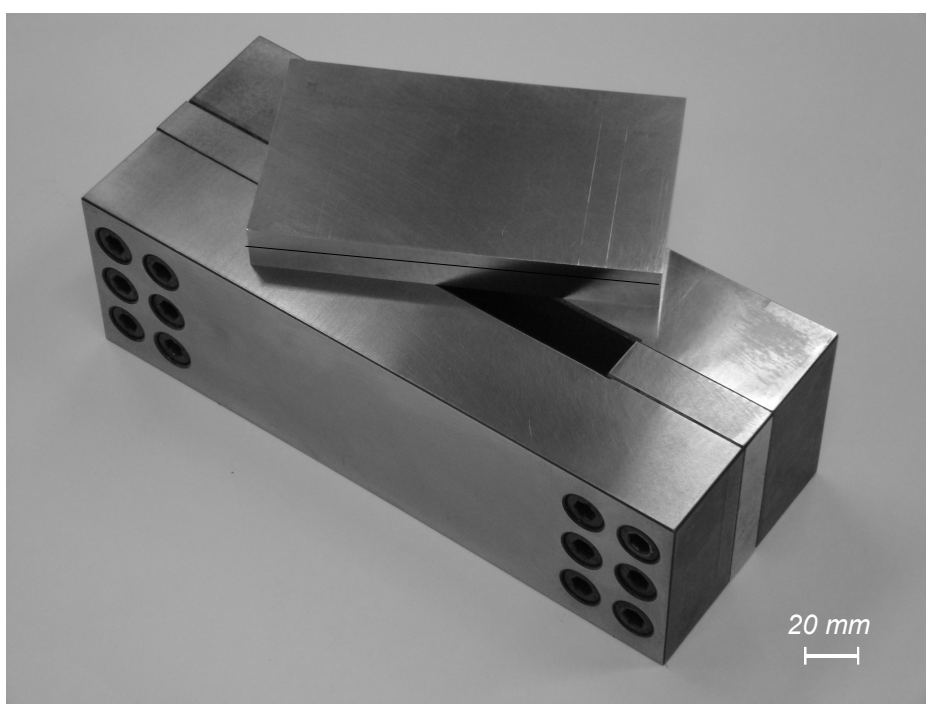

Figura 58: Foto do molde de prensagem utilizado na fabricação dos Laminados. 


\section{APÊNDICE B - Dispositivo para o Ensaio de Adesão: Projeto e Montagem}

Projeto do dispositivo fabricado para o ensaio de adesão baseado na norma (ASTM D3167 - 03a, 2004). Todas as cotas das figuras são dadas em milímetros. O dispositivo é confeccionado em aço inox e permite, por meio de mancais de rolamento, o movimento giratório dos roletes e o movimento de balanço da peça em torno do eixo superior que é preso à máquina de ensaios.
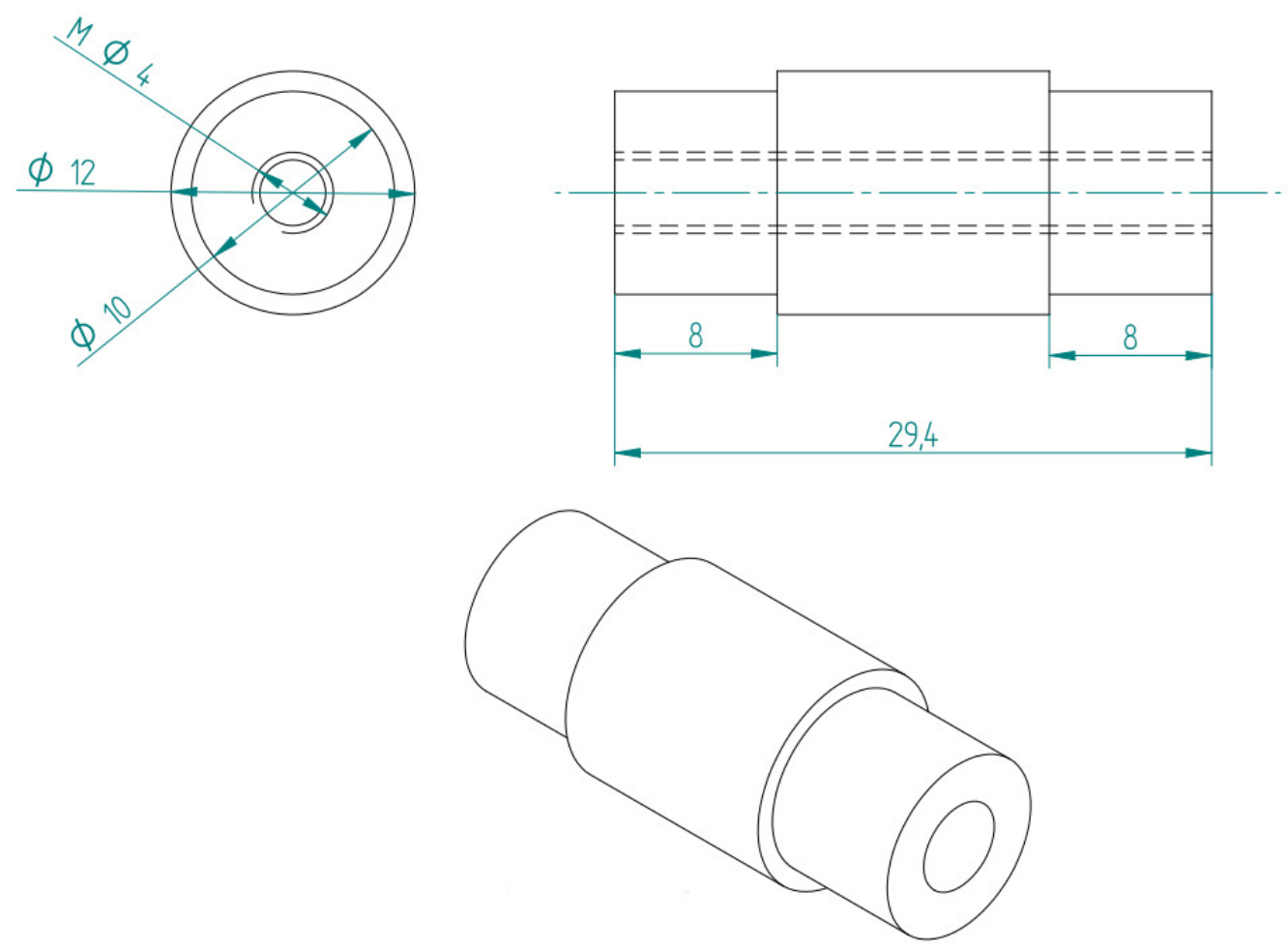

Figura 59: Pino para apoio dos roletes com encaixe para rolamentos. 


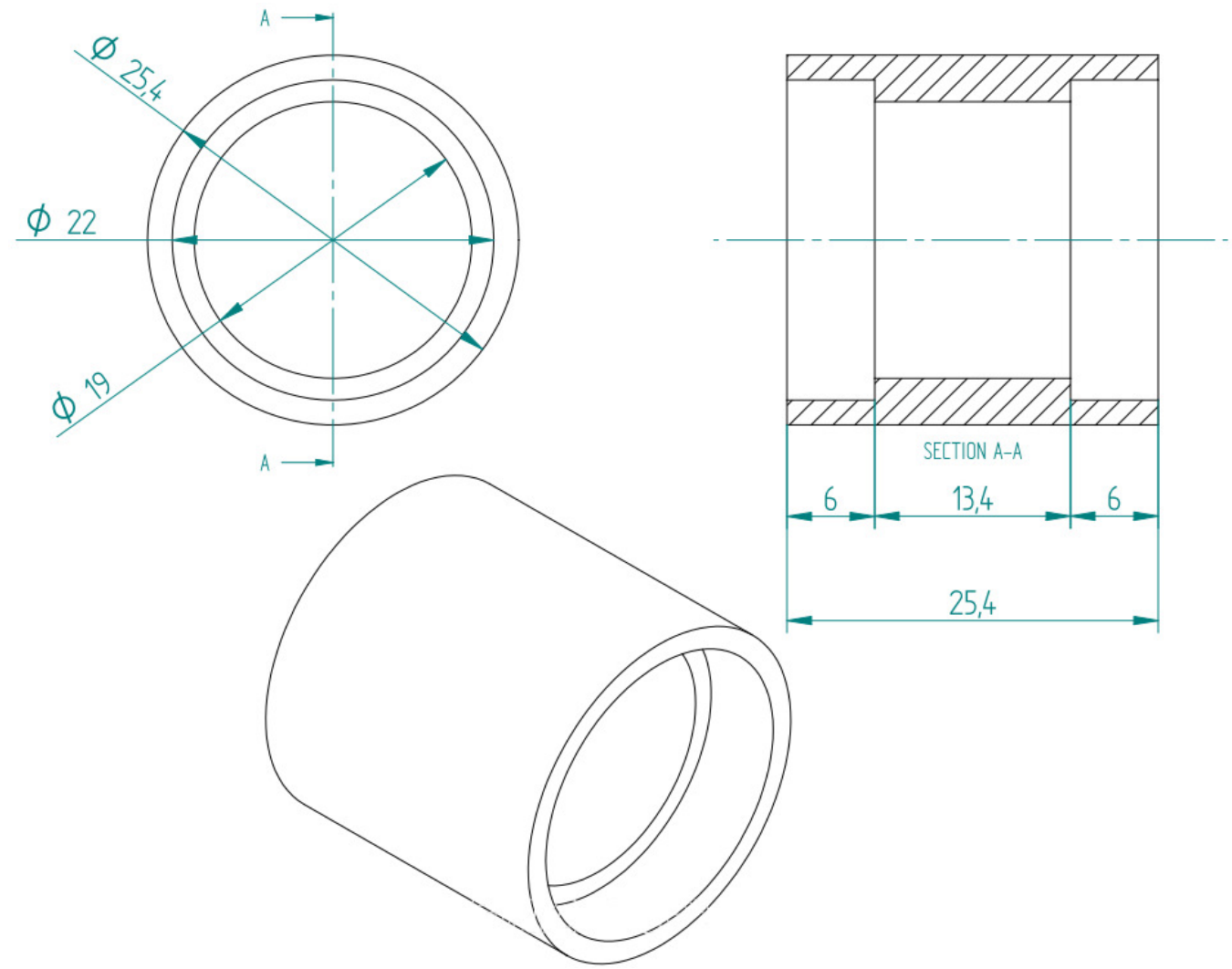

Figura 60: Roletes de apoio para o CDP de adesão.
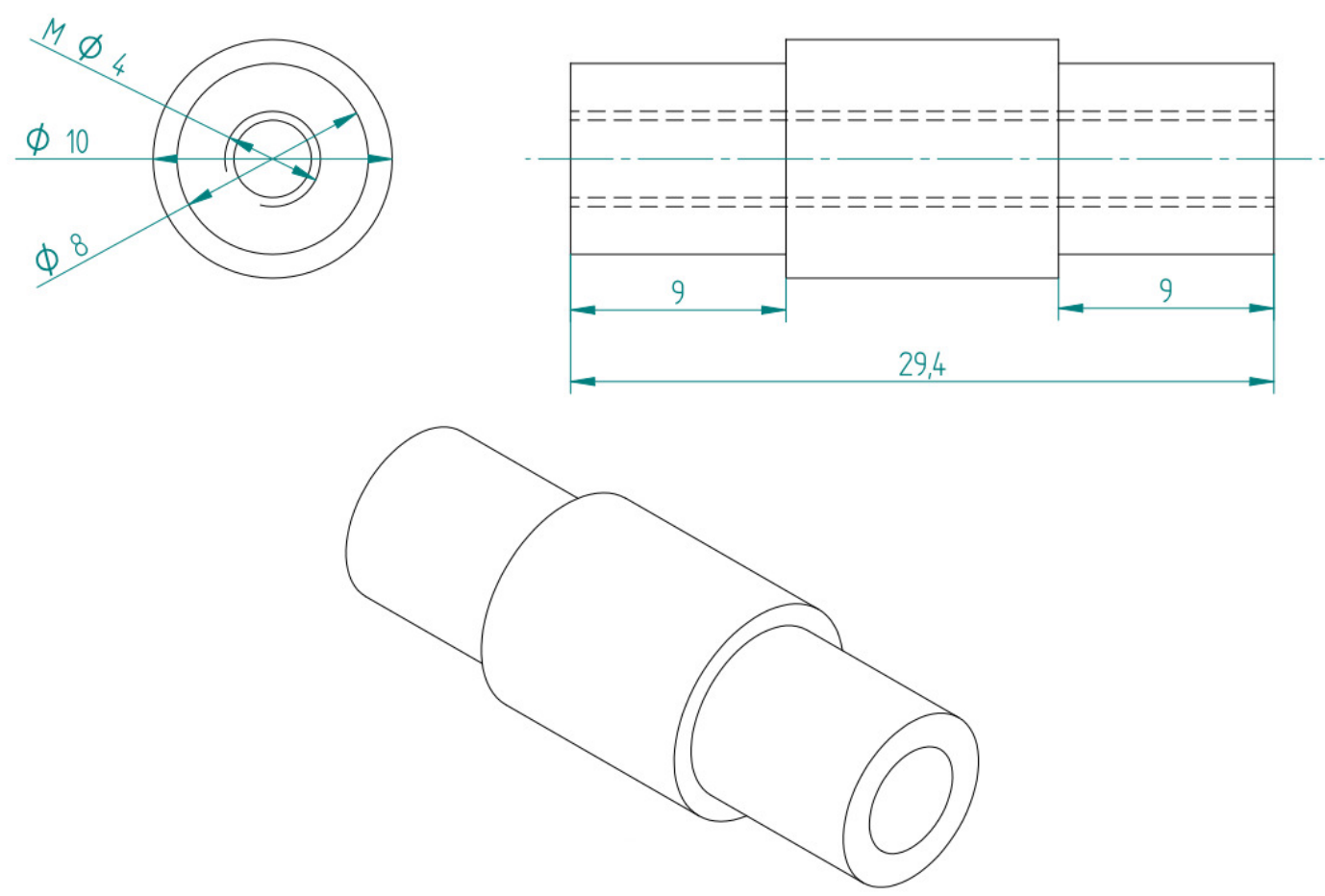

Figura 61: Pino para apoio superior com encaixe para rolamentos. 

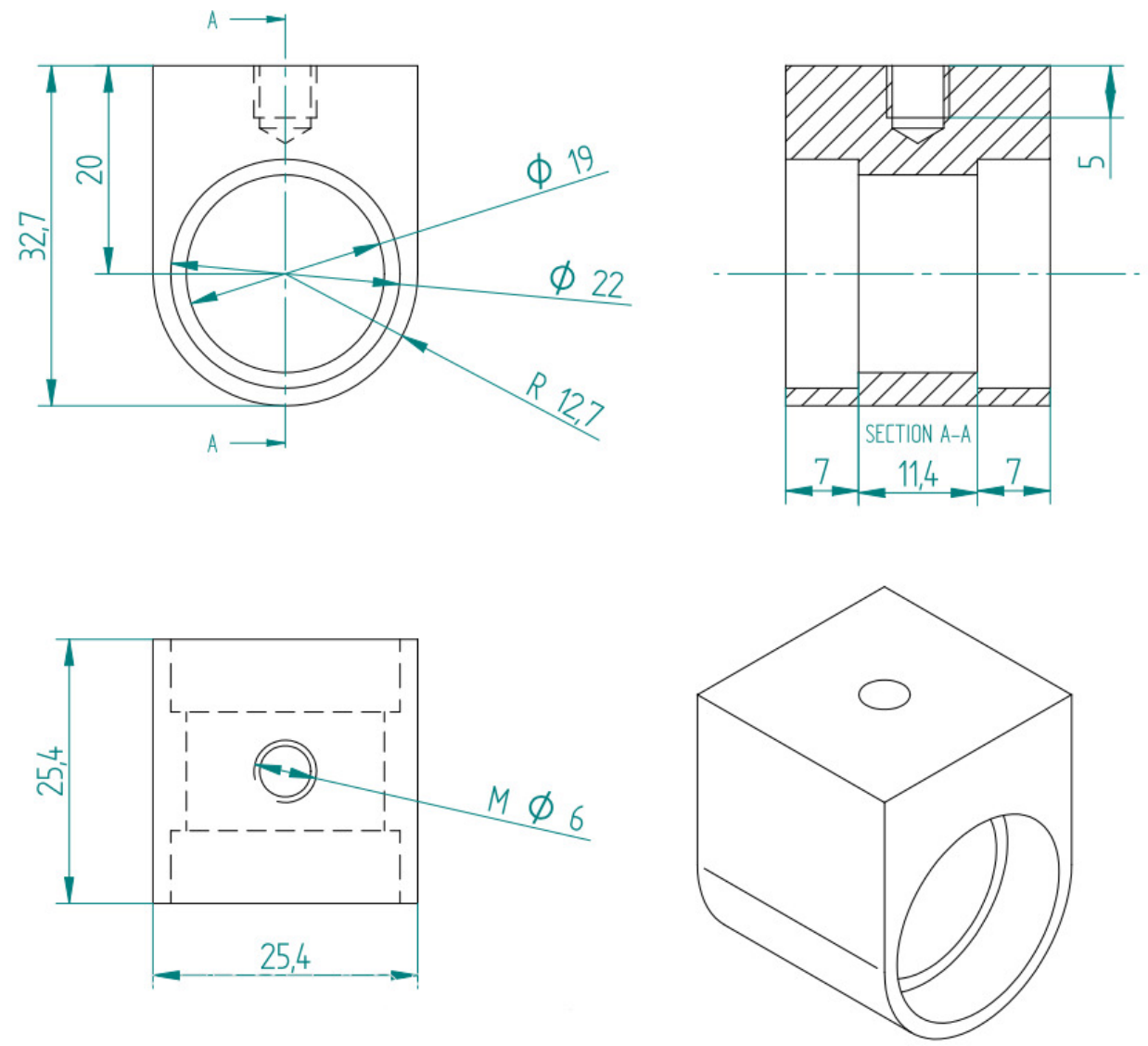

Figura 62: Apoio superior de encaixe na máquina de ensaios.
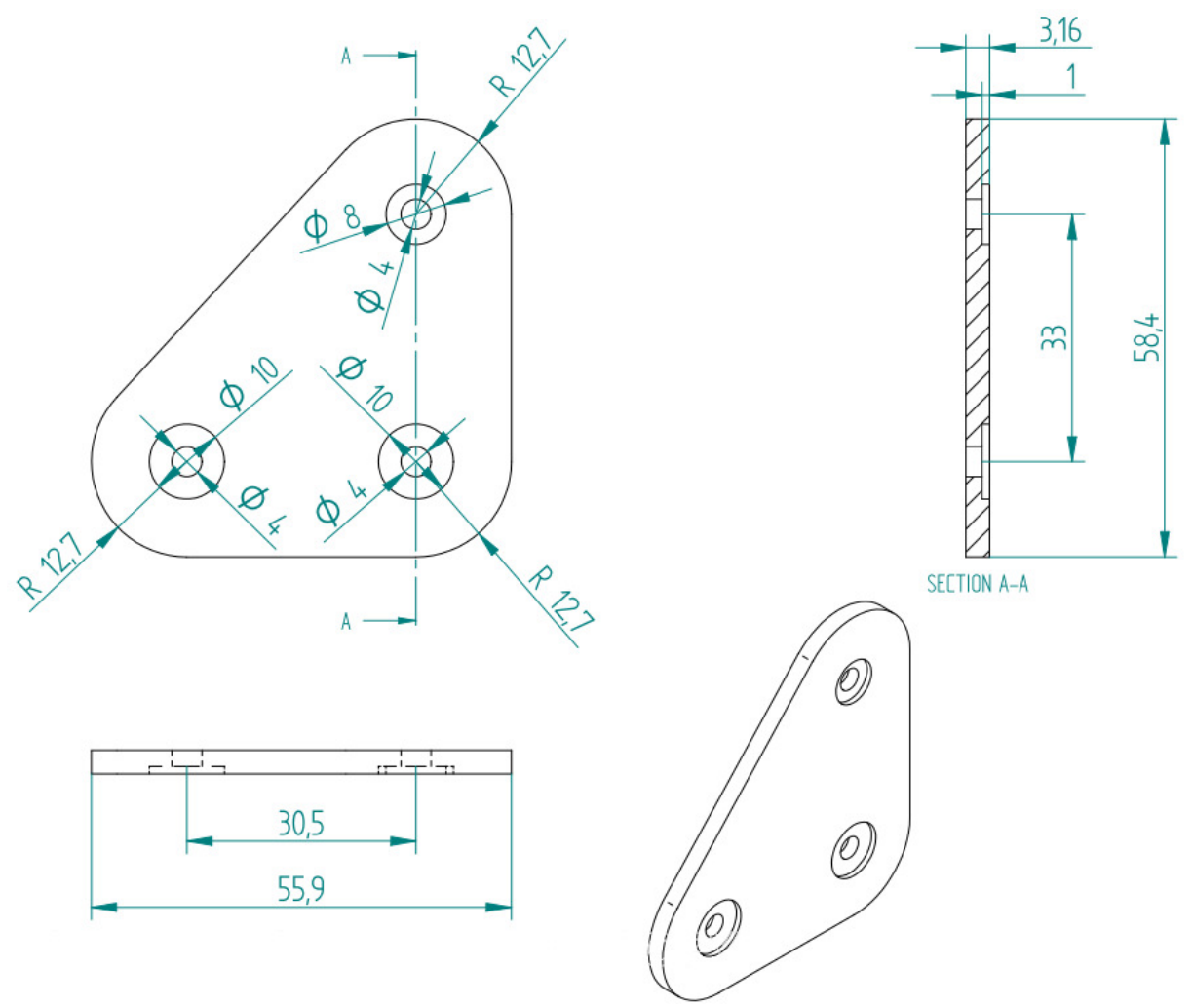

Figura 63: Lateral do dispositivo de adesão. 

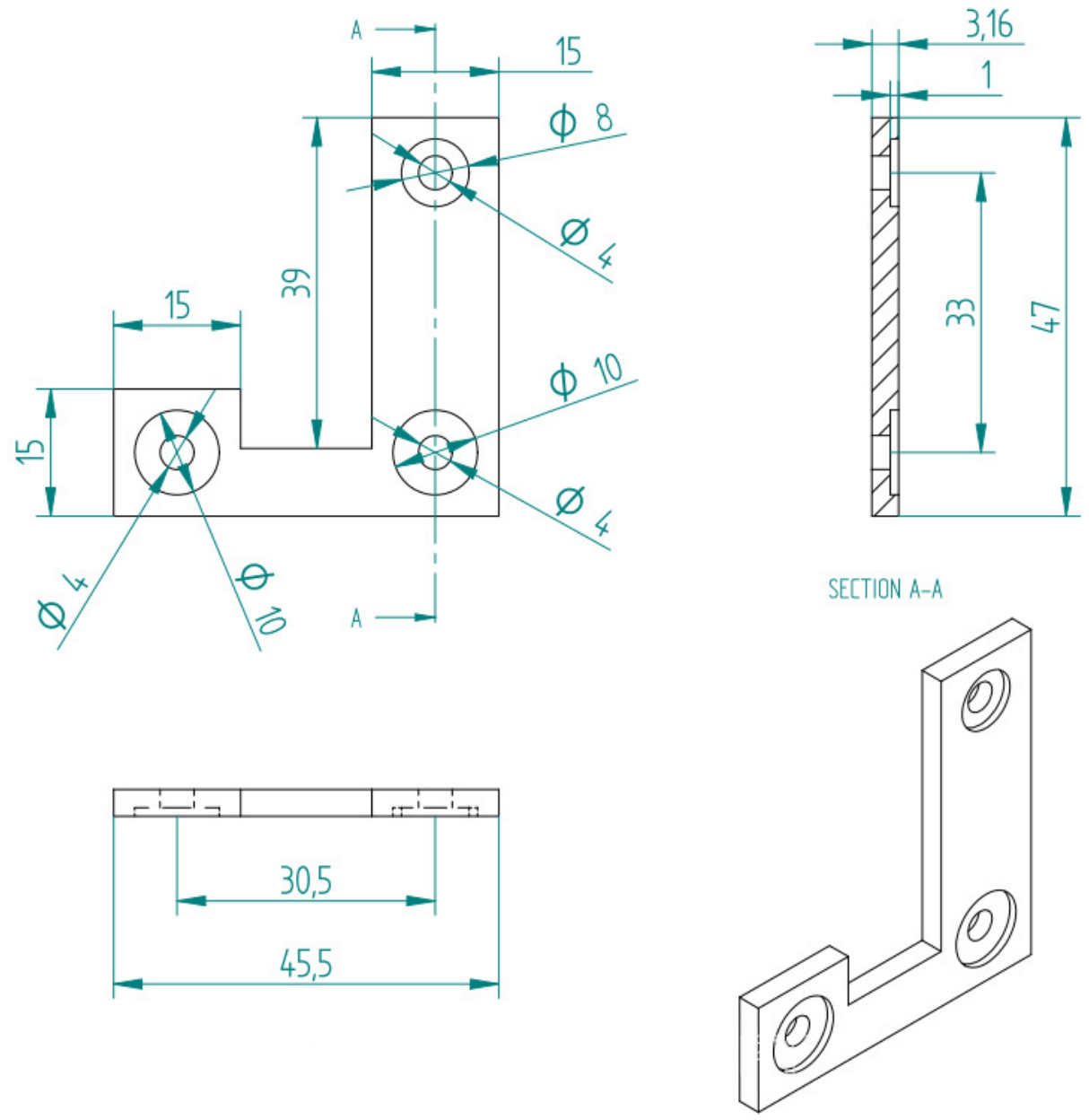

Figura 64: Lateral do dispositivo de adesão para visualização do ensaio.
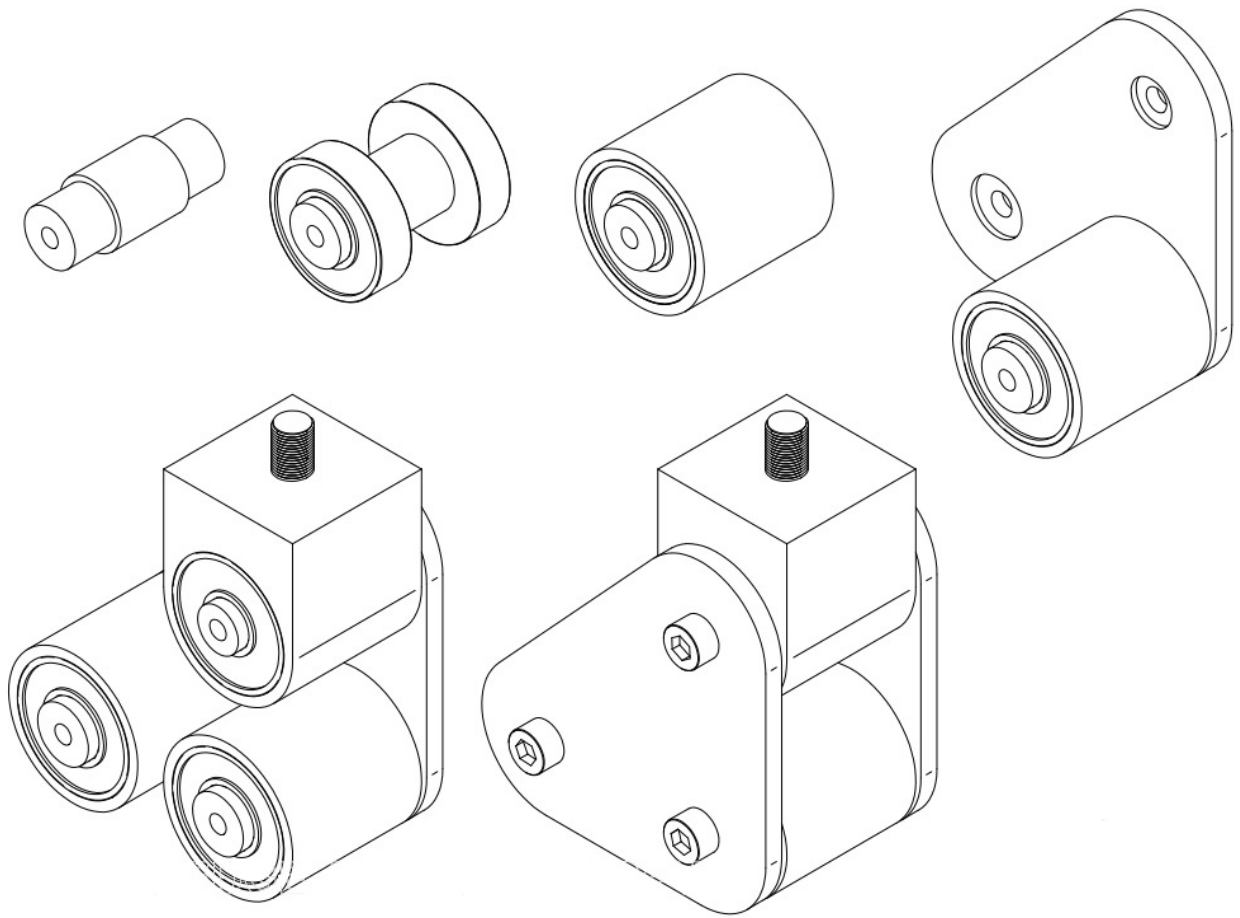

Figura 65: Montagem do dispositivo para o ensaio de adesão. 

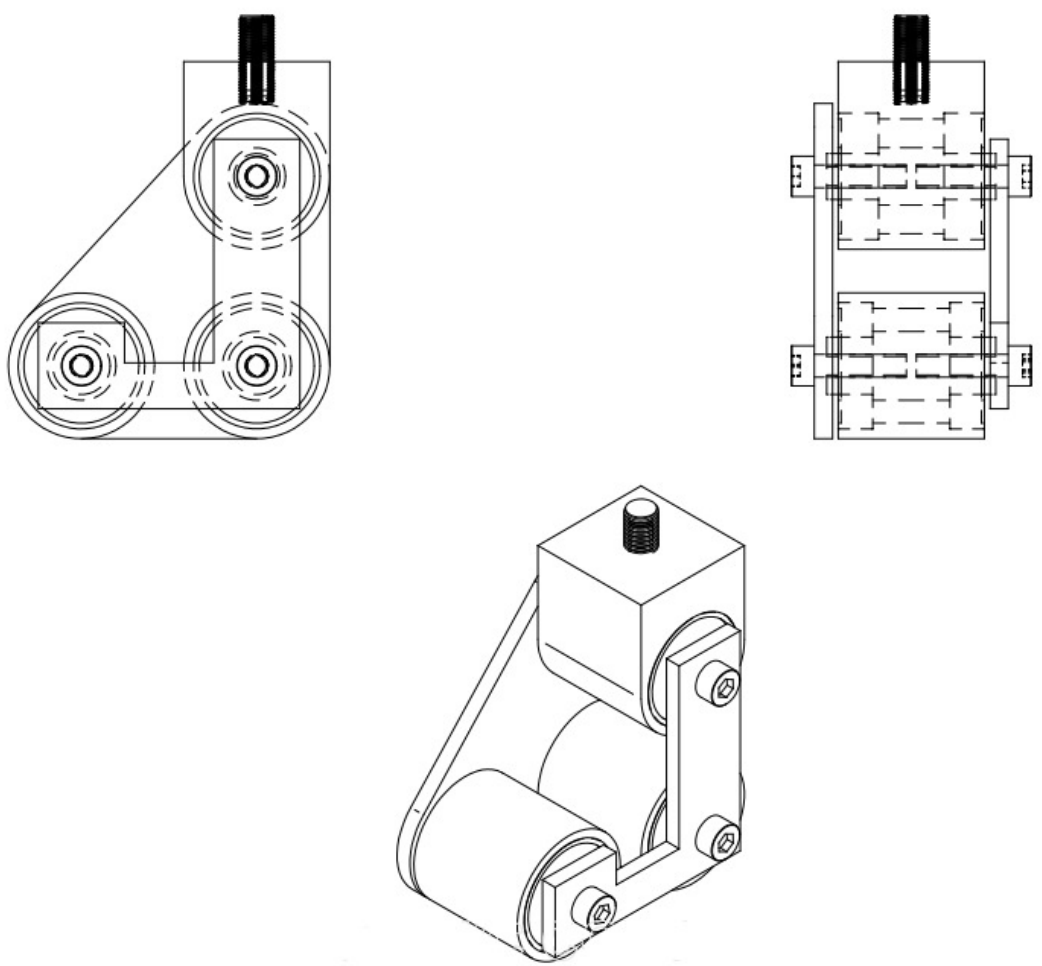

Figura 66: Montagem do dispositivo com lateral para visualização.
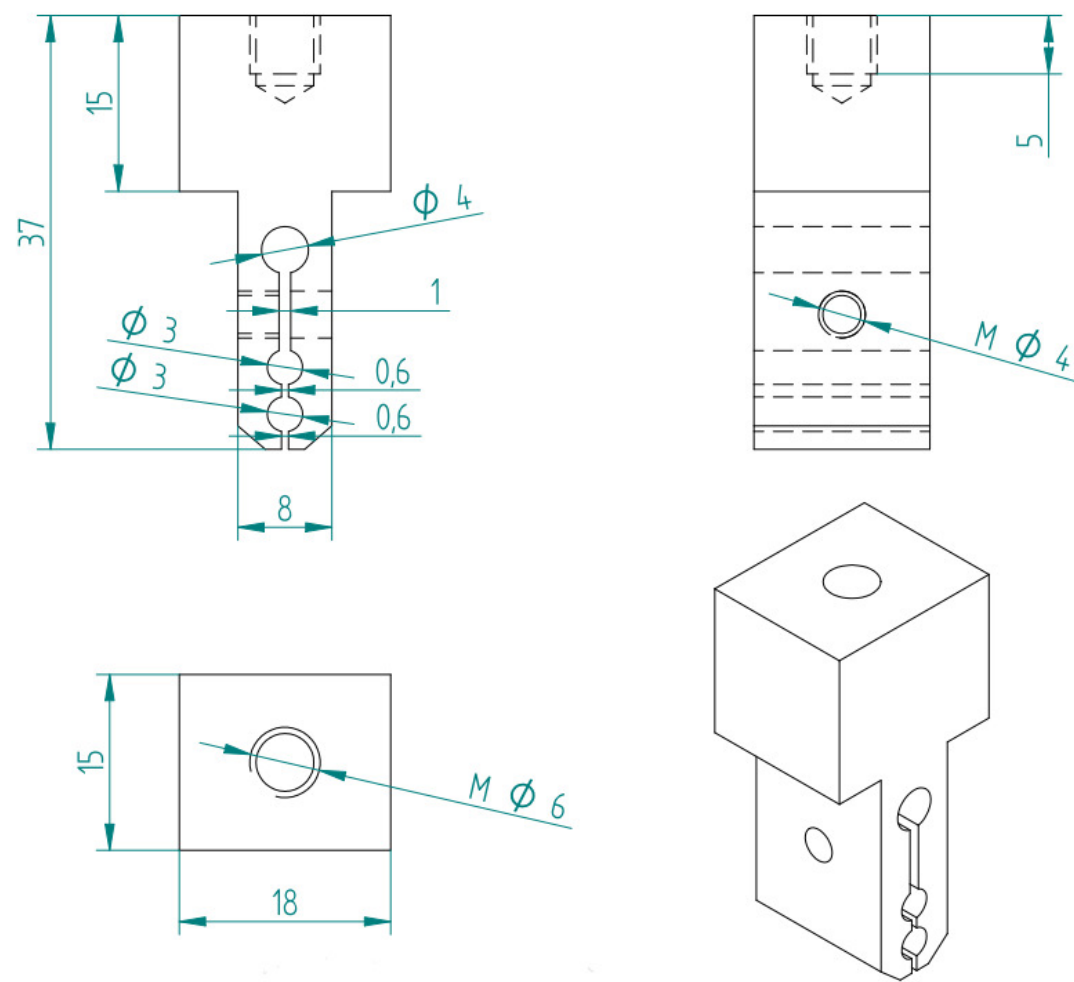

Figura 67: Fabricação da garra para fixação da última camada para execução do ensaio. 


\section{ANEXO A - Publicações}

\section{A.1 Artigos completos publicados em anais de con- gressos nacionais}

RIUL, C.; CANTO, R.B.; TITA, V.; de CARVALHO, J. Avaliação do comportamento mecânico de compósitos estruturais de politetrafluoretileno (PTFE) com fibras longas. Anais do V congresso nacional de engenharia mecânica-CONEM, Salvador - BA, 2008.

RIUL, C.; CANTO, R.B.; TITA, V.; de CARVALHO, J. Estudo da influência de parâmetros de fabricação nas propriedades mecânicas de compósitos estruturais de politetrafluoretileno com fibras contínuas. Anais do Congresso Brasileiro de Engenharia e Ciência dos Materiais - CBECiMat, Porto de Galinhas - PE, 2008.

RIUL, C.; CANTO, R.B.; TITA, V.; de CARVALHO, J. Metodologia de fabricação de compósitos estruturais de politetrafluoretileno (PTFE) com fibras contínuas. Anais do V Congresso Brasileiro de Engenharia de Fabricação - COBEF, Belo Horizonte - BA, 2008.

\section{A.2 Artigos completos publicados em anais de con- gressos internacionais}

RIUL, C.; CANTO, R.B.; TITA, V.; de CARVALHO, J. Process parameters investigation on the fibre-matrix adhesion Of continuous fibres reinforced polytetrafluoroethylene (PTFE). 17th International Conference on Composite Materials - ICCM-17, Edinburgh - Escócia, 2009.

\section{A.3 Artigos completos em periódicos internacionais - submetido}

RIUL, C.; CANTO, R.B.; TITA, V.; de CARVALHO, J. Methodology for manufacturing process of structural composite of polytetrafluorethylene (PTFE) with long fibres. Journal of Modern Manufacturing Technology, 2009. Serials Publications, ISSN: 0974-8415. 


\section{A.4 Artigos completos em periódicos internacionais - em preparação}

RIUL, C.; CANTO, R.B.; TITA, V.; de CARVALHO, J. Study of manufacturing process of composite laminates of polytetrafluoroethylene (PTFE) reinforced with continuous glass-Fibres. Composites Science and Technology, 2009. 